\title{
Design, Synthesis, and Evaluation of a Novel Series of Macrocyclic Inhibitors of Norovirus 3CL Protease.
}

\author{
Vishnu C. Damalanka, ${ }^{a}$ Yunjeong Kim, ${ }^{b}$ Anushka C. Galasiti Kankanamalage, ${ }^{a}$ Gerald \\ H. Lushington, ${ }^{c}$ Nurjahan Mehzabeen, ${ }^{d}$ Kevin P. Battaile, ${ }^{e}$ Scott Lovell, ${ }^{d}$ Kyeong-Ok \\ Chang, ${ }^{\mathrm{b}, * *}$ William C. Groutas, ${ }^{\mathrm{a}, *}$
}

${ }^{a}$ Department of Chemistry, Wichita State University, Wichita, Kansas 67260, USA

${ }^{b}$ Department of Diagnostic Medicine \& Pathobiology, College of Veterinary Medicine, Kansas State University, Manhattan, Kansas 66506, USA

${ }^{c}$ LiS Consulting, Lawrence, KS 66046, USA

${ }^{\mathrm{d}}$ Protein Structure Laboratory, The University of Kansas, Lawrence, Kansas 66047, USA

EIMCA-CAT, Hauptman-Woodward Medical Research Institute, APS Argonne National Laboratory, Argonne, IL 60439, USA

authors to whom correspondence should be addressed.

"Department of Chemistry, Wichita State University, Wichita, KS 67260 Tel. (316) 978 7374; Fax: (316) 9783431

e-mail: bill.groutas@wichita.edu

** Department of Diagnostic Medicine \& Pathobiology, Manhattan, KS 66506 Tel. (785) 532 3849; Fax: (785) 5324039

e-mail:kchang@vet.ksu.edu 


\section{ABSTRACT}

Norovirus infections have a major impact on public health worldwide, yet there is a current dearth of norovirus-specific therapeutics and prophylactics. This report describes the discovery of a novel class of macrocyclic inhibitors of norovirus $3 \mathrm{C}$-like protease, a cysteine protease that is essential for virus replication. SAR, structural, and biochemical studies were carried out to ascertain the effect of structure on pharmacological activity and permeability. Insights gained from these studies have laid a solid foundation for capitalizing on the therapeutic potential of the series of inhibitors described herein. 


\section{Introduction}

Noroviruses belong to the family Caliciviridae and are classified into at least six genogroups (GI-GVI) [1-3]. Human noroviruses are the primary cause of non-bacterial acute gastroenteritis worldwide [4-5], and are associated with high morbidity and a heavy economic burden [6-8]. In the U.S. alone noroviruses account for $>20$ million cases annually and impact most severely the young and elderly, as well as immunocompromised individuals [9-12]. Combating norovirus infections presents a formidable challenge because of their robustness, high infectivity, ease of transmission via multiple routes [13-14], the current dearth of norovirus-specific therapeutics/prophylactics and vaccines [15-21], as well as a sub-optimal understanding of norovirus biology and pathophysiology [22-26].

Noroviruses are small, single-stranded, positive sense RNA viruses whose genome (7-8 kb) is covalently linked to a viral protein (VPg, virion protein, genome-linked) at the 5 ' end and polyadenylated at the 3 ' end $[1,24]$. The genome consists of three open reading frames (ORFs) that encode a $200 \mathrm{kDa}$ polyprotein (ORF1), a major capsid protein VP1 (ORF2) and a small basic protein VP2 (ORF3) [1,24]. The polyprotein is processed by a virus-encoded protease to generate six mature non-structural proteins, including the viral protease (3C-like protease, 3 CLpro or NS6 ${ }^{\text {pro }}$ ) and the RNA dependent RNA polymerase $\left(N S 7^{\mathrm{pol}}\right)$. Co- and post-translational processing of the polyprotein by 3 CLpro is essential for virus replication, consequently, 3CLpro is an attractive target for the discovery of anti-norovirus small molecule therapeutics and prophylactics [15-20]. 
Norovirus 3CLpro, including Norwalk virus (NV) 3CLpro, is a cysteine protease with a Cys-His-Glu catalytic triad, an extended binding site, and a chymotrypsin-like fold [2731]. The protease displays a primary substrate specificity requirement for a $P_{1}$ glutamine or glutamic acid residue, or equivalent [32]. We have recently described an array of transition state inhibitors and transition state mimics of NV 3CLpro [15]. In continuing our studies in this area, we describe herein the structure-guided design of a novel series of macrocyclic inhibitors of the protease, as well as pertinent structural, biochemical, and cell-based studies.

\section{Results and Discussion}

\subsection{Inhibitor design rationale.}

Cocrystal structures of NV 3CLpro with peptidyl inhibitors reveal a network of backbone hydrogen bonds involving Ala158, Ala160, Gln110 and His30, as well as two critical hydrogen bonds between His157 and Thr134 and the carbonyl oxygen of the $\mathrm{P}_{1}$ Gln side chain $[27,29,33]$. The backbone hydrogen bonds mimic an antiparallel $\beta$-sheet and serve to correctly orient and position the inhibitor to the active site [34-35]. It was envisaged that the construction of a macrocyclic structure (Figure 1, structure (I)) capable of (a) maintaining the aforementioned favorable binding interactions and, (b) having a flexible diversity site that is well-suited to exploiting $\mathrm{H}$-bonding and hydrophobic interactions with the $S_{3}-S_{4}$ subsites and modulating physicochemical properties, could potentially result in the identification of a molecule that displays high potency and drug-like characteristics [36-37]. Additional advantages frequently accrued by macrocyclization include higher pharmacological activity and selectivity, enhanced permeability, and improved stability [38-40]. The interaction of inhibitor (I) with the 
protease was further probed using different warheads, ring sizes, and $P_{2}$ residues, a $P_{1}$ alkoxyamide side chain replacement for the $P_{1}$ Gln side chain that could potentially engage in intramolecular $\mathrm{H}$-bonding, thereby attenuating cellular permeability [41-46] and, finally, structural variants focused on $R_{1}$ which projects toward the $S_{3}-S_{4}$ subsites and affords opportunities for favorable binding interactions.

\subsection{Chemistry.}

The synthesis of inhibitors $\mathbf{1 1 - 2 1}$ by coupling compounds 3a-k (Scheme 1) with compound $\mathbf{6 a}$ (Scheme 2B) to yield acyclic compounds $\mathbf{7 a - k}$ (Scheme 3). The reaction sequence outlined in Scheme 1 is flexible and permits ready manipulation of the ring size using appropriate alkenyl Grignard reagents. Furthermore, the nature of the $P_{2}$ residue $\left(R_{2}\right)$ could be readily manipulated by reacting intermediates 1a-f (Scheme 1 ) with an appropriate amino acid ester isocyanate $4 a-d$ (Scheme 2A). Ring closure using a metathesis reaction furnished compounds $\mathbf{8 a}-\boldsymbol{k}$ which, upon sequential catalytic hydrogenation, reduction with lithium borohydride, and Dess-Martin periodinane oxidation yielded aldehydes 11-21. With the exception of compounds 14 and 36 , these were obtained as diastereomeric mixtures. Aldehydes 23-24 having an unsaturated linker were synthesized in an analogous manner (Scheme 4). Aldehyde bisulfite adducts $\mathbf{2 5 - 2 9}$ and $\alpha$-ketoamide $\mathbf{3 1}$ were synthesized as shown in Scheme 5. Finally, coupling of intermediate $3 \boldsymbol{c}$ with $\mathbf{6 b}$ (Scheme $2 \mathrm{C}$ ) followed by further elaboration of the product yielded aldehyde $\mathbf{3 6}$ (Scheme 6).

\subsection{Biochemical Studies.}


The inhibitory activity of the synthesized compounds against NV 3CLpro and their anti-norovirus activity in a cell-based replicon system, were evaluated as described in the experimental section $[33,47]$. The determined $\mathrm{IC}_{50}$ in enzyme assay, $\mathrm{EC}_{50}$ against NV in the replicon harboring cells (HG23 cells) or murine norovirus (MNV) in RAW264.7 cells, and $\mathrm{CC}_{50}$ values in HG23 cells are listed in Tables 1 and they are the average of at least two determinations.

The low cellular permeability and susceptibility to proteolytic degradation of peptide-based inhibitors provided the impetus behind the design of macrocyclic inhibitor (I). It is evident from the results shown in Table 1 that, with the exception of compounds 18, 26, 19, and 27 (Table 1) that were inactive, the rest of the compounds inhibited NV 3CLpro and displayed antiviral activity in cell based assays in the replicon harboring cells (NV) as well as RAW264.7 cells (MNV) with $\mathrm{IC}_{50}$ and $\mathrm{EC}_{50}$ values in the low micromolar range. The antiviral activities against NV and MNV in cell based assays demonstrate that the compounds have good permeability in different cell types (hepatoma cells [HG23] and macrophage-like cells [RAW264.7]). The aldehyde and aldehyde bisulfite adducts had comparable potency, however, replacement of the warhead with an a-ketoamide (Table 1, compounds 13 and 25 versus $\alpha$-ketoamide 31) diminished activity. These observations are congruent with the results of previous studies with peptidyl and macrocyclic inhibitors of NV 3CLpro [48-49]. Replacement of the $P_{2}$ Leu $\left(R_{2}\right)$ residue with cyclohexylalanine (Cha) had a minor effect on potency. This is contrast to the significant boost in potency observed in the dipeptidyl series of acyclic inhibitors having a $P_{2}$ Cha [33]. As expected, a $P_{2}$ Ala $\left(R_{2}\right)$ residue resulted in greatly diminished potency, a reflection of the strong preference of NV 3CLpro for a Cha 
or Leu residue at the $\mathrm{P}_{2}$ position [32]. Surprisingly, substitution of a spirocyclohexylglycine (1-aminocyclohexaneglycine) at $P_{2}\left(R_{2}\right)$ resulted in a dramatic loss of activity (Table 1 , compounds $18,26,19$, and 27 ). In those instances, where the diastereomers were separable, these displayed comparable potencies (Table 1, compounds $14 A-B$ and $36 A-B)$.

Delineation of the structural determinants impacting pharmacological activity, as well as demonstration of the mechanism of action, was made possible by determining a high resolution cocrystal structure of inhibitor 13 with NV 3CLpro. Examination of the active site revealed the presence of prominent difference electron density with inhibitor 13 covalently bound to Cys 139 and the entire inhibitor could be traced (Figure 2). The interactions between NV 3CLpro and $\mathbf{1 3}$ are shown in Figure 3 and electrostatic surface representations of the NV 3CLpro with the inhibitor nestled in the active site are shown in Figure 4. A network of $\mathrm{H}$-bonds involving the backbone of inhibitor $\mathbf{1 3}$ and residues Gln110, Ala158, and Ala160 that serve to position the inhibitor correctly at the active site are clearly evident. Surprisingly, the His157 and Thr134 residues that are present in the vicinity of the Gln side chain and ordinarily engage in $\mathrm{H}$-bonding interactions with the Gln side chain oxygen [33] are absent and seemingly displaced by Pro136, which forms a $\mathrm{H}$-bond with the oxygen of the tetrahedral adduct (Figure 3). Thus, the loss of the pair of $\mathrm{H}$-bonds between the Gln side chain oxygen and the His157 and Thr134 residues may account for the observed potency (vide infra). The inhibitor is covalently bonded to the active site Cys139 residue providing unequivocal demonstration of the mechanism of action of (I). The $m$-chlorophenyl group of inhibitor $\mathbf{1 3}$ is positioned within a hydrophobic cleft, as shown in Figure 5. Extending the position of the phenyl ring 
(Table 1, compounds 11-12, 20 and 28) resulted in a two to four-fold decrease in potency. Furthermore, one of the macrocycles having an unsaturated linker (compound 24, Table 1) was more potent than the corresponding macrocycle with a saturated linker (Table 1/compounds 14A-B) while the second one (Table 1/23) was $\sim 2$-fold more potent than compound 12 (Table 1). In order to enhance binding and permeability, the $P_{1}$ Gln side chain was modified by introducing an additional $\mathrm{H}$-bonding site. The structural modification did not have a major effect on potency (Table 1, compounds $36 \boldsymbol{A}-\boldsymbol{B}$ ).

The m-chlorophenyl moiety occupies a predominantly hydrophobic pocket (Figure 5), consequently, this site was probed by synthesizing macrocycles having an $n-$ pentyl chain. The resulting compounds were found to be $\sim 2$-fold less active (Table 1 , compounds $21 / 29$ and compounds 13/25). Inhibitor 21 is bound to the active site similarly to inhibitor $\mathbf{1 3}$ (Figures 6 and 7) and engages in similar $\mathrm{H}$-bonding interactions (Figure 8), however, the Pro136 $\mathrm{H}$-bond is missing. The latter, along with the higher entropic penalty associated with the alkyl chain, partially accounts for the lower affinity. The n-pentyl chain is clearly shown to engage in hydrophobic interactions (Figure 9). Modification of this portion of the inhibitor to facilitate the formation of new hydrogen bonds with the side chains of Thr161 or Thr168 could potentially enhance affinity (Figures 5 and 9).

\section{Conclusions}

Noroviruses are a leading cause of acute gastroenteritis in all age groups worldwide and have a significant impact on public health. There are currently no norovirus-specific therapeutics or prophylactics. In this report we describe the design, 
synthesis, and anti-norovirus activity of a novel class of macrocyclic inhibitors of NV 3CLpro. These studies provide new insights into the interaction of macrocyclic inhibitors with NV 3CLpro and demonstrate the nuanced interplay of structure, pharmacological activity, and cellular permeability. They also lay the ground work for conducting further studies related to the development of anti-norovirus therapeutics.

\section{Experimental section}

\subsection{General}

Reagents and dry solvents were purchased from various chemical suppliers (Aldrich, Acros Organics, Chemlmpex, TCI America, Oakwood chemicals, Bachem, and Fisher) and were used as obtained. Silica gel (230-450 mesh) used for flash chromatography was purchased from Sorbent Technologies (Atlanta, GA). Thin layer chromatography was performed using Analtech silica gel plates. The ${ }^{1} \mathrm{H}$ spectra were recorded in $\mathrm{CDCl}_{3}$ or DMSO- $\mathrm{d}_{6}$ on a Varian XL-400 NMR spectrometer and are reported relative to TMS $(\delta \mathrm{H}=0.00 \mathrm{ppm})$. High resolution mass spectra (HRMS) were performed at the University of Kansas Mass Spectrometry lab using an LCT Premier mass spectrometer (Waters, Milford, MA) equipped with a time of flight mass analyzer and an electrospray ion source or a G6230B TOF MS (Agilent Technologies, Santa Clara, CA). Visualization was accomplished using UV light and/ or iodine.

\subsubsection{Synthesis of compounds $\mathbf{1 a}-\boldsymbol{f}$. General procedure.}

To a $250 \mathrm{~mL}$ round bottom flask kept under nitrogen atmosphere was added a $0.5 \mathrm{M}$ solution (35 mmol) of the appropriate Grignard reagent (3-butenyl magnesium bromide or 4-pentenyl magnesium bromide) in THF and the solution was cooled to $0-5$ 
${ }^{\circ} \mathrm{C}$. A solution of the appropriate aldehyde $(35 \mathrm{mmol})$ in dry THF $(20 \mathrm{~mL})$ was added dropwise to the cooled Grignard solution over $\sim 1 \mathrm{~h}$. The reaction mixture was allowed to warm up to room temperature and stirred for $5 \mathrm{~h}$ under nitrogen. The disappearance of the aldehyde was monitored by TLC. The reaction mixture was cooled to $0-5^{\circ} \mathrm{C}$ and acidified to $\mathrm{pH} \sim 3.0$ using $5 \%$ aqueous hydrochloric acid. The organic solvent was evaporated off and the residue was extracted with ethyl acetate $(2 \times 150 \mathrm{~mL})$. The combined organic extracts were washed with brine $(50 \mathrm{~mL})$ dried over anhydrous $\mathrm{Na}_{2} \mathrm{SO}_{4}$, filtered, and concentrated. The crude product was purified by column chromatography to yield alcohols $\mathbf{1 a - 1 f}$ as oils.

\subsubsection{1-phenylpent-4-en-1-ol 1a}

Oil (yield 80\%); ${ }^{1} \mathrm{H}$ NMR (400 MHz, $\left.\mathrm{CDCl}_{3}-d\right) \delta$ ppm 1.68 - $1.99(\mathrm{~m}, 2 \mathrm{H}), 1.99$ - $2.33(\mathrm{~m}$, $2 \mathrm{H}), 4.58$ - $4.74(\mathrm{~m}, 1 \mathrm{H}), 4.90$ - $5.11(\mathrm{~m}, 2 \mathrm{H}), 5.73$ - $5.94(\mathrm{~m}, 1 \mathrm{H}), 7.20$ - $7.50(\mathrm{~m}, 5$ H). HRMS (ESI) calcd for $\mathrm{C}_{11} \mathrm{H}_{15} \mathrm{O}:[\mathrm{M}+\mathrm{H}]^{+}: 163.1123$ Found: 163.1126.

\subsubsection{1-phenylhex-5-en-2-ol 1b}

Oil (yield 80\%); ${ }^{1} \mathrm{H}$ NMR (400 MHz, $\left.\mathrm{CDCl}_{3}-d\right) 1.53-1.69(\mathrm{~m}, 2 \mathrm{H}), 1,91-2.02(\mathrm{~m}$, $2 \mathrm{H}), 2.70-2.93(\mathrm{~m}, 2 \mathrm{H}), 3.95-4.08(\mathrm{~m}, 1 \mathrm{H}), 4.88-5.09(\mathrm{~m}, 3 \mathrm{H}), 5.67-5.91(\mathrm{~m}, 1$ $\mathrm{H}), 7.23$ - $7.34(\mathrm{~m}, 5 \mathrm{H})$. HRMS (ESI) calcd for $\mathrm{C}_{12} \mathrm{H}_{17} \mathrm{O}:[\mathrm{M}+\mathrm{H}]^{+}: 177.1279$ Found: 177.1285 .

\subsubsection{1-(3-chlorophenyl) pent-4-en-1-ol 1c}

Oil, yield (80\%), ${ }^{1} \mathrm{H}$ NMR (400 MHz, $\left.\mathrm{CDCl}_{3}\right) \delta$ ppm 1.71 - $1.96(\mathrm{~m}, 2 \mathrm{H}), 2.04-$ $2.24(\mathrm{~m}, 2 \mathrm{H}), 4.69(\mathrm{~s}, 1 \mathrm{H}), 4.97$ - $5.13(\mathrm{~m}, 2 \mathrm{H}), 5.77$ - $5.93(\mathrm{~m}, 1 \mathrm{H}), 7.17$ - $7.50(\mathrm{~m}, 4$ H). HRMS (ESI) calcd for $\mathrm{C}_{11} \mathrm{H}_{14} \mathrm{ClO}:[\mathrm{M}+\mathrm{H}]^{+}: 197.0733$ Found: 197.0735 .

\subsubsection{1-(3-chlorophenyl) hex-5-en-1-ol 1d}


Oil (yield 75\%); ${ }^{1} \mathrm{H}$ NMR $\left(400 \mathrm{MHz}, \mathrm{CDCl}_{3}-d\right) \delta \mathrm{ppm} 1.26$ - $1.62(\mathrm{~m}, 1 \mathrm{H}), 1.59-$ $1.85(\mathrm{~m}, 1 \mathrm{H}), 1.83$ - $1.89(\mathrm{~m}, 2 \mathrm{H}), 2.02-2.13(\mathrm{~m}, 2 \mathrm{H}), 4.61$ - $4.71(\mathrm{~m}, 1 \mathrm{H}), 4.95$ - 5.08 (m, $3 \mathrm{H}), 5.69-5.86(\mathrm{~m}, 1 \mathrm{H}), 7.16-7.30(\mathrm{~m}, 3 \mathrm{H}), 7.35(\mathrm{~s}, 1 \mathrm{H})$. HRMS (ESI) calcd for $\mathrm{C}_{12} \mathrm{H}_{16} \mathrm{ClO}:[\mathrm{M}+\mathrm{H}]^{+}: 211.0890$ Found: 211.0894.

\subsubsection{1-phenyloct-7-en-4-ol 1e}

Oil (yield 55\%); ${ }^{1} \mathrm{H}$ NMR (400 MHz, $\left.\mathrm{CDCl}_{3}-d\right) \delta$ ppm 1.41 - $1.59(\mathrm{~m}, 4 \mathrm{H}), 1.61$ $1.86(\mathrm{~m}, 2 \mathrm{H}), 2.04-2.26(\mathrm{~m}, 2 \mathrm{H}), 2.57-2.71(\mathrm{t}, 2 \mathrm{H}), 3.59-3.70(\mathrm{~m}, 1 \mathrm{H}), 4.91-5.10$ $(\mathrm{m}, 3 \mathrm{H}), 5.76-5.89(\mathrm{~m}, 1 \mathrm{H}), 7.14-7.20(\mathrm{~d}, 2 \mathrm{H}), 7.23$ - 7.30 (t, $3 \mathrm{H})$. HRMS (ESI) calcd for $\mathrm{C}_{14} \mathrm{H}_{21} \mathrm{O}:[\mathrm{M}+\mathrm{H}]^{+}: 205.1592$ Found: 205.1598.

\subsubsection{Dec-1-en-5-ol $1 f$}

Oil (yield 93\%); ${ }^{1} \mathrm{H}$ NMR (400 MHz, $\left.\mathrm{CDCl}_{3}-d\right) \delta \mathrm{ppm} 0.82-0.91(\mathrm{t}, 2 \mathrm{H}), 1.21-$ $1.33(\mathrm{~m}, 4 \mathrm{H}), 1.35-1.44(\mathrm{~m}, 2 \mathrm{H}), 1.47$ - $1.61(\mathrm{~m}, 2 \mathrm{H}), 2.05-2.25(\mathrm{~m}, 2 \mathrm{H}), 3.55-$ $3.63(\mathrm{~m}, 1 \mathrm{H}), 4.90-5.07(\mathrm{~m}, 3 \mathrm{H}), 5.76-5.89(\mathrm{~m}, 1 \mathrm{H})$. HRMS (ESI) calcd for $\mathrm{C}_{10} \mathrm{H}_{21} \mathrm{O}$ : $[\mathrm{M}+\mathrm{H}]^{+}: 157.1592$ Found: 157.1954 .

\subsubsection{Synthesis of carbamates $2 \boldsymbol{a}-\boldsymbol{k}$. General procedure.}

A solution of compound $\mathbf{1}(35 \mathrm{mmol})$ in dry acetonitrile $(60 \mathrm{~mL})$ was treated with trimethylamine $(7.1 \mathrm{~g} ; 70 \mathrm{mmol})$ followed by an appropriate amino acid methyl ester isocyanate $4(35 \mathrm{mmol})$. The resulting reaction mixture was refluxed for $3 \mathrm{~h}$ and then allowed to cool to room temperature. The disappearance of the alcohol was monitored by TLC. The solvent was evaporated and the residue was taken up in ethyl acetate (250 $\mathrm{mL})$ and the organic layer was washed with $5 \%$ aqueous $\mathrm{HCl}(2 \times 50 \mathrm{~mL})$ and saturated $\mathrm{NaCl}(50 \mathrm{~mL})$. The organic layer was dried over anhydrous sulfate, filtered, and concentrated to yield an oily product. Purification by flash chromatography yielded esters $\mathbf{2} \mathbf{a}-\boldsymbol{k}$ as colorless oils.

\subsubsection{Methyl (((1-phenylpent-4-en-1-yl) oxy) carbonyl)-L-leucinate 2a}


Oil (yield 80\%); ${ }^{1} \mathrm{H}$ NMR (400 MHz, $\left.\mathrm{CDCl}_{3}-d\right) \delta \mathrm{ppm} 0.68-1.05(\mathrm{~d}, 6 \mathrm{H}), 1.40-$ $1.73(\mathrm{~m}, 1 \mathrm{H}), 1.73-1.95(\mathrm{~m}, 2 \mathrm{H}), 1.95-2.21(\mathrm{~m}, 4 \mathrm{H}), 3.64-3.86(\mathrm{~s}, 3 \mathrm{H}), 4.45$ - 4.53 $(\mathrm{m}, 1 \mathrm{H}), 4.86-5.20(\mathrm{~m}, 2 \mathrm{H}), 5.54-5.69(\mathrm{~m}, 1 \mathrm{H}), 5.69-5.92(\mathrm{~m}, 1 \mathrm{H}), 7.17$ - $7.35(\mathrm{~m}$, $5 \mathrm{H}), 7.40-7.50(\mathrm{~d}, 1 \mathrm{H})$. HRMS (ESI) calcd for $\mathrm{C}_{19} \mathrm{H}_{28} \mathrm{NO}_{4}:[\mathrm{M}+\mathrm{H}]^{+}: 334.2018$ Found: 334.2021.

4.1.2.2. Methyl (((1-phenylhex-5-en-2-yl) oxy) carbonyl)-L-leucinate $\mathbf{2 b}$

Oil (yield 80\%); ${ }^{1} \mathrm{H}$ NMR (400 MHz, $\left.\mathrm{CDCl}_{3}\right) \delta$ ppm 0.81 - $0.97(\mathrm{~d}, 6 \mathrm{H}), 1.53$ $1.69(\mathrm{~m}, 5 \mathrm{H}), 1,91-2.02(\mathrm{~m}, 2 \mathrm{H}), 2.70-2.93(\mathrm{~m}, 2 \mathrm{H}), 3.71-3.78(\mathrm{~s}, 3 \mathrm{H}), 4.18-4.28$ $(\mathrm{m}, 1 \mathrm{H}), 4.88$ - $5.09(\mathrm{~m}, 3 \mathrm{H}), 5.67-5.91(\mathrm{~m}, 1 \mathrm{H}), 6.20-660(\mathrm{br}, 1 \mathrm{H}), 7.13$ - $7.43(\mathrm{~m}$, $5 \mathrm{H}), 7.71-7.80(\mathrm{~d}, 1 \mathrm{H})$. HRMS (ESI) calcd for $\mathrm{C}_{20} \mathrm{H}_{30} \mathrm{NO}_{4}:[\mathrm{M}+\mathrm{H}]^{+}: 348.2175$ Found: 348.2180 .

4.1.2.3. Methyl (((1-(3-chlorophenyl) pent-4-en-1-yl) oxy) carbonyl)-L-leucinate 2c

Oil (yield 80\%); ${ }^{1} \mathrm{H}$ NMR (400 MHz, $\left.\mathrm{CDCl}_{3}-d\right) \delta$ ppm $0.84-1.06(\mathrm{~d}, 6 \mathrm{H}), 1.41$ $1.72(\mathrm{~m}, 1 \mathrm{H}), 1.73-2.24(\mathrm{~m}, 5 \mathrm{H}), 2.42-2.57(\mathrm{~m}, 2 \mathrm{H}), 3.62-3.77(\mathrm{~d}, 3 \mathrm{H}), 4.23-4.42$ $(\mathrm{m}, 1 \mathrm{H}), 4.60$ - $4.74(\mathrm{~m}, 1 \mathrm{H}), 4.92-5.24(\mathrm{~m}, 1 \mathrm{H}), 5.54$ - $5.68(\mathrm{~m}, 1 \mathrm{H}), 5.72$ - $5.98(\mathrm{~m}$, $1 \mathrm{H}), 7.15-7.32(\mathrm{~m}, 3 \mathrm{H}), 7.41(\mathrm{~s}, 1 \mathrm{H})$. HRMS (ESI) calcd for $\mathrm{C}_{19} \mathrm{H}_{27} \mathrm{CINO}_{4}:[\mathrm{M}+\mathrm{H}]^{+}$: 368.1629 Found: 368.1633 .

4.1.2.4. Methyl (2S)-2-(((1-(3-chlorophenyl) pent-4-en-1-yl) oxy) carbonyl) amino)-3cyclohexylpropanoate $\mathbf{2 d}$

Oil (yield 75\%); ${ }^{1} \mathrm{H}$ NMR (400 MHz, $\left.\mathrm{CDCl}_{3}-d\right) \delta$ ppm $0.73-0.93(\mathrm{~m}, 4 \mathrm{H}), 1.03$ $1.31(\mathrm{~m}, 2 \mathrm{H}), 1.31-1.55(\mathrm{~m}, 2 \mathrm{H}), 1.55-1.75(\mathrm{~m}, 2 \mathrm{H}), 1.74-1.89(\mathrm{~m}, 4 \mathrm{H}), 2.00-2.21$ (m, $2 \mathrm{H}), 3.52$ - $3.61(\mathrm{~s}, 3 \mathrm{H}), 4.44-4.50(\mathrm{~m}, 1 \mathrm{H}), 4.95$ - $5.18(\mathrm{~m}, 3 \mathrm{H}), 5.67$ - $5.89(\mathrm{~m}, 2$ $\mathrm{H}), 7.14-7.35(\mathrm{~m}, 4 \mathrm{H}), 7.44-7.49(\mathrm{~s}, 1 \mathrm{H})$. HRMS (ESI) calcd for $\mathrm{C}_{22} \mathrm{H}_{31} \mathrm{CINO}_{4}:[\mathrm{M}+\mathrm{H}]$ +: 408.1942 Found: 408.1947.

4.1.2.5. Methyl (((1-(3-chlorophenyl) hex-5-en-1-yl) oxy) carbonyl)-L-leucinate $2 e$

Oil (yield 80\%); ${ }^{1} \mathrm{H}$ NMR (400 MHz, $\left.\mathrm{CDCl}_{3}-d\right) \delta$ ppm 0.87 - $0.92(\mathrm{~d}, 6 \mathrm{H}), 1.30$ $1.62(\mathrm{~m}, 3 \mathrm{H}), 1.61-1.84(\mathrm{~m}, 2 \mathrm{H}), 1.97-2.16(\mathrm{~m}, 4 \mathrm{H}), 3.61-3.70(\mathrm{~s}, 3 \mathrm{H}), 4.60-4.70$ $(\mathrm{m}, 1 \mathrm{H}), 4.89$ - $5.06(\mathrm{~m}, 2 \mathrm{H}), 5.66-5.87(\mathrm{~m}, 2 \mathrm{H}), 7.13$ - $7.38(\mathrm{~m}, 4 \mathrm{H}), 7.40-7.45$ (s, $1 \mathrm{H})$. HRMS (ESI) calcd for $\mathrm{C}_{20} \mathrm{H}_{29} \mathrm{CINO}_{4}:[\mathrm{M}+\mathrm{H}]^{+}: 382.1785$ Found: 382.1789 .

4.1.2.6. Methyl (((1-(3-chlorophenyl) pent-4-en-1-yl) oxy) carbonyl)-L-alaninate $2 f$ 
Oil (yield 80\%); ${ }^{1} \mathrm{H}$ NMR (400 MHz, $\left.\mathrm{CDCl}_{3}-d\right) \delta$ ppm 1.42 (d, J=7.03 Hz, $3 \mathrm{H}$ ), 1.75 - $1.92(\mathrm{~m}, 2 \mathrm{H}), 1.90$ - $2.14(\mathrm{~m}, 2 \mathrm{H}), 3.74(\mathrm{br} \mathrm{d}, J=16.01 \mathrm{~Hz}, 3 \mathrm{H}), 4.27$ - $4.39(\mathrm{~m}, 1$ $\mathrm{H}), 4.94$ - $5.09(\mathrm{~m}, 2 \mathrm{H}), 5.24$ - $5.44(\mathrm{~d}, 1 \mathrm{H}), 5.55$ - $5.68(\mathrm{~m}, 1 \mathrm{H}), 5.72$ - $5.87(\mathrm{~m}, 1 \mathrm{H})$, 7.26 (dd, $J=4.10,0.98 \mathrm{~Hz}, 4 \mathrm{H}$ ). HRMS (ESI) calcd for $\mathrm{C}_{16} \mathrm{H}_{21} \mathrm{CINO}_{4}:[\mathrm{M}+\mathrm{H}]^{+}: 326.1159$ Found: 326.1162 .

4.1.2.7. Methyl (((1-(3-chlorophenyl) hex-5-en-1-yl) oxy) carbonyl)-L-alaninate $\mathbf{2 g}$

Oil (yield 80\%); ${ }^{1} \mathrm{H}$ NMR (400 MHz, $\left.\mathrm{CDCl}_{3}-d\right) \delta \mathrm{ppm} 1.27$ - $1.56(\mathrm{~m}, 5 \mathrm{H}), 1.66$ $2.14(\mathrm{~m}, 4 \mathrm{H}), 3.71(\mathrm{br} \mathrm{d}, J=16.01 \mathrm{~Hz}, 3 \mathrm{H}), 4.24-4.39(\mathrm{~m}, 1 \mathrm{H}), 4.89-5.06(\mathrm{~m}, 2 \mathrm{H})$, 5.29 - 5.49 (m, $1 \mathrm{H}), 5.54$ - $5.83(\mathrm{~m}, 2 \mathrm{H}), 7.10$ - 7.36 (m, $4 \mathrm{H}) .8 .10-8.15$ (br s, $1 \mathrm{H})$. HRMS (ESI) calcd for $\mathrm{C}_{17} \mathrm{H}_{23} \mathrm{CINO}_{4}:[\mathrm{M}+\mathrm{H}]^{+}: 340.1316$ Found: 340.1322 .

4.1.2.8. Methyl 1-(((1-(3-chlorophenyl) pent-4-en-1-yl) oxy) carbonyl) amino) cyclohexane-1-carboxylate $\mathbf{2 h}$

Oil (yield 70\%); ${ }^{1} \mathrm{H}$ NMR (400 MHz, $\left.\mathrm{CDCl}_{3}-d\right) \delta$ ppm 1.18 - $1.66(\mathrm{~m}, 6 \mathrm{H}), 1.67$ $2.21(\mathrm{~m}, 6 \mathrm{H}), 2.23-2.40(\mathrm{~m}, 2 \mathrm{H}), 3.59(\mathrm{~s}, 3 \mathrm{H}), 4.53-4.73(\mathrm{~m}, 1 \mathrm{H}), 4.93-5.13(\mathrm{~m}, 2$ $\mathrm{H}), 5.48-5.64(\mathrm{~m}, 1 \mathrm{H}), 5.71-5.93(\mathrm{~m}, 1 \mathrm{H}), 7.24(\mathrm{~m}, 4 \mathrm{H})$. HRMS (ESI) calcd for $\mathrm{C}_{20} \mathrm{H}_{27} \mathrm{CINO}_{4}:[\mathrm{M}+\mathrm{H}]^{+}: 380.1629$ Found: 380.1635 .

4.1.2.9. Methyl 1-(((1-(3-chlorophenyl) hex-5-en-1-yl) oxy) carbonyl) amino) cyclohexane-1-carboxylate $2 i$

Oil, yield (65\%); ${ }^{1} \mathrm{H}$ NMR (400 MHz, $\left.\mathrm{CDCl}_{3}-d\right) \delta \mathrm{ppm} 1.30-2.16(\mathrm{~m}, 16 \mathrm{H}), 3.57$ - 3.65 (s, $3 \mathrm{H}), 4.62$ - $4.71(\mathrm{~m}, 1 \mathrm{H}), 4.88$ - 5.08 (m, $2 \mathrm{H}), 5.48$ - $5.63(\mathrm{~m}, 1 \mathrm{H}), 5.67$ $5.87(\mathrm{~m}, 1 \mathrm{H}), 7.11-7.30(\mathrm{~m}, 3 \mathrm{H}), 7.32$ - $7.39(\mathrm{~s}, 1 \mathrm{H})$. HRMS (ESI) calcd for $\mathrm{C}_{21} \mathrm{H}_{29} \mathrm{CINO}_{4}:[\mathrm{M}+\mathrm{H}]^{+}: 394.1785$ Found: 394.1790 .

4.1.2.10. Methyl (((1-phenyloct-7-en-4-yl) oxy) carbonyl)-L-leucinate 2j

Oil (yield 88\%); ${ }^{1} \mathrm{H}$ NMR (400 MHz, $\left.\mathrm{CDCl}_{3}-d\right) \delta$ ppm $0.83-0.96(\mathrm{~d}, 6 \mathrm{H}), 1.37-$ $1.92(\mathrm{~m}, 7 \mathrm{H}), 1.95-2.07(\mathrm{~m}, 3 \mathrm{H}), 2.49-2.65(\mathrm{t}, 2 \mathrm{H}), 3.63-3.73(\mathrm{~s}, 3 \mathrm{H}), 4.28-4.48$ $(\mathrm{m}, 1 \mathrm{H}), 4.71-4.81(\mathrm{~m}, 1 \mathrm{H}), 4.88-5.08(\mathrm{~m}, 2 \mathrm{H}), 5.48-5.63(\mathrm{~m}, 1 \mathrm{H}), 5.67-5.87(\mathrm{~m}$, $1 \mathrm{H}), 7.08-7.18(\mathrm{~m}, 2 \mathrm{H}), 7.18-7.28(\mathrm{~m}, 3 \mathrm{H})$. HRMS (ESI) calcd for $\mathrm{C}_{22} \mathrm{H}_{34} \mathrm{NO}_{4}:[\mathrm{M}+\mathrm{H}]$ + : 376.2488 Found: 376.2452 .

4.1.2.11. Methyl ((dec-1-en-5-yloxy) carbonyl)-L-leucinate $\mathbf{2 k}$

Oil (yield 91\%); ${ }^{1} \mathrm{H}$ NMR (400 MHz, $\left.\mathrm{CDCl}_{3}-d\right) \delta$ ppm $0.83-0.90$ (t, $\left.2 \mathrm{H}\right), 0.90-$ $0.98(\mathrm{~d}, 6 \mathrm{H}), 1.20-1.35(\mathrm{~m}, 6 \mathrm{H}), 1.45-1.70(\mathrm{~m}, 4 \mathrm{H}), 1.98-2.15(\mathrm{~m}, 4 \mathrm{H}), 3.69-$ 
$3.76(\mathrm{~s}, 3 \mathrm{H}), 4.30-4.43(\mathrm{~m}, 1 \mathrm{H}), 4.70-4.80(\mathrm{~m}, 1 \mathrm{H}), 4.90-5.05(\mathrm{~m}, 2 \mathrm{H}), 5.70-5.80$ $(\mathrm{m}, 1 \mathrm{H}), 7.80-7.89(\mathrm{~d}, 1 \mathrm{H})$. HRMS (ESI) calcd for $\mathrm{C}_{18} \mathrm{H}_{34} \mathrm{NO}_{4}:[\mathrm{M}+\mathrm{H}]^{+}: 328.2488$ Found: 328.2454 .

\subsubsection{Synthesis of acids (3a-g and 3j-k). General procedure A.}

A solution of ester $2(10 \mathrm{mmol})$ in tetrahydrofuran $(15 \mathrm{~mL})$ was treated with $1 \mathrm{M}$ aqueous $\mathrm{LiOH}(20 \mathrm{~mL})$. The reaction mixture was stirred for $3 \mathrm{~h}$ at room temperature while monitoring the disappearance of the ester by TLC. Most of the solvent was evaporated off and the solution was acidified to $\mathrm{pH} \sim 3$ using $5 \%$ hydrochloric acid (10 $\mathrm{mL})$. The aqueous layer was extracted with ethyl acetate $(2 \times 100 \mathrm{~mL})$ and the combined organic layer was washed with brine $(50 \mathrm{~mL})$. The organic layer was dried

over anhydrous sodium sulfate, filtered, and concentrated to yield compounds $\mathbf{3 a -} \mathbf{g}$ and 3j-k as colorless oils.

\subsubsection{1. (((1-phenylpent-4-en-1-yl) oxy) carbonyl)-L-leucine 3a}

Oil (yield 92\%); ${ }^{1} \mathrm{H}$ NMR (400 MHz, $\left.\mathrm{CDCl}_{3}-d\right) \delta$ ppm 0.68 - 1.05 (d, $6 \mathrm{H}$ ), 1.40 $1.73(\mathrm{~m}, 1 \mathrm{H}), 1.73$ - $1.95(\mathrm{~m}, 2 \mathrm{H}), 1.95$ - $2.21(\mathrm{~m}, 4 \mathrm{H}), 4.45$ - $4.53(\mathrm{~m}, 1 \mathrm{H}), 4.86-5.20$ (m, $2 \mathrm{H}), 5.54$ - $5.69(\mathrm{~m}, 1 \mathrm{H}), 5.69-5.92(\mathrm{~m}, 1 \mathrm{H}), 7.17$ - $7.35(\mathrm{~m}, 5 \mathrm{H}), 7.40$ - $7.50(\mathrm{~d}$, $1 \mathrm{H})$. HRMS (ESI) calcd for $\mathrm{C}_{18} \mathrm{H}_{26} \mathrm{NO}_{4}:[\mathrm{M}+\mathrm{H}]^{+}: 320.1862$ Found: 320.1865.

\subsubsection{2. (((1-phenylhex-5-en-2-yl) oxy) carbonyl)-L-leucine $\mathbf{3 b}$}

Oil (yield 91\%); $\left.1 \mathrm{H} \mathrm{NMR} \mathrm{(400} \mathrm{MHz,} \mathrm{CDCl}_{3}-d\right) \delta$ ppm $0.81-0.97$ (d, $\left.6 \mathrm{H}\right), 1.53$ $1.69(\mathrm{~m}, 5 \mathrm{H}), 1,91-2.02(\mathrm{~m}, 2 \mathrm{H}), 2.70$ - $2.93(\mathrm{~m}, 2 \mathrm{H}), 4.18$ - $4.28(\mathrm{~m}, 1 \mathrm{H}), 4.88$ - 5.09 (m, $3 \mathrm{H}), 5.67$ - $5.91(\mathrm{~m}, 1 \mathrm{H}), 6.20-660$ (br., $1 \mathrm{H}), 7.13$ - $7.43(\mathrm{~m}, 5 \mathrm{H}), 7.71-7.80(\mathrm{~d}$, $1 \mathrm{H})$. HRMS (ESI) calcd for $\mathrm{C}_{19} \mathrm{H}_{28} \mathrm{NO}_{4}:[\mathrm{M}+\mathrm{H}]^{+}: 334.2018$ Found: 334.2022.

\subsubsection{3. (((1-(3-chlorophenyl) pent-4-en-1-yl) oxy) carbonyl)-L-leucine 3c}

Oil (yield 92\%); ${ }^{1} \mathrm{H}$ NMR (400 MHz, $\left.\mathrm{CDCl}_{3}-d\right) \delta$ ppm 0.84 - $1.06(\mathrm{~d}, 6 \mathrm{H}), 1.41$ $1.72(\mathrm{~m}, 1 \mathrm{H}), 1.73$ - 2.24 (m, $5 \mathrm{H}), 2.42$ - 2.57 (m, $2 \mathrm{H}), 4.23$ - 4.42 (m, $1 \mathrm{H}), 4.60$ - 4.74 
$(\mathrm{m}, 1 \mathrm{H}), 4.92$ - $5.24(\mathrm{~m}, 1 \mathrm{H}), 5.54$ - $5.68(\mathrm{~m}, 1 \mathrm{H}), 5.72$ - $5.98(\mathrm{~m}, 1 \mathrm{H}), 7.15$ - $7.32(\mathrm{~m}$, $3 \mathrm{H}), 7.41(\mathrm{~s}, 1 \mathrm{H})$. HRMS (ESI) calcd for $\mathrm{C}_{18} \mathrm{H}_{25} \mathrm{CINO}_{4}:[\mathrm{M}+\mathrm{H}]^{+}: 354.1472$ Found: 354.1475 .

4.1.3.4. (2S)-2-(((1-(3-chlorophenyl) pent-4-en-1-yl) oxy) carbonyl) amino)-3cyclohexylpropanoic acid $\mathbf{3 d}$

Oil (yield 90\%); ${ }^{1} \mathrm{H}$ NMR (400 MHz, $\left.\mathrm{CDCl}_{3}-d\right) \delta$ ppm 0.77 - $1.30(\mathrm{~m}, 7 \mathrm{H}), 1.58$ $2.21(\mathrm{~m}, 8 \mathrm{H}), 4.25$ - $4.44(\mathrm{~m}, 2 \mathrm{H}), 4.65$ - $4.73(\mathrm{~m}, 1 \mathrm{H}), 4.95$ - $5.22(\mathrm{~m}, 2 \mathrm{H}), 5.53$ - 5.71 $(\mathrm{m}, 1 \mathrm{H}), 5.71-5.88(\mathrm{~m}, 1 \mathrm{H}), 7.14-7.41(\mathrm{~m}, 4 \mathrm{H}), 7.44-7.49(\mathrm{~s}, 1 \mathrm{H})$. HRMS (ESI) calcd for $\mathrm{C}_{21} \mathrm{H}_{29} \mathrm{CINO}_{4}:[\mathrm{M}+\mathrm{H}]^{+}: 394.1785$ Found: 394.1791 .

4.1.3.5. (((1-(3-chlorophenyl) hex-5-en-1-yl) oxy) carbonyl)-L-leucine $3 e$

Oil (yield 95\%); ${ }^{1} \mathrm{H}$ NMR (400 MHz, $\left.\mathrm{CDCl}_{3}-d\right) \delta$ ppm 0.85 - 1.00 (d, $6 \mathrm{H}$ ), 1.41 $1.78(\mathrm{~m}, 5 \mathrm{H}), 1.95$ - $2.17(\mathrm{~m}, 4 \mathrm{H}), 4.29$ - $4.48(\mathrm{~m}, 1 \mathrm{H}), 4.63$ - $4.73(\mathrm{~m}, 1 \mathrm{H}), 4.84-5.01$ $(\mathrm{m}, 1 \mathrm{H}), 5.18$ - $5.30(\mathrm{~m}, 2 \mathrm{H}), 5.72$ - $5.85(\mathrm{~m}, 2 \mathrm{H}), 7.14$ - 7.40 (m, $4 \mathrm{H})$. HRMS (ESI) calcd for $\mathrm{C}_{19} \mathrm{H}_{27} \mathrm{CINO}_{4}:[\mathrm{M}+\mathrm{H}]^{+}: 368.1629$ Found: 368.1637.

4.1.3.6. (((1-(3-chlorophenyl) pent-4-en-1-yl) oxy) carbonyl)-L-alanine $\mathbf{3 f}$

Oil (yield 92\%); ${ }^{1} \mathrm{H}$ NMR (400 MHz, $\left.\mathrm{CDCl}_{3}-d\right) \delta$ ppm 1.34 - 1.47 (d, $3 \mathrm{H}$ ), 1.75 $1.91(\mathrm{~m}, 2 \mathrm{H}), 1.91$ - $2.11(\mathrm{~m}, 2 \mathrm{H}), 4.28$ - $4.46(\mathrm{~m}, 1 \mathrm{H}), 4.97$ - $5.13(\mathrm{~m}, 2 \mathrm{H}), 5.35$ - 5.46 $(\mathrm{m}, 1 \mathrm{H}), 5.57-5.66(\mathrm{~m}, 1 \mathrm{H}), 5.73-5.87(\mathrm{~m}, 1 \mathrm{H}), 7.28(\mathrm{br} \mathrm{d}, J=5.47 \mathrm{~Hz}, 3 \mathrm{H}), 7.31$ $7.42(\mathrm{~s}, 1 \mathrm{H})$. HRMS (ESI) calcd for $\mathrm{C}_{15} \mathrm{H}_{19} \mathrm{CINO}_{4}:[\mathrm{M}+\mathrm{H}]^{+}: 312.1003$ Found: 312.1010.

\subsubsection{7. (((1-(3-chlorophenyl) hex-5-en-1-yl) oxy) carbonyl)-L-alanine $3 g$}

Oil (yield 92\%); ${ }^{1} \mathrm{H}$ NMR (400 MHz, $\left.\mathrm{CDCl}_{3}-d\right) \delta \mathrm{ppm} 1.27$ - $1.56(\mathrm{~m}, 5 \mathrm{H}), 1.66$ $2.14(\mathrm{~m}, 4 \mathrm{H}), 4.24$ - $4.39(\mathrm{~m}, 1 \mathrm{H}), 4.89$ - $5.06(\mathrm{~m}, 2 \mathrm{H}), 5.29$ - $5.49(\mathrm{~m}, 1 \mathrm{H}), 5.54$ - 5.83 $(\mathrm{m}, 2 \mathrm{H}), 7.10-7.36(\mathrm{~m}, 4 \mathrm{H}) \cdot 8.10-8.15$ (br s, $1 \mathrm{H})$. HRMS (ESI) calcd for $\mathrm{C}_{16} \mathrm{H}_{21} \mathrm{CINO}_{4}:[\mathrm{M}+\mathrm{H}]^{+}: 326.1159$ Found: 326.1168 .

4.1.3.8. (((1-phenyloct-7-en-4-yl) oxy) carbonyl)-L-leucine 3j 
Oil (yield 94\%); ${ }^{1} \mathrm{H}$ NMR (400 MHz, $\left.\mathrm{CDCl}_{3}-d\right) \delta \mathrm{ppm} 0.83-0.96(\mathrm{~d}, 6 \mathrm{H}), 1.37-$ $1.92(\mathrm{~m}, 7 \mathrm{H}), 1.95-2.07(\mathrm{~m}, 3 \mathrm{H}), 2.49-2.65(\mathrm{t}, 2 \mathrm{H}), 4.28-4.48(\mathrm{~m}, 1 \mathrm{H}), 4.71-4.81$ $(\mathrm{m}, 1 \mathrm{H}), 4.88$ - $5.08(\mathrm{~m}, 2 \mathrm{H}), 5.48$ - $5.63(\mathrm{~m}, 1 \mathrm{H}), 5.67$ - $5.87(\mathrm{~m}, 1 \mathrm{H}), 7.08$ - $7.18(\mathrm{~m}$, $2 \mathrm{H}), 7.18-7.28(\mathrm{~m}, 3 \mathrm{H}), 8.10-8.16(\mathrm{~d}, 1 \mathrm{H})$. HRMS (ESI) calcd for $\mathrm{C}_{21} \mathrm{H}_{32} \mathrm{NO}_{4}:[\mathrm{M}+\mathrm{H}]$ $+: 362.2331$ Found 362.2333 .

\subsubsection{9. ((Dec-1-en-5-yloxy) carbonyl)-L-leucine $3 k$}

Oil (yield 91\%); ${ }^{1} \mathrm{H}$ NMR (400 MHz, $\left.\mathrm{CDCl}_{3}-d\right) \delta$ ppm $0.83-0.90$ (t, $2 \mathrm{H}$ ), $0.90-$ $0.98(\mathrm{~d}, 6 \mathrm{H}), 1.20-1.35(\mathrm{~m}, 6 \mathrm{H}), 1.45-1.70(\mathrm{~m}, 4 \mathrm{H}), 1.98-2.15(\mathrm{~m}, 4 \mathrm{H}), 4.30-$ $4.43(\mathrm{~m}, 1 \mathrm{H}), 4.70-4.80(\mathrm{~m}, 1 \mathrm{H}), 4.90-5.05(\mathrm{~m}, 2 \mathrm{H}), 5.70-5.80(\mathrm{~m}, 1 \mathrm{H}), 7.80-$ $7.89(d, 1 \mathrm{H})$. HRMS (ESI) calcd for $\mathrm{C}_{17} \mathrm{H}_{32} \mathrm{NO}_{4}:[\mathrm{M}+\mathrm{H}]^{+}: 314.2331$ Found 314.2339.

\subsubsection{Synthesis of acids $3 h-i$. General procedure B.}

A solution of ester $2 \boldsymbol{a}$ or $\mathbf{2 i}(10 \mathrm{mmol})$ in tetrahydrofuran $(10 \mathrm{~mL})$ and methanol $(10 \mathrm{~mL})$ was treated with $2 \mathrm{M}$ aqueous $\mathrm{LiOH}(20 \mathrm{~mL})$ and the reaction mixture was heated to $60^{\circ} \mathrm{C}$ for $12 \mathrm{~h}$ with stirring. The disappearance of the ester was monitored by TLC. The reaction mixture was cooled to room temperature, the solvent was removed under reduced pressure, and the solution was acidified to $\mathrm{pH} \sim 3$ using $5 \%$ hydrochloric acid ( 20 mL). The aqueous layer was extracted with ethyl acetate $(2 \times 100 \mathrm{~mL})$ and the combined extracts were washed with brine $(50 \mathrm{~mL})$. The organic layer was dried over anhydrous $\mathrm{Na}_{2} \mathrm{SO}_{4}$, filtered, and concentrated to yield compounds $3 h-i$ as oils.

4.1.3.10. 1-(((1-(3-chlorophenyl) pent-4-en-1-yl) oxy) carbonyl) amino) cyclohexane-1carboxylic acid $3 \mathrm{~h}$

Oil (yield 90\%); ${ }^{1} \mathrm{H}$ NMR (400 MHz, $\left.\mathrm{CDCl}_{3}\right) \delta \mathrm{ppm} 1.18-1.66(\mathrm{~m}, 6 \mathrm{H}), 1.67-$ $2.21(\mathrm{~m}, 6 \mathrm{H}), 2.23$ - 2.40 (m, $2 \mathrm{H}), 4.69$ (dd, J=7.62, $5.27 \mathrm{~Hz}, 1 \mathrm{H}), 4.94$ - 5.09 (m, $2 \mathrm{H})$, 5.57 - $5.62(\mathrm{~m}, 1 \mathrm{H}), 5.72$ - $5.90(\mathrm{~m}, 1 \mathrm{H}), 7.14$ - $7.17(\mathrm{~m}, 1 \mathrm{H}), 7.15$ - $7.31(\mathrm{~m}, 4 \mathrm{H})$. HRMS (ESI) calcd for $\mathrm{C}_{19} \mathrm{H}_{25} \mathrm{CINO}_{4}:[\mathrm{M}+\mathrm{H}]^{+}: 366.1472$ Found 366.1478. 
4.1.3.11. 1-(((1-(3-chlorophenyl) hex-5-en-1-yl) oxy) carbonyl) amino) cyclohexane-1carboxylic acid $3 i$

Oil (yield 95\%); ${ }^{1} \mathrm{H}$ NMR (400 MHz, $\left.\mathrm{CDCl}_{3}\right) \delta$ ppm 1.30 - $2.16(\mathrm{~m}, 16 \mathrm{H}), 4.62$ $4.71(\mathrm{~m}, 1 \mathrm{H}), 4.88$ - $5.08(\mathrm{~m}, 2 \mathrm{H}), 5.48$ - $5.63(\mathrm{~m}, 1 \mathrm{H}), 5.67$ - $5.87(\mathrm{~m}, 1 \mathrm{H}), 7.11$ - 7.30 $(\mathrm{m}, 3 \mathrm{H}), 7.32-7.39(\mathrm{~s}, 1 \mathrm{H})$. HRMS (ESI) calcd for $\mathrm{C}_{20} \mathrm{H}_{27} \mathrm{CINO}_{4}:[\mathrm{M}+\mathrm{H}]^{+}: 380.1629$ Found 380.1637 .

4.1.4. Synthesis of amino acid methyl ester isocyanates $\mathbf{4 a - d .}$. General procedure.

The appropriate amino acid methyl ester hydrochloride $(55 \mathrm{mmol})$ was placed in a dry $500-\mathrm{mL}$ RB flask and then dried overnight on the vacuum pump. The flask was flushed with nitrogen and dry dioxane $(150 \mathrm{~mL})$ was added followed by trichloromethyl chloroformate (16.26 g, $82.5 \mathrm{mmol})$. After refluxing for $12 \mathrm{~h}$, the solvent was removed on the rotary evaporator and the residue was vacuum distilled to yield pure isocyanates 4a-d as colorless oils.

\subsubsection{Synthesis of compounds 5a-b. General procedure.}

To a solution of Boc-L-glutamic acid $\alpha$-methyl ester $(80 \mathrm{mmol})$ in dry DMF (200 $\mathrm{mL}$ ) were added $\mathrm{EDCl}(19.93 \mathrm{~g} ; 104 \mathrm{mmol}), \mathrm{HOBt}(15.92 \mathrm{~g} ; 104 \mathrm{mmol})$ and the reaction mixture was stirred for $30 \mathrm{~min}$ at room temperature. Following the sequential addition of allylamine/O-allylhydroxylamine hydrochloride $(120 \mathrm{mmol})$ and DIEA (20.68 g; 160 $\mathrm{mmol}$ ), the reaction mixture was stirred for $16 \mathrm{~h}$ at room temperature. Completion of the reaction was monitored by TLC. The solvent was removed and the residue was partitioned between ethyl acetate $(400 \mathrm{~mL})$ and $5 \%$ aqueous $\mathrm{HCl}(100 \mathrm{~mL})$. The layers were separated and the organic layer was further washed with saturated aqueous $\mathrm{NaHCO}_{3}(2 \times 100 \mathrm{~mL})$, followed by saturated $\mathrm{NaCl}(100 \mathrm{~mL})$. The organic layer was 
dried over anhydrous sodium sulfate, filtered and concentrated to yield a yellow-colored oily product. Purification by flash chromatography yielded a white solid.

\subsubsection{Methyl $N^{5}$-allyl- $N^{2}$-(tert-butoxycarbonyl)-L-glutaminate $5 a$}

White solid (yield 85\%); m.p. 69-70 ${ }^{\circ}$; ${ }^{1} \mathrm{H}$ NMR $\left(400 \mathrm{MHz}, \mathrm{CDCl}_{3}-d\right) \delta$ ppm 1.42 $1.50(\mathrm{~s}, 9 \mathrm{H}), 1.90-2.00(\mathrm{~m}, 1 \mathrm{H}), 2.16-2.28(\mathrm{~m} .1 \mathrm{H}), 3.74-3.80(\mathrm{~s}, 3 \mathrm{H}), 3.91-4.00$ (t, 2 H), $4.34-4.41$ (m, 1 H), $5.09-5.22$ (m, 2 H), $5.30-5.40$ (br. s, 1 H), $5.78-5.94$ $(\mathrm{m}, 1 \mathrm{H}), 6.10-6.20$ (br. s, $1 \mathrm{H}$ ). HRMS (ESI) calcd for $\mathrm{C}_{14} \mathrm{H}_{25} \mathrm{~N}_{2} \mathrm{O}_{5}:[\mathrm{M}+\mathrm{H}]^{+}: 301.1763$ Found 301.1771 .

\subsubsection{Methyl $N^{5}$-(allyloxy)- $N^{2}$-(tert-butoxycarbonyl)-L-glutaminate $5 \boldsymbol{b}$}

Sticky oil (yield 54\%); ${ }^{1} \mathrm{H}$ NMR (400 MHz, $\left.\mathrm{CDCl}_{3}-d\right) \delta$ ppm $1.41-1.50$ (s, $\left.9 \mathrm{H}\right), 1.78-$ 1.96 (br. s, 1 H), 2.12 - 2.28 (m. 4 H), $3.72-3.80$ (s, 3 H), $4.24-4.37$ (m, 2 H), 4.44 4.51 (m, 1 H), 5.29 - 5.50 (m, 2 H), 5.92 - 6.07 (m, 1 H), 9.29 - 9.42 (br. s, 1 H). HRMS (ESI) calcd for $\mathrm{C}_{14} \mathrm{H}_{25} \mathrm{~N}_{2} \mathrm{O}_{6}:[\mathrm{M}+\mathrm{H}]^{+}: 317.1713$ Found 317.1718 .

4.1.6. Synthesis of compounds 6a-b. General procedure.

To a solution of compound $5(43 \mathrm{mmol})$ in dry DCM $(30 \mathrm{~mL})$ was added a solution of $4 \mathrm{M} \mathrm{HCl}$ in dioxane $(130 \mathrm{~mL})$ with stirring. The reaction mixture was stirred for $3 \mathrm{~h}$ at room temperature. The disappearance of the starting material was monitored by TLC. The solvent was evaporated under reduced pressure and compound 6 was used in the next step without further purification.

\subsubsection{Synthesis of acyclic compounds $7 \mathbf{a}-\mathbf{k}$ and $\mathbf{3 2}$.}

General procedure. To a solution of compound $3(15 \mathrm{mmol})$ in dry DMF (40 mL) was added $\mathrm{EDCl}(3.74 \mathrm{~g}, 19.5 \mathrm{mmol}, 1.30 \mathrm{eq})$, HOBt (2.97 g, $19.5 \mathrm{mmol}, 1.30 \mathrm{eq})$ and the mixture was stirred for $30 \mathrm{~min}$ at room temperature. In a separate flask, a solution of 
compound $6 a(3.55 \mathrm{~g}, 15 \mathrm{mmol})$ in DMF $(20 \mathrm{~mL})$ cooled to $0-5^{\circ} \mathrm{C}$ was treated with diisopropyl ethylamine (DIEA) $(7.75 \mathrm{~g}, 60 \mathrm{mmol}, 4 \mathrm{eq})$, stirred for $30 \mathrm{~min}$, and then added to the reaction mixture containing acid $\mathbf{3}$. The reaction mixture was stirred for 16 $\mathrm{h}$ while monitoring the reaction by TLC. The solvent was removed and the residue was partitioned between ethyl acetate $(300 \mathrm{~mL})$ and $10 \%$ citric acid $(50 \mathrm{~mL})$. The layers were separated and the organic layer was further washed with saturated aqueous $\mathrm{NaHCO}_{3}(2 \times 50 \mathrm{~mL})$, followed by brine $(50 \mathrm{~mL})$. The organic layer was dried over anhydrous sodium sulfate, filtered and concentrated to yield a yellow-colored oily product. Purification by flash chromatography yielded esters 7a-k.

4.1.7.1. Methyl $\quad N^{5}$-allyl- $N^{2}-((((1-p h e n y l p e n t-4-e n-1-y l) \quad$ oxy $) \quad$ carbonyl)-L-leucyl)-Lglutaminate $7 a$

Oil (yield 62\%); ${ }^{1} \mathrm{H}$ NMR (400 MHz, $\left.\mathrm{CDCl}_{3}-d\right) \delta$ ppm 0.68 - 1.05 (d, $\left.6 \mathrm{H}\right), 1.40-$ $1.73(\mathrm{~m}, 3 \mathrm{H}), 1.73-1.95(\mathrm{~m}, 2 \mathrm{H}), 1.95-2.21(\mathrm{~m}, 6 \mathrm{H}), 3.64-3.76(\mathrm{~s}, 3 \mathrm{H}), 4.45-4.53$ $(\mathrm{m}, 4 \mathrm{H}), 4.86$ - $5.20(\mathrm{~m}, 4 \mathrm{H}), 5.54$ - $5.69(\mathrm{~m}, 2 \mathrm{H}), 5.69$ - $5.92(\mathrm{~m}, 2 \mathrm{H}), 7.17$ - $7.35(\mathrm{~m}$, $5 \mathrm{H}), 7.40-7.50(\mathrm{~d}, 1 \mathrm{H}), 7.90-7.80(\mathrm{~d}, 1 \mathrm{H})$. HRMS (ESI) calcd for $\mathrm{C}_{27} \mathrm{H}_{40} \mathrm{~N}_{3} \mathrm{O}_{6}$ : $[\mathrm{M}+\mathrm{H}]^{+}:$502.2917 Found 502.2921.

4.1.7.2. Methyl $\quad N^{5}$-allyl- $N^{2}-(((1-$ phenylhex-5-en-2-yl) oxy) carbonyl)-L-leucyl)-Lglutaminate $7 \mathbf{b}$

Oil (yield 60\%); ${ }^{1} \mathrm{H}$ NMR $\left(400 \mathrm{MHz}, \mathrm{CDCl}_{3}-d\right) \delta \mathrm{ppm} 0.81-0.97(\mathrm{~d}, 6 \mathrm{H}), 1.53-$ $1.69(\mathrm{~m}, 5 \mathrm{H}), 1,91-2.02(\mathrm{~m}, 6 \mathrm{H}), 2.70-2.93(\mathrm{~m}, 2 \mathrm{H}), 3.73(\mathrm{~s}, 3 \mathrm{H}), 3.80$ - 3.94 (t, 2 H), 4.40 - $4.62(\mathrm{~m}, 2 \mathrm{H}), 4.88$ - $5.04(\mathrm{~m}, 2 \mathrm{H}), 5.06$ - $5.26(\mathrm{~m}, 2 \mathrm{H}), 5.68$ - $5.87(\mathrm{~m}, 3 \mathrm{H})$, $6.20-6.41$ (br. d, $1 \mathrm{H}), 6.91-7.10(\mathrm{~d}, 1 \mathrm{H}), 7.14-7.36(\mathrm{~m}, 5 \mathrm{H}), 7.85-7.92(\mathrm{~d}, 1 \mathrm{H})$. HRMS (ESI) calcd for $\mathrm{C}_{28} \mathrm{H}_{42} \mathrm{~N}_{3} \mathrm{O}_{6}:[\mathrm{M}+\mathrm{H}]^{+}: 516.3074$ Found 516.3080.

4.1.7.3. Methyl $N^{5}$-allyl- $N^{2}-((((1-(3-c h l o r o p h e n y l) \quad$ pent-4-en-1-yl) oxy) carbonyl)-Lleucyl)-L-glutaminate $7 c$ 
Oil (yield 65\%); ${ }^{1} \mathrm{H}$ NMR (400 MHz, $\left.\mathrm{CDCl}_{3}-d\right) \delta \mathrm{ppm} 0.74-1.02(\mathrm{~d}, 6 \mathrm{H}), 1.43$ $2.13(\mathrm{~m}, 4 \mathrm{H}), 2.13$ - $2.38(\mathrm{~m}, 6 \mathrm{H}), 3.60$ - $3.71(\mathrm{~s}, 3 \mathrm{H}), 4.07$ - $4.24(\mathrm{~m}, 1 \mathrm{H}), 4.41$ - 4.61 $(\mathrm{m}, 2 \mathrm{H}), 4.91-5.25(\mathrm{~m}, 1 \mathrm{H}), 5.25-5.42(\mathrm{~m}, 2 \mathrm{H}), 5.50$ - $5.68(\mathrm{~m}, 2 \mathrm{H}), 5.70$ - $5.92(\mathrm{~m}$, $2 \mathrm{H}), 6.07$ - $6.26(\mathrm{~m}, 2 \mathrm{H}), 6.30$ - $6.39(\mathrm{~m}, 1 \mathrm{H}), 6.96$ - $7.34(\mathrm{~m}, 4 \mathrm{H}), 7.7$ - $7.8(\mathrm{~d}, 1 \mathrm{H})$, $8.1-8.2(\mathrm{~d}, 1 \mathrm{H})$. HRMS (ESI) calcd for $\mathrm{C}_{27} \mathrm{H}_{39} \mathrm{CIN}_{3} \mathrm{O}_{6}:[\mathrm{M}+\mathrm{H}]^{+}: 536.2527$ Found 536.2534 .

4.1.7.4. Methyl $N^{5}$-allyl- $N^{2}-((2 S)-2-(((1-(3-c h l o r o p h e n y l)$ pent-4-en-1-yl) oxy) carbonyl) amino)-3-cyclohexylpropanoyl) glutaminate $7 d$

Oil (yield70\%); ${ }^{1} \mathrm{H}$ NMR (400 MHz, $\left.\mathrm{CDCl}_{3}-d\right) \delta$ ppm $0.75-1.59(\mathrm{~m}, 4 \mathrm{H}), 1.55-$ $1.73(\mathrm{~m}, 4 \mathrm{H}), 1.74$ - $1.89(\mathrm{~m}, 4 \mathrm{H}), 1.89$ - $2.14(\mathrm{~m}, 5 \mathrm{H}), 2.14$ - $2.31(\mathrm{~m}, 4 \mathrm{H}), 3.65$ - 3.76 (d, 3 H), 3.76 - $4.02(\mathrm{~m}, 1 \mathrm{H}), 4.07$ - $4.29(\mathrm{~m}, 1 \mathrm{H}), 4.40$ - $4.61(\mathrm{~m}, 2 \mathrm{H}), 4.93$ - $5.38(\mathrm{~m}, 2$ H), 5.43 - $5.64(\mathrm{~m}, 2 \mathrm{H}), 5.69-5.90(\mathrm{~m}, 3 \mathrm{H}), 6.10$ - $6.20(\mathrm{~d}, 1 \mathrm{H}), 6.35$ - $6.44(\mathrm{~d}, 1 \mathrm{H})$, $6.86-7.05(\mathrm{~d}, 1 \mathrm{H}), 7.12-7.37(\mathrm{~m}, 4 \mathrm{H})$. HRMS (ESI) calcd for $\mathrm{C}_{30} \mathrm{H}_{43} \mathrm{CIN}_{3} \mathrm{O}_{6}:[\mathrm{M}+\mathrm{H}]^{+}$: 576.2840 Found 576.2848 .

4.1.7.5. Methyl $N^{5}$-allyl- $N^{2}-(((1-(3-c h l o r o p h e n y l)$ hex-5-en-1-yl) oxy) carbonyl)-L-leucyl)L-glutaminate $7 e$

Oil (yield 75\%); ${ }^{1} \mathrm{H}$ NMR (400 MHz, $\mathrm{CDCl}_{3}-d$ ) $\delta$ ppm 0.82 - 1.03 (d, $6 \mathrm{H}$ ), 1.20 $2.32(\mathrm{~m}, 13 \mathrm{H}), 3.73(\mathrm{br} \mathrm{d}, \mathrm{J}=12.89 \mathrm{~Hz}, 3 \mathrm{H}), 4.03-4.20(\mathrm{~m}, 2 \mathrm{H}), 4.38$ - $4.59(\mathrm{~m}, 2 \mathrm{H})$, 4.89 - $5.03(\mathrm{~m}, 2 \mathrm{H}), 5.08$ - $5.32(\mathrm{~m}, 2 \mathrm{H}), 5.48$ - $5.67(\mathrm{~m}, 1 \mathrm{H}), 5.68$ - $5.94(\mathrm{~m}, 1 \mathrm{H}), 5.98$ - $6.12(\mathrm{~m}, 1 \mathrm{H}), 6.21$ - 6.34 (br s, $1 \mathrm{H}), 6.86$ - 7.03 (br s, $2 \mathrm{H}), 7.13$ - 7.37 (m, $4 \mathrm{H})$. HRMS (ESI) calcd for $\mathrm{C}_{28} \mathrm{H}_{41} \mathrm{CIN}_{3} \mathrm{O}_{6}:[\mathrm{M}+\mathrm{H}]^{+}: 550.2684$ Found 550.2691 .

4.1.7.6. Methyl $N^{5}$-allyl- $N^{2}-(((1-(3-c h l o r o p h e n y l) \quad$ pent-4-en-1-yl) oxy) carbonyl)-Lalanyl)-L-glutaminate $7 f$

Oil (yield 80\%); ${ }^{1} \mathrm{H}$ NMR (400 MHz, $\mathrm{CDCl}_{3}-d$ ) $\delta$ ppm 1.39 (d, J=7.03 Hz, $3 \mathrm{H}$ ), 1.75 - $1.91(\mathrm{~m}, 4 \mathrm{H}), 1.91$ - $2.11(\mathrm{~m}, 4 \mathrm{H}), 3.66$ - $3.71(\mathrm{~s}, 3 \mathrm{H}), 4.17$ - 4.27 (d, $2 \mathrm{H}), 4.41$ $4.61(\mathrm{~m}, 2 \mathrm{H}), 4.92$ - $5.25(\mathrm{~m}, 4 \mathrm{H}), 5.47$ - $5.65(\mathrm{~m}, 1 \mathrm{H}), 5.71$ - $5.88(\mathrm{~m}, 2 \mathrm{H}), 6.15-6.20$ (br s, $1 \mathrm{H}$ ), 6.40 - 6.45 (br s, $1 \mathrm{H}$ ), 7.12 - 7.32 (m, $4 \mathrm{H}$ ), 7.50 - 7.60 (d, $1 \mathrm{H})$. HRMS (ESI) calcd for $\mathrm{C}_{24} \mathrm{H}_{33} \mathrm{CIN}_{3} \mathrm{O}_{6}:[\mathrm{M}+\mathrm{H}]^{+}:$494.2058 Found 494.2067. 
4.1.7.7. Methyl $N^{5}$-allyl- $N^{2}-(((1-(3-c h l o r o p h e n y l)$ hex-5-en-1-yl) oxy) carbonyl)-L-alanyl)L-glutaminate $7 g$

Oil (yield 80\%); ${ }^{1} \mathrm{H}$ NMR (400 MHz, $\left.\mathrm{CDCl}_{3}-d\right) \delta$ ppm 1.30- $1.39(\mathrm{~m}, 2 \mathrm{H}), 1.39-$ 1.42 (d, J=7.03 Hz, 3 H), 1.75 - 1.91 (m, $4 \mathrm{H}), 1.91$ - $2.11(\mathrm{~m}, 4 \mathrm{H}), 3.66$ - 3.71 (s, $3 \mathrm{H})$, 4.17 - $4.27(\mathrm{~d}, 2 \mathrm{H}), 4.41$ - $4.61(\mathrm{~m}, 2 \mathrm{H}), 4.92$ - $5.25(\mathrm{~m}, 4 \mathrm{H}), 5.47$ - $5.65(\mathrm{~m}, 1 \mathrm{H}), 5.71$ - 5.88 (m, 2 H), 6.15- 6.20 (br s, 1 H), 6.40 - 6.45 (br s, 1 H), 7.12 - 7.32 (m, 4 H), 7.50 $7.60(d, 1 \mathrm{H})$. HRMS (ESI) calcd for $\mathrm{C}_{25} \mathrm{H}_{35} \mathrm{CIN}_{3} \mathrm{O}_{6}:[\mathrm{M}+\mathrm{H}]^{+}: 508.2214$ Found 508.2218.

4.1.7.8. Methyl $N^{5}$-allyl- $N^{2}-(1-(((1-(3-c h l o r o p h e n y l) \quad$ pent-4-en-1-yl) oxy) carbonyl) amino) cyclohexane-1-carbonyl)-L-glutaminate $7 \mathrm{~h}$

Oil (yield 55\%); ${ }^{1} \mathrm{H}$ NMR (400 MHz, $\left.\mathrm{CDCl}_{3}\right) \delta$ ppm $1.20-1.48(\mathrm{~m}, 5 \mathrm{H}), 1.49-$ $1.74(\mathrm{~m}, 5 \mathrm{H}), 1.75-1.90(\mathrm{~m}, 4 \mathrm{H}), 1.90-2.35(\mathrm{~m}, 4 \mathrm{H}), 3.71(\mathrm{~s}, 3 \mathrm{H}), 3.76-3.91(\mathrm{~m}, 2$ H), 4.41 - $4.61(\mathrm{~m}, 1 \mathrm{H}), 4.95$ - $5.26(\mathrm{~m}, 4 \mathrm{H}), 5.72$ - 5.91 (m, 3 H), 6.29 - 6.45 (br. d, 1 H), 6.57 - 6.71 (br. s, $1 \mathrm{H}$ ), 6.95 - 7.06 (d, $1 \mathrm{H}), 7.15$ - 7.35 (m, $4 \mathrm{H})$. HRMS (ESI) calcd for $\mathrm{C}_{28} \mathrm{H}_{39} \mathrm{ClN}_{3} \mathrm{O}_{6}:[\mathrm{M}+\mathrm{H}]^{+}: 548.2527$ Found 548.2531.

4.1.7.9. Methyl $N^{5}$-allyl- $N^{2}-(1-(((1-(3-c h l o r o p h e n y l) ~ h e x-5-e n-1-y l)$ oxy) carbonyl) amino) cyclohexane-1-carbonyl)-L-glutaminate $7 i$

Oil (yield 57\%); ${ }^{1} \mathrm{H}$ NMR (400 MHz, $\left.\mathrm{CDCl}_{3}-d\right) \delta \mathrm{ppm} 1.16-1.53(\mathrm{~m}, 7 \mathrm{H}), 1.54-$ $1.74(\mathrm{~m}, 7 \mathrm{H}), 1.75-2.34(\mathrm{~m}, 6 \mathrm{H}), 3.71(\mathrm{~s}, 3 \mathrm{H}), 3.73-3.90(\mathrm{~m}, 2 \mathrm{H}), 4.39-4.63(\mathrm{~m}, 1$ H), 4.90 - $5.27(\mathrm{~m}, 4 \mathrm{H}), 5.41$ - $5.61(\mathrm{~m}, 1 \mathrm{H}), 5.65$ - $5.91(\mathrm{~m}, 2 \mathrm{H}), 6.29$ - 6.44 (br. $\mathrm{s}, 1$ H), 6.60 - $6.66(\mathrm{~d}, 1 \mathrm{H}), 6.89-7.03(\mathrm{~d}, 1 \mathrm{H}), 7.13$ - $7.18(\mathrm{~m}, 3 \mathrm{H}), 7.21$ - $7.31(\mathrm{~s}, 1 \mathrm{H})$. HRMS (ESI) calcd for $\mathrm{C}_{29} \mathrm{H}_{41} \mathrm{CIN}_{3} \mathrm{O}_{6}:[\mathrm{M}+\mathrm{H}]^{+}: 562.2684$ Found 562.2685 .

4.1.7.10. Methyl $\quad N^{5}$-allyl- $N^{2}-(((1-$ phenyloct-7-en-4-yl) oxy) carbonyl)-L-leucyl)-Lglutaminate $7 j$

White solid (yield 62\%); m.p $99-100^{\circ} \mathrm{C}$. ${ }^{1} \mathrm{H}$ NMR (400 MHz, $\left.\mathrm{CDCl}_{3}-d\right) \delta \mathrm{ppm}$ $0.90-0.99$ (d, $6 \mathrm{H}), 1.46-1.74(\mathrm{~m}, 7 \mathrm{H}), 1.75-1.82(\mathrm{t}, 2 \mathrm{H}), 1.90-2.12(\mathrm{~m}, 4 \mathrm{H}), 2.14$ $-2.35(\mathrm{~m}, 2 \mathrm{H}), 2.52-2.60(\mathrm{t}, 2 \mathrm{H}), 3.70-3.75(\mathrm{~s}, 3 \mathrm{H}), 3.80-3.90(\mathrm{~d}, 2 \mathrm{H}), 4.10-4.20$ $(\mathrm{m}, 1 \mathrm{H}), 4.48$ - $4.59(\mathrm{~m}, 1 \mathrm{H}), 4.71-4.84(\mathrm{~m}, 1 \mathrm{H}), 4.90$ - $5.23(\mathrm{~m}, 4 \mathrm{H}), 5.70$ - $5.90(\mathrm{~m}$, 2 H), 6.20 - 6.30 (br. s, 1 H), $6.30-6.40$ (br. s, 1 H), 6.93 - 6.70 (d, 1 H), 7.11 - 7.20 (d, 
$2 \mathrm{H}), 7.22-7.30(\mathrm{~m}, 3 \mathrm{H})$. HRMS (ESI) calcd for $\mathrm{C}_{30} \mathrm{H}_{46} \mathrm{~N}_{3} \mathrm{O}_{6}:[\mathrm{M}+\mathrm{H}]^{+}: 544.3387$ Found 544.3390 .

4.1.7.11. Methyl $N^{5}$-allyl- $N^{2}$-(((dec-1-en-5-yloxy) carbonyl)-L-leucyl)-L-glutaminate 7k

White solid (yield 70\%); m.p $103-104^{\circ} \mathrm{C} .{ }^{1} \mathrm{H}$ NMR (400 MHz, $\left.\mathrm{CDCl}_{3}-d\right) \delta \mathrm{ppm}$ $0.83-0.91$ (t, $2 \mathrm{H}), 0.91-0.99(\mathrm{~d}, 6 \mathrm{H}), 1.20-1.35(\mathrm{~m}, 6 \mathrm{H}), 1.45-1.70(\mathrm{~m}, 4 \mathrm{H}), 1.98$ - $2.12(\mathrm{~m}, 4 \mathrm{H}), 2.14-2.35(\mathrm{~m}, 2 \mathrm{H}), 2.52-2.60(\mathrm{t}, 2 \mathrm{H}), 3.72-3.76(\mathrm{~s}, 3 \mathrm{H}), 3.80-$ $3.90(\mathrm{~d}, 2 \mathrm{H}), 4.10-4.20(\mathrm{~m}, 1 \mathrm{H}), 4.50-4.60(\mathrm{~m}, 1 \mathrm{H}), 4.66-4.78(\mathrm{~m}, 1 \mathrm{H}), 4.91-5.24$ (m, 4 H), 5.71 - 5.90 (m, 2 H), 6.35 - 6.50 (br. s, 2 H), $6.91-7.00$ (d, 1 H). HRMS (ESI) calcd for $\mathrm{C}_{26} \mathrm{H}_{46} \mathrm{~N}_{3} \mathrm{O}_{6}:[\mathrm{M}+\mathrm{H}]^{+}: 496.3387$ Found 496.3388.

4.1.7.12. Methyl $N^{5}$-(allyloxy)- $N^{2}-(((1-(3-c h l o r o p h e n y l)$ pent-4-en-1-yl)oxy)carbonyl)-Lleucyl)-L-glutaminate 32

Oil (yield 52\%); ${ }^{1} \mathrm{H}$ NMR (400 MHz, $\left.\mathrm{CDCl}_{3}-d\right) \delta$ ppm $0.83-1.00$ (dd, $6 \mathrm{H}$ ), $1.23-$ 1.29 (t, $2 \mathrm{H}), 1.43-2.15(\mathrm{~m}, 5 \mathrm{H}), 2.14-2.35(\mathrm{~m}, 4 \mathrm{H}), 3.69-3.80(\mathrm{~d}, 3 \mathrm{H}), 4.03-4$. $22(\mathrm{~m}, 2 \mathrm{H}), 4.32-4.48(\mathrm{~m}, 2 \mathrm{H}), 4.93-5.06(\mathrm{~m}, 2 \mathrm{H}), 5.23-5.44(\mathrm{~m}, 2 \mathrm{H}), 5.50-5.61$ $(\mathrm{m}, 1 \mathrm{H}), 5.73-5.84(\mathrm{~m}, 1 \mathrm{H}), 5.87-6.05(\mathrm{~m}, 1 \mathrm{H}), 6.76-6.89$ (br. s, $1 \mathrm{H}), 7.13-7.20$ (s, $1 \mathrm{H}), 7.23-7.33(\mathrm{~m}, 3 \mathrm{H}), 9.22-9.29(\mathrm{~d}, 1 \mathrm{H}), 9.43-9.51(\mathrm{~d}, 1 \mathrm{H})$. HRMS (ESI) calcd for $\mathrm{C}_{27} \mathrm{H}_{39} \mathrm{ClN}_{3} \mathrm{O}_{7}:[\mathrm{M}+\mathrm{H}]^{+}:$552.2477 Found 552.2479.

4.1.8. Synthesis of compounds $\mathbf{8} \mathbf{a}-\mathbf{k}$ and 33. General procedure for ring closing metathesis.

A solution of acyclic diene $7(1.21 \mathrm{mmol})$ in dry DCM $(1.5 \mathrm{~L})$ was degassed for 30 min using nitrogen. Chloro dicyclohexyl borane $(1 \mathrm{M}$ in hexane) $(1.21 \mathrm{~mL} ; 1.21$ mmol) and Grubb's $2^{\text {nd }}$ generation catalyst (104 mg; 10 mol\%) were added and degassing was continued for $10 \mathrm{~min}$. The reaction mixture was heated to $45{ }^{\circ} \mathrm{C}$ and stirred for 30 min under a nitrogen atmosphere. An additional portion of Grubb's $2^{\text {nd }}$ generation catalyst (52 mg; $5 \mathrm{~mol} \%$ ) was added and the solution stirred for $16 \mathrm{~h}$ at 45 ${ }^{\circ} \mathrm{C}$ under a nitrogen atmosphere. The reaction was quenched by adding activated 
charcoal $(600 \mathrm{mg})$ and stirring the reaction for $18 \mathrm{~h}$ at room temperature. The reaction mixture was filtered through a Celite bed and the solvent was removed on the rotary evaporator. The crude residue was purified by flash chromatography to give macrocyclic esters $\mathbf{8} a-k$ as off-white solids.

4.1.8.1. Methyl (4S,7S, E)-4-isobutyl-2,5,10-trioxo-17-phenyl-1-oxa-3,6,11triazacycloheptadec-13-ene-7-carboxylate 8a

Off-white solid (yield 65\%); m.p $79-80^{\circ} \mathrm{C} .{ }^{1} \mathrm{H}$ NMR $\left(400 \mathrm{MHz}, \mathrm{CDCl}_{3}-d\right) \delta \mathrm{ppm}$ 0.68 - 1.05 (d, $6 \mathrm{H}), 1.40$ - $1.73(\mathrm{~m}, 3 \mathrm{H}), 1.73$ - $1.95(\mathrm{~m}, 2 \mathrm{H}), 1.95$ - $2.21(\mathrm{~m}, 6 \mathrm{H}), 3.64$ - $3.76(\mathrm{~s}, 3 \mathrm{H}), 3.80$ - $3.89(\mathrm{~m}, 2 \mathrm{H}), 4.45$ - $4.53(\mathrm{~m}, 2 \mathrm{H}), 5.51$ - $5.74(\mathrm{~m}, 2 \mathrm{H}), 5.76$ $5.90(\mathrm{~m}, 1 \mathrm{H}), 7.17$ - $7.35(\mathrm{~m}, 5 \mathrm{H}), 7.40-7.50(\mathrm{~d}, 1 \mathrm{H}), 7.90-7.80(\mathrm{~d}, 1 \mathrm{H}), 8.25-$ $8.35(\mathrm{~d}, 1 \mathrm{H})$. HRMS (ESI) calcd for $\mathrm{C}_{25} \mathrm{H}_{36} \mathrm{~N}_{3} \mathrm{O}_{6}:[\mathrm{M}+\mathrm{H}]^{+}: 474.2604$ Found: 474.2608.

4.1.8.2. Methyl (4S,7S, E)-17-benzyl-4-isobutyl-2,5,10-trioxo-1-oxa-3,6,11triazacycloheptadec-13-ene-7-carboxylate $8 \mathbf{b}$

Off-white solid (yield 68\%); m.p $70-71^{\circ} \mathrm{C} .{ }^{1} \mathrm{H}$ NMR (400 MHz, $\left.\mathrm{CDCl}_{3}-d\right) \delta \mathrm{ppm}$ $0.81-0.97(\mathrm{~d}, 6 \mathrm{H}), 1.53-1.69(\mathrm{~m}, 4 \mathrm{H}), 1,91-2.02(\mathrm{~m}, 5 \mathrm{H}), 2.70-2.93(\mathrm{~m}, 2 \mathrm{H}), 3.73$ - $3.80(\mathrm{~s}, 3 \mathrm{H}), 3.80$ - $3.94(\mathrm{~m}, 2 \mathrm{H}), 4.40-4.62(\mathrm{~m}, 2 \mathrm{H}), 4.88-5.04(\mathrm{~m}, 1 \mathrm{H}), 5.06$ $5.26(\mathrm{~m}, 2 \mathrm{H}), 5.68$ - 5.87 (m, $2 \mathrm{H}), 6.20$ - 6.41 (br. d, $1 \mathrm{H}), 6.91$ - 7.10 (d, $1 \mathrm{H}), 7.14$ $7.36(\mathrm{~m}, 5 \mathrm{H}), 7.85-7.92(\mathrm{~d}, 1 \mathrm{H})$. HRMS (ESI) calcd for $\mathrm{C}_{26} \mathrm{H}_{38} \mathrm{~N}_{3} \mathrm{O}_{6}:[\mathrm{M}+\mathrm{H}]^{+}$: 488.2761 Found: 488.2767.

4.1.8.3. Methyl (4S,7S, E)-17-(3-chlorophenyl)-4-isobutyl-2,5,10-trioxo-1-oxa-3,6,11triazacycloheptadec-13-ene-7-carboxylate $8 \mathrm{c}$

Off-white solid (yield 70\%); m.p $84-85{ }^{\circ} \mathrm{C} .{ }^{1} \mathrm{H}$ NMR (400 MHz, $\mathrm{CDCl}_{3}-d$ ) $\delta \mathrm{ppm}$ 0.74 - 0.99 (d, $6 \mathrm{H}), 1.42$ - $1.83(\mathrm{~m}, 3 \mathrm{H}), 2.11$ - $2.43(\mathrm{~m}, 6 \mathrm{H}), 2.47$ - $2.64(\mathrm{~m}, 2 \mathrm{H}), 3.28$ $3.40(\mathrm{~m}, 2 \mathrm{H}), 3.69-3.81(\mathrm{~s}, 3 \mathrm{H}), 3.81$ - $3.96(\mathrm{t}, 2 \mathrm{H}), 4.62-4.77(\mathrm{~m}, 1 \mathrm{H}), 5.24-5.35$ $(\mathrm{m}, 1 \mathrm{H}), 5.54-5.75(\mathrm{~m}, 1 \mathrm{H}), 5.91$ - $6.03(\mathrm{~m}, 1 \mathrm{H}), 6.14$ - $6.24(\mathrm{~d}, 1 \mathrm{H}), 6.96$ - $7.34(\mathrm{~m}, 4$ $\mathrm{H}), 8.02-8.11(\mathrm{~d}, 1 \mathrm{H}), 8.60-8.65(\mathrm{~d}, 1 \mathrm{H})$. HRMS (ESI) calcd for $\mathrm{C}_{25} \mathrm{H}_{35} \mathrm{CIN}_{3} \mathrm{O}_{6}$ : $[\mathrm{M}+\mathrm{H}]^{+}:$508.2214 Found: 508.2219. 
4.1.8.4. Methyl (4S,7S, E)-17-(3-chlorophenyl)-4-(cyclohexylmethyl)-2,5,10-trioxo-1-oxa3,6,11-triazacycloheptadec-13-ene-7-carboxylate 8d

Off-white solid (yield 69\%); m.p (A: $\left.74-75^{\circ} \mathrm{C}\right),\left(B: 177-178^{\circ} \mathrm{C}\right) .{ }^{1} \mathrm{H}$ NMR (400 $\left.\mathrm{MHz}, \mathrm{CDCl}_{3}-d\right) \delta$ ppm 0.66 - $0.93(\mathrm{~m}, 11 \mathrm{H}), 0.95-2.32(\mathrm{~m}, 10 \mathrm{H}), 3.61$ - $3.74(\mathrm{~s}, 3 \mathrm{H})$, 3.74 - $3.86(\mathrm{~d}, 2 \mathrm{H}), 4.00$ - $4.20(\mathrm{~m}, 1 \mathrm{H}), 4.29$ - $4.51(\mathrm{~m}, 1 \mathrm{H}), 4.84-5.01(\mathrm{~m}, 1 \mathrm{H}), 5.42$ - $5.83(\mathrm{~m}, 2 \mathrm{H}), 5.94$ - $6.11(\mathrm{~m}, 1 \mathrm{H}), 6.22$ - $6.31(\mathrm{~d}, 1 \mathrm{H}), 6.75$ - $6.92(\mathrm{~d}, 1 \mathrm{H}), 7.04-7.27$ (m, $4 \mathrm{H})$. HRMS (ESI) calcd for $\mathrm{C}_{28} \mathrm{H}_{38} \mathrm{CIN}_{3} \mathrm{NaO}_{6}$ : $[\mathrm{M}+\mathrm{Na}]^{+}: 570.2347$ Found: 570.2346 .

4.1.8.5. Methyl (4S,7S, E)-18-(3-chlorophenyl)-4-isobutyl-2,5,10-trioxo-1-oxa-3,6,11triazacyclooctadec-13-ene-7-carboxylate $8 \boldsymbol{e}$

Off-white solid (yield 70\%); m.p $63-64^{\circ} \mathrm{C} .{ }^{1} \mathrm{H}$ NMR (400 MHz, $\mathrm{CDCl}_{3}-d$ ) $\delta$ ppm 0.82 $1.03(\mathrm{~d}, 6 \mathrm{H}), 1.20$ - $2.32(\mathrm{~m}, 7 \mathrm{H}), 2.35-2.49(\mathrm{~m}, 6 \mathrm{H}), 3.76(\mathrm{~s}, 3 \mathrm{H}), 4.01$ - $4.25(\mathrm{~m}, 2$ H), 4.49 - $4.58(\mathrm{~m}, 2 \mathrm{H}), 5.48$ - $5.86(\mathrm{~m}, 3 \mathrm{H}), 6.32-6.38(\mathrm{~d}, 1 \mathrm{H}), 6.89-6.93(\mathrm{~d}, 1 \mathrm{H})$, $7.13-7.44(\mathrm{~m}, 4 \mathrm{H}), 8.05-8.11(\mathrm{br} \mathrm{s}, 1 \mathrm{H})$. HRMS (ESI) calcd for $\mathrm{C}_{26} \mathrm{H}_{37} \mathrm{CIN}_{3} \mathrm{O}_{6}$ : $[\mathrm{M}+\mathrm{H}]$ + : 522.2371 Found: 522.2378.

4.1.8.6. Methyl (4S,7S, E)-17-(3-chlorophenyl)-4-methyl-2,5,10-trioxo-1-oxa-3,6,11triazacycloheptadec-13-ene-7-carboxylate $8 f$

Off-white solid (yield 70\%); m.p $105-106^{\circ} \mathrm{C} .{ }^{1} \mathrm{H}$ NMR (400 MHz, $\left.\mathrm{CDCl}_{3}-d\right) \delta$ ppm 1.32 $1.50(\mathrm{~d}, 3 \mathrm{H}), 1.55$ - $2.44(\mathrm{~m}, 4 \mathrm{H}), 2.44$ - $2.75(\mathrm{~m}, 4 \mathrm{H}), 3.66-3.70(\mathrm{~s}, 3 \mathrm{H}), 4.05-4.10$ (d, $2 \mathrm{H}), 4.50$ - $4.61(\mathrm{~m}, 1 \mathrm{H}), 4.66$ - $4.82(\mathrm{~m}, 1 \mathrm{H}), 5.46$ - $5.73(\mathrm{~m}, 2 \mathrm{H}), 5.89$ - $6.01(\mathrm{~m}, 1$ H), $6.20-6.25$ (d, 1 H),6.91- 6.95 (br s, 1 H), 7.07 - 7.42 (m, 4 H), $8.50-8.54$ (br s, 1 H). HRMS (ESI) calcd for $\mathrm{C}_{22} \mathrm{H}_{29} \mathrm{CIN}_{3} \mathrm{O}_{6}:[\mathrm{M}+\mathrm{H}]^{+}: 466.1745$ Found: 466.1751.

4.1.8.7. Methyl (4S,7S, E)-18-(3-chlorophenyl)-4-methyl-2,5,10-trioxo-1-oxa-3,6,11triazacyclooctadec-13-ene-7-carboxylate $8 g$

Off-white solid (yield 70\%); m.p $74-75^{\circ} \mathrm{C} .{ }^{1} \mathrm{H}$ NMR (400 MHz, $\mathrm{CDCl}_{3}-d$ ) $\delta \mathrm{ppm}$ $1.20-1.30(\mathrm{~m}, 2 \mathrm{H}), 1.37(\mathrm{br} \mathrm{d}, J=7.03 \mathrm{~Hz}, 3 \mathrm{H}), 1.56-2.49(\mathrm{~m}, 8 \mathrm{H}), 3.76(\mathrm{~s}, 3 \mathrm{H})$, 3.81 - $3.90(\mathrm{~m}, 2 \mathrm{H}), 4.54-4.86(\mathrm{~m}, 2 \mathrm{H}), 5.48-5.80(\mathrm{~m}, 3 \mathrm{H}), 6.14-6.32$ (br d, $1 \mathrm{H}$ ), $6.90-7.02(\mathrm{~d}, 1 \mathrm{H}), 7.06-7.38(\mathrm{~m}, 4 \mathrm{H}), 7.70-7.75$ (br s, $1 \mathrm{H})$. HRMS (ESI) calcd for $\mathrm{C}_{23} \mathrm{H}_{31} \mathrm{CIN}_{3} \mathrm{O}_{6}:[\mathrm{M}+\mathrm{H}]^{+}: 480.1901$ Found: 480.1907. 
4.1.8.8. Methyl (20S, E)-10-(3-chlorophenyl)-8,17,22-trioxo-9-oxa-7,16,21-triazaspiro [5.16] docos-13-ene-20-carboxylate $8 \mathrm{~h}$

Off-white solid (yield 70\%); m.p $105-106^{\circ} \mathrm{C} .{ }^{1} \mathrm{H}$ NMR $\left(400 \mathrm{MHz}, \mathrm{CDCl}_{3}-d\right) \delta$ ppm 1.20 - 1.26 (m, $4 \mathrm{H}), 1.35$ - $1.76(\mathrm{~m}, 4 \mathrm{H}), 1.77$ - 1.90 (m, $5 \mathrm{H}), 2.26-2.49(\mathrm{~m}, 6$ H), 3.69 - $3.72(\mathrm{~s}, 3 \mathrm{H}), 3.381$ - $3.88(\mathrm{~m}, 2 \mathrm{H}), 4.35$ - $4.49(\mathrm{~m}, 1 \mathrm{H}), 5.46$ - $5.70(\mathrm{~m}, 2 \mathrm{H})$, $5.91-6.04(\mathrm{~m}, 1 \mathrm{H}), 6.08-6.15(\mathrm{~d}, 1 \mathrm{H}), 7.14-7.38(\mathrm{~m}, 4 \mathrm{H}), 7.87-7.96(\mathrm{~d}, 1 \mathrm{H})$. HRMS (ESI) calcd for $\mathrm{C}_{26} \mathrm{H}_{35} \mathrm{CIN}_{3} \mathrm{O}_{6}:[\mathrm{M}+\mathrm{H}]^{+}: 520.2214$ Found: 520.2222.

4.1.8.9. Methyl (21S, E)-10-(3-chlorophenyl)-8,18,23-trioxo-9-oxa-7,17,22-triazaspiro [5.17] tricos-14-ene-21-carboxylate $8 \mathrm{i}$

Off-white solid (yield 72\%); m.p $87-88^{\circ} \mathrm{C} .{ }^{1} \mathrm{H}$ NMR $\left(400 \mathrm{MHz}, \mathrm{CDCl}_{3}-d\right) \delta \mathrm{ppm}$ 1.20 - $1.26(\mathrm{~m}, 4 \mathrm{H}), 1.35$ - $1.55(\mathrm{~m}, 6 \mathrm{H}), 1.55$ - $1.74(\mathrm{~m}, 5 \mathrm{H}), 2.05$ - $2.36(\mathrm{~m}, 4 \mathrm{H}), 2.37$ - $2.55(\mathrm{~m}, 2 \mathrm{H}), 3.76(\mathrm{~d}, \mathrm{~J}=2.34 \mathrm{~Hz}, 3 \mathrm{H}), 3.80$ - $3.87(\mathrm{~m}, 2 \mathrm{H}), 4.53$ - $4.74(\mathrm{~m}, 1 \mathrm{H}), 5.59$ - $5.75(\mathrm{~m}, 2 \mathrm{H}), 6.38$ - $6.51(\mathrm{~d}, 1 \mathrm{H}), 6.51$ - $6.61(\mathrm{~d}, 1 \mathrm{H}), 6.83$ - $6.91(\mathrm{~d}, 1 \mathrm{H}), 7.13$ - 7.39 (m, $4 \mathrm{H})$. HRMS (ESI) calcd for $\mathrm{C}_{27} \mathrm{H}_{37} \mathrm{CIN}_{3} \mathrm{O}_{6}:[\mathrm{M}+\mathrm{H}]^{+}: 534.2371$ Found: 534.2381.

4.1.8.10. Methyl (4S, 7S, Z)-4-isobutyl-2,5,10-trioxo-17-(3-phenylpropyl)-1-oxa-3,6,11triazacycloheptadec-13-ene-7-carboxylate $8 j$

Off-white solid (yield 68\%); m.p $\left.72-73^{\circ} \mathrm{C} .{ }^{1} \mathrm{H} \mathrm{NMR} \mathrm{(400} \mathrm{MHz,} \mathrm{CDCl}_{3}-d\right) \delta \mathrm{ppm}$ $0.86-1.02(\mathrm{~d}, 6 \mathrm{H}), 1.46-1.86(\mathrm{~m}, 7 \mathrm{H}), 2.04-2.36(\mathrm{~m}, 8 \mathrm{H}), 2.52-2.60(\mathrm{t}, 2 \mathrm{H}), 3.70$ - 3.77 (s, $3 \mathrm{H}), 3.82-3.93(\mathrm{~d}, 2 \mathrm{H}), 4.13-4.23(\mathrm{~m}, 1 \mathrm{H}), 4.63-4.80(\mathrm{~m}, 1 \mathrm{H}), 5.00-$ $5.08(\mathrm{t}, 1 \mathrm{H}), 5.33-5.63(\mathrm{~m}, 2 \mathrm{H}), 5.73-5.83(\mathrm{~d}, 1 \mathrm{H}), 6.00-6.06(\mathrm{~d}, 1 \mathrm{H}), 6.93-6.70$ $(\mathrm{d}, 1 \mathrm{H}), 7.10$ - $7.20(\mathrm{~d}, 2 \mathrm{H}), 7.22$ - $7.32(\mathrm{~m}, 3 \mathrm{H})$. HRMS (ESI) calcd for $\mathrm{C}_{28} \mathrm{H}_{42} \mathrm{~N}_{3} \mathrm{O}_{6}$ : $[\mathrm{M}+\mathrm{H}]^{+}:$516.3074 Found: 516.3079 .

4.1.8.11. Methyl (4S, 7S, Z)-4-isobutyl-2,5,10-trioxo-17-pentyl-1-oxa-3,6,11triazacycloheptadec-13-ene-7-carboxylate $8 \mathbf{k}$

Off-white solid (yield 54\%); m.p $64-65^{\circ} \mathrm{C} .{ }^{1} \mathrm{H}$ NMR $\left(400 \mathrm{MHz}, \mathrm{CDCl}_{3}-d\right) \delta \mathrm{ppm}$ $0.85-0.92(\mathrm{t}, 2 \mathrm{H}), 0.93-1.04(\mathrm{~d}, 6 \mathrm{H}), 1.22-1.37(\mathrm{~m}, 6 \mathrm{H}), 1.43-1.92(\mathrm{~m}, 6 \mathrm{H}), 2.12$ - $2.40(\mathrm{~m}, 4 \mathrm{H}), 2.52-2.64(\mathrm{~m}, 2 \mathrm{H}), 3.70-3.78(\mathrm{~s}, 3 \mathrm{H}), 3.80-3.90(\mathrm{~d}, 2 \mathrm{H}), 4.15$ $4.25(\mathrm{~m}, 1 \mathrm{H}), 4.50-4.60(\mathrm{~m}, 1 \mathrm{H}), 4.62-4.78(\mathrm{~m}, 2 \mathrm{H}), 4.91-5.24(\mathrm{~m}, 1 \mathrm{H}), 5.42-$ 
$5.50(\mathrm{~m}, 2 \mathrm{H}), 5.84-5.89(\mathrm{~d}, 1 \mathrm{H}), 6.03-6.09$ (d, $1 \mathrm{H}), 6.31-6.37$ (br. s, $1 \mathrm{H})$. HRMS (ESI) calcd for $\mathrm{C}_{24} \mathrm{H}_{42} \mathrm{~N}_{3} \mathrm{O}_{6}:[\mathrm{M}+\mathrm{H}]^{+}: 468.3074$ Found: 468.3081 .

4.1.8.12. Methyl (6S,9S,E)-13-(3-chlorophenyl)-9-isobutyl-3,8,11-trioxo-1,12-dioxa2,7,10-triazacyclooctadec-16-ene-6-carboxylate 33

Off-white solid (yield 52\%); m.p $160-161^{\circ} \mathrm{C} .{ }^{1} \mathrm{H}$ NMR $\left(400 \mathrm{MHz}, \mathrm{CDCl}_{3}-d\right) \delta$ ppm $0.84-0.99$ (d, $6 \mathrm{H}), 1.23-1.29$ (t, $2 \mathrm{H}), 1.49-2.57$ (t, $8 \mathrm{H}), 3.72-3.79(\mathrm{~s}, 3 \mathrm{H})$, $3.82-3.90(\mathrm{~d}, 1 \mathrm{H}), 4.03-4.17(\mathrm{~d}, 2 \mathrm{H}), 4.24-4.43(\mathrm{~m}, 1 \mathrm{H}), 4.59-4.74(\mathrm{~m}, 1 \mathrm{H})$, $5.18-5.24(\mathrm{~d}, 1 \mathrm{H}), 5.52-5.67(\mathrm{~m}, 2 \mathrm{H}), 5.68-5.96(\mathrm{~m}, 1 \mathrm{H}), 6.24-6.32(\mathrm{~d}, 1 \mathrm{H})$, $7.13-7.21(\mathrm{~s}, 1 \mathrm{H}), 7.25-7.36(\mathrm{~m}, 3 \mathrm{H}), 9.24-9.30(\mathrm{~d}, 1 \mathrm{H})$. HRMS (ESI) calcd for $\mathrm{C}_{25} \mathrm{H}_{35} \mathrm{ClN}_{3} \mathrm{O}_{7}:[\mathrm{M}+\mathrm{H}]^{+}:$524.2164 Found: 524.2171.

4.1.9. Synthesis of compounds $9 \mathbf{a}-\mathbf{k}$ and 34. General procedure for the hydrogenation reaction.

To a solution of the appropriate olefin $8(1.0 \mathrm{mmol})$ in anhydrous ethanol $(10 \mathrm{~mL})$ was added palladium on carbon (10\% Pd-C, 2.0 eq) and the mixture was stirred under a hydrogen atmosphere (a balloon was used) at room temperature and atmospheric pressure for $18 \mathrm{~h}$. The mixture was filtered through Celite and the filtrate was concentrated in vacuo to yield a crude product which was purified by flash chromatography to yield compounds $9 a-k$ as white solids.

4.1.9.1. Methyl (4S,7S)-4-isobutyl-2,5,10-trioxo-17-phenyl-1-oxa-3,6,11triazacycloheptadecane-7-carboxylate 9a

White solid (yield 92\%); m.p $85-86^{\circ} \mathrm{C} .{ }^{1} \mathrm{H}$ NMR (400 MHz, $\left.\mathrm{CDCl}_{3}-d\right) \delta$ ppm 0.68 - $1.05(\mathrm{~d}, 6 \mathrm{H}), 1.40$ - $1.73(\mathrm{~m}, 5 \mathrm{H}), 1.73$ - $1.95(\mathrm{~m}, 4 \mathrm{H}), 1.95$ - $2.21(\mathrm{~m}, 6 \mathrm{H}), 3.20$ 3.29 (t, 2 H), 3.64 - $3.76(\mathrm{~s}, 3 \mathrm{H}), 4.45$ - $4.53(\mathrm{~m}, 2 \mathrm{H}), 5.76-5.90(\mathrm{~m}, 1 \mathrm{H}), 7.17$ - 7.35 $(\mathrm{m}, 5 \mathrm{H}), 7.40-7.50(\mathrm{~d}, 1 \mathrm{H}), 8.25-8.35(\mathrm{~d}, 1 \mathrm{H}), 8.72-8.80(\mathrm{~d}, 1 \mathrm{H})$. HRMS (ESI) calcd for $\mathrm{C}_{25} \mathrm{H}_{38} \mathrm{~N}_{3} \mathrm{O}_{6}:[\mathrm{M}+\mathrm{H}]^{+}: 476.2761$ Found: 476.2768. 
4.1.9.2. Methyl (4S,7S)-17-benzyl-4-isobutyl-2,5,10-trioxo-1-oxa-3,6,11triazacycloheptadecane-7-carboxylate $9 b$

White solid (yield 95\%); m.p $190-191^{\circ} \mathrm{C} .{ }^{1} \mathrm{H}$ NMR (400 MHz, $\left.\mathrm{CDCl}_{3}\right) \delta \mathrm{ppm} 0.81$ - 0.97 (d, $6 \mathrm{H}), 1.53$ - $1.69(\mathrm{~m}, 6 \mathrm{H}), 1,91-2.02(\mathrm{~m}, 5 \mathrm{H}), 2.20-2.31(4 \mathrm{H}), 2.70$ - 2.93 (m, $2 \mathrm{H}), 3.21-3.31(\mathrm{t}, 2 \mathrm{H}), 3.73-3.80(\mathrm{~s}, 3 \mathrm{H}), 4.40$ - $4.62(\mathrm{~m}, 2 \mathrm{H}), 4.88$ - $5.04(\mathrm{~m}, 1$ H), 6.20 - 6.41 (br. d, 1 H), 6.91 - $7.10(\mathrm{~d}, 1 \mathrm{H}), 7.14$ - $7.36(\mathrm{~m}, 5 \mathrm{H}), 7.85-7.92(\mathrm{~d}, 1$ H). HRMS (ESI) calcd for $\mathrm{C}_{26} \mathrm{H}_{40} \mathrm{~N}_{3} \mathrm{O}_{6}:[\mathrm{M}+\mathrm{H}]^{+}: 490.2917$ Found: 490.2921.

4.1.9.3. Methyl (4S,7S)-17-(3-chlorophenyl)-4-isobutyl-2,5,10-trioxo-1-oxa-3,6,11triazacycloheptadecane-7-carboxylate $9 c$

White solid (yield 95\%); m.p $149-150^{\circ} \mathrm{C} .{ }^{1} \mathrm{H}$ NMR (400 MHz, $\left.\mathrm{CDCl}_{3}-d\right) \delta \mathrm{ppm}$ $0.74-0.99(\mathrm{~d}, 6 \mathrm{H}), 1.42$ - $1.83(\mathrm{~m}, 3 \mathrm{H}), 2.11$ - $2.43(\mathrm{~m}, 6 \mathrm{H}), 2.47-2.64(\mathrm{~m}, 2 \mathrm{H}), 3.28$ 3.40 (m, 2 H), 3.69 - 3.81 (s, $3 \mathrm{H}), 3.81$ - $3.96(\mathrm{t}, 2 \mathrm{H}), 4.50-5.60(\mathrm{~m}, 1 \mathrm{H}), 4.62-4.77$ $(\mathrm{m}, 1 \mathrm{H}), 5.91-6.03(\mathrm{~m}, 1 \mathrm{H}), 6.14-6.24(\mathrm{~d}, 1 \mathrm{H}), 6.96-7.34(\mathrm{~m}, 4 \mathrm{H}), 8.02-8.11(\mathrm{~d}, 1$ $\mathrm{H}), 8.60-8.65(\mathrm{~d}, 1 \mathrm{H})$. HRMS (ESI) calcd for $\mathrm{C}_{25} \mathrm{H}_{37} \mathrm{CIN}_{3} \mathrm{O}_{6}:[\mathrm{M}+\mathrm{H}]^{+}: 510.2371$ Found: 510.2378 .

4.1.9.4. Methyl (4S,7S)-17-(3-chlorophenyl)-4-(cyclohexylmethyl)-2,5,10-trioxo-1-oxa3,6,11-triazacycloheptadecane-7-carboxylate $9 d$

White solid (yield 95\%); m.p (A: $71-72^{\circ} \mathrm{C}$, B: $\left.161-162^{\circ} \mathrm{C}\right) .{ }^{1} \mathrm{H}$ NMR $(400 \mathrm{MHz}$, $\left.\mathrm{CDCl}_{3}-d\right) \delta 0.66-0.93(\mathrm{~m}, 12 \mathrm{H}), 0.95-2.32(\mathrm{~m}, 10 \mathrm{H}), 3.18-3.21(\mathrm{t}, 2 \mathrm{H}), 3.63-3.81$ (s, $3 \mathrm{H}), 3.96-4.10(\mathrm{t}, 2 \mathrm{H}), 4.00-4.20(\mathrm{~m}, 1 \mathrm{H}), 4.29-4.51(\mathrm{~m}, 1 \mathrm{H}), 4.84-5.01(\mathrm{~m}, 1$ H), $5.94-6.11(m, 1 H), 6.22-6.31(d, 1 H), 6.75-6.92(d, 1 H),, 7.12$ - $7.27(m, 4 H)$, $8.25-8.40$ (br. s, $1 \mathrm{H}$ ), $8.82-8.90$ (d, $1 \mathrm{H}$ ). HRMS (ESI) calcd for $\mathrm{C}_{28} \mathrm{H}_{41} \mathrm{CIN}_{3} \mathrm{O}_{6}:[\mathrm{M}+\mathrm{H}]$ + : 550.2684 Found: 550.2689 .

4.1.9.5. Methyl (4S,7S)-18-(3-chlorophenyl)-4-isobutyl-2,5,10-trioxo-1-oxa-3,6,11triazacyclooctadecane-7-carboxylate $9 e$

White solid (yield 94\%); m.p $122-123^{\circ} \mathrm{C} .{ }^{1} \mathrm{H}$ NMR (400 MHz, $\left.\mathrm{CDCl}_{3}-d\right) \delta \mathrm{ppm}$ $0.74-0.99(\mathrm{~d}, 6 \mathrm{H}), 1.42-1.83(\mathrm{~m}, 5 \mathrm{H}), 2.11$ - $2.43(\mathrm{~m}, 6 \mathrm{H}), 2.47$ - $2.64(\mathrm{~m}, 2 \mathrm{H}), 3.28$ $3.40(\mathrm{~m}, 2 \mathrm{H}), 3.69-3.81(\mathrm{~s}, 3 \mathrm{H}), 3.81-3.96(\mathrm{t}, 2 \mathrm{H}), 4.50-5.60(\mathrm{~m}, 1 \mathrm{H}), 4.62-4.77$ 
(m, $1 \mathrm{H}), 5.91-6.03(\mathrm{~m}, 1 \mathrm{H}), 6.14-6.24(\mathrm{~d}, 1 \mathrm{H}), 6.96-7.34(\mathrm{~m}, 4 \mathrm{H}), 8.02-8.11(\mathrm{~d}, 1$ $\mathrm{H}), 8.60-8.65(\mathrm{~d}, 1 \mathrm{H})$. HRMS (ESI) calcd for $\mathrm{C}_{26} \mathrm{H}_{39} \mathrm{CIN}_{3} \mathrm{O}_{6}:[\mathrm{M}+\mathrm{H}]^{+}: 525.2527$ Found: 524.2533 .

4.1.9.6. Methyl (4S,7S)-17-(3-chlorophenyl)-4-methyl-2,5,10-trioxo-1-oxa-3,6,11triazacycloheptadecane-7-carboxylate $9 f$

White solid (yield 93\%); m.p $131-132^{\circ} \mathrm{C}$. ${ }^{1} \mathrm{H}$ NMR (400 MHz, $\left.\mathrm{CDCl}_{3}-d\right) \delta \mathrm{ppm}$ 0.82 - $0.99(\mathrm{~m}, 4 \mathrm{H}), 1.40(\mathrm{~d}, \mathrm{~J}=6.64 \mathrm{~Hz}, 3 \mathrm{H}), 1.52$ - $1.84(\mathrm{~m}, 2 \mathrm{H}), 1.82$ - $2.06(\mathrm{~m}, 2 \mathrm{H})$, 2.09 - $2.50(\mathrm{~m}, 4 \mathrm{H}), 3.12$ - $3.31(\mathrm{~m}, 2 \mathrm{H}), 3.70$ - $3.81(\mathrm{~s}, 3 \mathrm{H}), 4.65$ - $4.77(\mathrm{~m}, 1 \mathrm{H}), 5.18$ - $5.26(\mathrm{~m}, 1 \mathrm{H}), 5.84-5.93(\mathrm{~m}, 1 \mathrm{H}), 6.17-6.33(\mathrm{br} \mathrm{s}, 1 \mathrm{H}), 6.52-6.63(\mathrm{~d}, 1 \mathrm{H}), 7.10$ $7.30(\mathrm{~m}, 4 \mathrm{H}), 7.30-7.44(\mathrm{~m}, 1 \mathrm{H})$. HRMS (ESI) calcd for $\mathrm{C}_{22} \mathrm{H}_{31} \mathrm{CIN}_{3} \mathrm{O}_{6}:[\mathrm{M}+\mathrm{H}]^{+}$: 468.1901 Found: 468.1911.

4.1.9.7. Methyl (4S,7S)-18-(3-chlorophenyl)-4-methyl-2,5,10-trioxo-1-oxa-3,6,11triazacyclooctadecane-7-carboxylate $9 \mathrm{~g}$

White solid (yield 93\%); m.p $100-101^{\circ} \mathrm{C} .{ }^{1} \mathrm{H}$ NMR (400 MHz, $\left.\mathrm{CDCl}_{3}-d\right) \delta \mathrm{ppm}$ 0.75 - $0.96(\mathrm{~m}, 4 \mathrm{H}), 1.37$ - $1.58(\mathrm{~d}, \mathrm{~m}, 5 \mathrm{H}), 1.65$ - $1.81(\mathrm{~m}, 2 \mathrm{H}), 1.81$ - $2.10(\mathrm{~m}, 2 \mathrm{H})$, 2.10 - $2.54(\mathrm{~m}, 4 \mathrm{H}), 3.21$ - $3.34(\mathrm{t}, 2 \mathrm{H}), 3.75(\mathrm{~s}, 3 \mathrm{H}), 4.17$ - $4.28(\mathrm{~m}, 1 \mathrm{H}), 4.56-4.70$ $(\mathrm{m}, 1 \mathrm{H}), 5.25$ - 5.40 (br s, $1 \mathrm{H}), 5.47$ - $5.82(\mathrm{~m}, 1 \mathrm{H}), 6.14$ - 6.29 (br s, $1 \mathrm{H}), 7.01$ - 7.51 (m, $4 \mathrm{H}) .7 .90-8.00$ (br s, $1 \mathrm{H})$. HRMS (ESI) calcd for $\mathrm{C}_{23} \mathrm{H}_{33} \mathrm{CIN}_{3} \mathrm{O}_{6}:[\mathrm{M}+\mathrm{H}]^{+}: 482.2058$ Found: 482.2069 .

4.1.9.8. Methyl (20S)-10-(3-chlorophenyl)-8,17,22-trioxo-9-oxa-7,16,21-triazaspiro [5.16] docosane-20-carboxylate $9 \mathrm{~h}$

White solid (yield 95\%); m.p $105-106^{\circ} \mathrm{C} .{ }^{1} \mathrm{H}$ NMR (400 MHz, $\left.\mathrm{CDCl}_{3}-d\right) \delta \mathrm{ppm}$ 0.84 - $0.97(\mathrm{~m}, 2 \mathrm{H}), 1.09-1.40(\mathrm{~m}, 7 \mathrm{H}), 1.40-2.65(\mathrm{~m}, 13 \mathrm{H}), 3.10-3.28(\mathrm{~m}, 2 \mathrm{H})$, 3.67 - $3.70(\mathrm{~s}, 3 \mathrm{H}), 4.31$ - $4.44(\mathrm{~m}, 1 \mathrm{H}), 5.81$ - $5.90(\mathrm{~m}, 1 \mathrm{H}), 6.47$ - $6.62(\mathrm{t}, 1 \mathrm{H}), 7.11$ 7.39 (m, $4 \mathrm{H}$ ), 8.26 - 8.30 (br. S, $1 \mathrm{H}$ ), 8.64 - 8.79 (br. s, $1 \mathrm{H}$ ). HRMS (ESI) calcd for $\mathrm{C}_{26} \mathrm{H}_{37} \mathrm{CIN}_{3} \mathrm{O}_{6}:[\mathrm{M}+\mathrm{H}]^{+}: 522.2371$ Found: 522.2389.

4.1.9.9. Methyl (21S)-10-(3-chlorophenyl)-8,18,23-trioxo-9-oxa-7,17,22-triazaspiro [5.17] tricosane-21-carboxylate $9 \mathrm{i}$ 
White solid (yield 95\%); m.p $91-92^{\circ} \mathrm{C}$. ${ }^{1} \mathrm{H}$ NMR $\left(400 \mathrm{MHz}, \mathrm{CDCl}_{3}-d\right) \delta \mathrm{ppm} 0.83$ - 0.91 (m, $2 \mathrm{H}), 1.12$ - $2.11(\mathrm{~m}, 14 \mathrm{H}), 2.18$ - 2.40 (m, $8 \mathrm{H}), 3.28$ - $3.38(\mathrm{~m}, 2 \mathrm{H}), 3.76$ (s, $3 \mathrm{H}), 4.55$ - $4.69(\mathrm{~m}, 1 \mathrm{H}), 5.52$ - $5.61(\mathrm{~m}, 1 \mathrm{H}), 6.29$ - 6.37 (br. s, $1 \mathrm{H}), 6.44$ - 6.59 (br. s, $1 \mathrm{H}$ ), $6.63-6.73$ (br. s, $1 \mathrm{H}$ ), $7.13-7.39\left(\mathrm{~m}, 4 \mathrm{H}\right.$ ). HRMS (ESI) calcd for $\mathrm{C}_{27} \mathrm{H}_{39} \mathrm{CIN}_{3} \mathrm{O}_{6}$ : $[\mathrm{M}+\mathrm{H}]^{+}:$536.2527 Found: 536.2543.

4.1.9.10. Methyl (4S, 7S)-4-isobutyl-2,5,10-trioxo-17-(3-phenylpropyl)-1-oxa-3,6,11triazacycloheptadecane-7-carboxylate $9 j$

White solid (yield 97\%); m.p $200-20{ }^{\circ} \mathrm{C} .{ }^{1} \mathrm{H}$ NMR $\left(400 \mathrm{MHz}, \mathrm{CDCl}_{3}-d\right) \delta \mathrm{ppm}$ $0.85-1.01(\mathrm{~d}, 6 \mathrm{H}), 1.15-1.81(\mathrm{~m}, 10 \mathrm{H}), 2.09-2.19(\mathrm{~m}, 9 \mathrm{H}), 2.54-2.67(\mathrm{t}, 2 \mathrm{H})$, $3.02-3.14$ (t, $2 \mathrm{H}), 3.68-3.77$ (s, $3 \mathrm{H}), 3.90-3.98(\mathrm{~d}, 1 \mathrm{H}), 4.66-4.75(\mathrm{~m}, 1 \mathrm{H}), 4.90$ - $5.00(\mathrm{~m}, 2 \mathrm{H}), 6.07$ - $6.16(\mathrm{~d}, 1 \mathrm{H}), 6.17-6.24(\mathrm{~d}, 1 \mathrm{H}), 7.10$ - $7.20(\mathrm{~d}, 2 \mathrm{H}), 7.24$ - 7.34 $(\mathrm{m}, 3 \mathrm{H})$. HRMS (ESI) calcd for $\mathrm{C}_{28} \mathrm{H}_{44} \mathrm{~N}_{3} \mathrm{O}_{6}:[\mathrm{M}+\mathrm{H}]^{+}: 518.3230$ Found: 518.3253.

4.1.9.11. Methyl (4S, 7S)-4-isobutyl-2,5,10-trioxo-17-pentyl-1-oxa-3,6,11triazacycloheptadecane-7-carboxylate $\mathbf{9 k}$

White solid (yield 96\%); m.p $203-204^{\circ} \mathrm{C} .{ }^{1} \mathrm{H}$ NMR (400 MHz, $\left.\mathrm{CDCl}_{3}-d\right) \delta \mathrm{ppm}$ $0.83-0.90(\mathrm{t}, 2 \mathrm{H}), 0.91-1.01(\mathrm{~d}, 6 \mathrm{H}), 1.20-1.34(\mathrm{~m}, 8 \mathrm{H}), 1.38-1.84(\mathrm{~m}, 9 \mathrm{H}), 2.24$ - 2.51 (m, 4 H), $3.02-3.17$ (br m, 1 H), $3.44-3.55$ (br. s, 1 H), $3.69-3.78$ (s, $3 \mathrm{H}$ ), $3.90-4.00(d, 1 H), 4.65-4.75(m, 2 H), 4.86-4.98(d, 2 H), 5.84-5.89(d, 1 H), 6.09$ $-6.14(\mathrm{~d}, 1 \mathrm{H}), 6.16-6.24(\mathrm{~d}, 1 \mathrm{H}), 8.03-8.13$ (br. $\mathrm{s}, 1 \mathrm{H})$. HRMS (ESI) calcd for $\mathrm{C}_{24} \mathrm{H}_{44} \mathrm{~N}_{3} \mathrm{O}_{6}:[\mathrm{M}+\mathrm{H}]^{+}: 470.3230$ Found: 470.3271.

4.1.9.12. Methyl (6S,9S)-13-(3-chlorophenyl)-9-isobutyl-3,8,11-trioxo-1,12-dioxa-2,7,10triazacyclooctadecane-6-carboxylate 34

White solid (yield 92\%); m.p $73-73^{\circ} \mathrm{C} .{ }^{1} \mathrm{H}$ NMR (400 MHz, $\left.\mathrm{CDCl}_{3}-d\right) \delta \mathrm{ppm} 0.87$ - 1.00 (d, $6 \mathrm{H}), 1.16$ - $1.34(\mathrm{~m}, 3 \mathrm{H}), 1.36-1.78(\mathrm{~m}, 9 \mathrm{H}), 1.83-2.05$ (t, $2 \mathrm{H}), 2.14-$ $2.30(\mathrm{~m}, 2 \mathrm{H}), 3.74-3.82(\mathrm{~s}, 3 \mathrm{H}), 3.83-4.16(\mathrm{t}, 2 \mathrm{H}), 4.61-4.76(\mathrm{~m}, 1 \mathrm{H}), 5.10-5.19$ $(\mathrm{m}, 1 \mathrm{H}), 5.71-5.83(\mathrm{~m}, 1 \mathrm{H}), 7.15-7.23(\mathrm{~s}, 1 \mathrm{H}), 7.23-7.39(\mathrm{~m}, 3 \mathrm{H}), 9.12-9.19(\mathrm{~d}$, $1 \mathrm{H}), 9.76-9.80(\mathrm{~d}, 1 \mathrm{H})$. HRMS (ESI) calcd for $\mathrm{C}_{25} \mathrm{H}_{37} \mathrm{CIN}_{3} \mathrm{O}_{7}:[\mathrm{M}+\mathrm{H}]^{+}: 526.2320$ Found: 526.2332 . 


\subsubsection{Synthesis of alcohols $\mathbf{1 0 a}-\mathbf{k}$ and $\mathbf{3 5}$. General procedure}

To a solution of an appropriate macrocyclic ester $9(5 \mathrm{mmol})$ in anhydrous THF (30 mL) was added dropwise a solution of lithium borohydride in THF (2M in THF, 7.5

$\mathrm{mL}, 15 \mathrm{mmol}$ ) and the reaction mixture was stirred for $30 \mathrm{~min}$ at room temperature. Absolute ethyl alcohol $(15 \mathrm{~mL})$ was added and the reaction mixture was stirred at room temperature overnight. The reaction mixture was then acidified by adding $1.0 \mathrm{M}$ aqueous potassium bisulfate until the $\mathrm{pH}$ of the solution was $\sim 3$. Removal of the solvent left a residue which was taken up in ethyl acetate $(150 \mathrm{~mL})$. The organic layer was washed with brine $(25 \mathrm{~mL})$, dried over anhydrous sodium sulfate, filtered, and concentrated to yield compounds $\mathbf{1 0 a - k}$ as white solids.

4.1.10.1. (4S,7S)-7-(Hydroxymethyl)-4-isobutyl-17-phenyl-1-oxa-3,6,11triazacycloheptadecane-2,5,10-trione 10a

White solid (yield 93\%); m.p $144-145^{\circ} \mathrm{C} .{ }^{1} \mathrm{H}$ NMR (400 MHz, $\left.\mathrm{CDCl}_{3}-d\right) \delta \mathrm{ppm}$ 0.68 - $1.05(\mathrm{~d}, 6 \mathrm{H}), 1.40$ - $1.73(\mathrm{~m}, 5 \mathrm{H}), 1.73$ - $1.95(\mathrm{~m}, 4 \mathrm{H}), 1.95$ - $2.21(\mathrm{~m}, 6 \mathrm{H}), 3.20$ - 3.29 (t, 2 H), 3.35 - $3.46(\mathrm{~m}, 2 \mathrm{H}), 4.45-4.53(\mathrm{~m}, 2 \mathrm{H}), 5.76-5.90(\mathrm{~m}, 1 \mathrm{H}), 7.17$ $7.35(\mathrm{~m}, 5 \mathrm{H}), 7.40-7.50(\mathrm{~d}, 1 \mathrm{H}), 8.25-8.35(\mathrm{~d}, 1 \mathrm{H}), 8.72-8.80(\mathrm{~d}, 1 \mathrm{H})$. HRMS (ESI) calcd for $\mathrm{C}_{24} \mathrm{H}_{38} \mathrm{~N}_{3} \mathrm{O}_{5}:[\mathrm{M}+\mathrm{H}]^{+}: 448.2811$ Found: 448.2834 .

4.1.10.2. (4S,7S)-17-Benzyl-7-(hydroxymethyl)-4-isobutyl-1-oxa-3,6,11triazacycloheptadecane-2,5,10-trione $10 \mathrm{~b}$

White solid (yield 96\%); m.p $214-215^{\circ} \mathrm{C} .{ }^{1} \mathrm{H}$ NMR (400 MHz, $\left.\mathrm{CDCl}_{3}-d\right) \delta \mathrm{ppm}$ 0.81 - $0.97(\mathrm{~d}, 6 \mathrm{H}), 1.53$ - $1.69(\mathrm{~m}, 6 \mathrm{H}), 1,91-2.02(\mathrm{~m}, 5 \mathrm{H}), 2.20-2.31(4 \mathrm{H}), 2.70$ $2.93(\mathrm{~m}, 2 \mathrm{H}), 3.21-3.31(\mathrm{t}, 2 \mathrm{H}), 3.52-3.60(\mathrm{~m}, 2 \mathrm{H}), 4.40-4.62(\mathrm{~m}, 3 \mathrm{H}), 4.88-5.04$ $(\mathrm{m}, 1 \mathrm{H}), 6.20-6.41($ br. $d, 1 \mathrm{H}), 6.91-7.10(\mathrm{~d}, 1 \mathrm{H}), 7.14-7.36(\mathrm{~m}, 5 \mathrm{H}), 7.85-7.92$ (d, $1 \mathrm{H})$. HRMS (ESI) calcd for $\mathrm{C}_{25} \mathrm{H}_{40} \mathrm{~N}_{3} \mathrm{O}_{5}:[\mathrm{M}+\mathrm{H}]^{+}: 462.2968$ Found: 462.2984. 
4.1.10.3. (4S,7S)-17-(3-Chlorophenyl)-7-(hydroxymethyl)-4-isobutyl-1-oxa-3,6,11triazacycloheptadecane-2,5,10-trione 10c

White solid (yield 95\%); m.p $98-99^{\circ} \mathrm{C} .{ }^{1} \mathrm{H}$ NMR (400 MHz, DMSO- $\left.d_{6}\right) \delta \mathrm{ppm}$ 0.74 - 0.99 (d, $6 \mathrm{H}), 1.42$ - $1.83(\mathrm{~m}, 3 \mathrm{H}), 2.11$ - $2.43(\mathrm{~m}, 6 \mathrm{H}), 2.47$ - $2.64(\mathrm{~m}, 2 \mathrm{H}), 3.28$ - $3.40(\mathrm{~m}, 2 \mathrm{H}), 3.4$ - $3.5(\mathrm{~m}, 2 \mathrm{H}), 3.81$ - $3.96(\mathrm{t}, 2 \mathrm{H}), 4.50-5.60(\mathrm{~m}, 1 \mathrm{H}), 4.62-4.77$ $(\mathrm{m}, 1 \mathrm{H}), 5.91-6.03(\mathrm{~m}, 1 \mathrm{H}), 6.14-6.24(\mathrm{~d}, 1 \mathrm{H}), 6.96-7.34(\mathrm{~m}, 4 \mathrm{H}), 8.02-8.11(\mathrm{~d}, 1$ $\mathrm{H}), 8.60-8.65(\mathrm{~d}, 1 \mathrm{H})$. HRMS (ESI) calcd for $\mathrm{C}_{24} \mathrm{H}_{37} \mathrm{CIN}_{3} \mathrm{O}_{5}:[\mathrm{M}+\mathrm{H}]^{+}: 482.2422$ Found: 482.2444 .

4.1.10.4. (4S,7S)-17-(3-Chlorophenyl)-4-(cyclohexylmethyl)-7-(hydroxymethyl)-1-oxa3,6,11-triazacycloheptadecane-2,5,10-trione 10d

White solid (yield 93\%); m.p (A: $71-72^{\circ} \mathrm{C}$, B: $\left.161-162^{\circ} \mathrm{C}\right) .{ }^{1} \mathrm{H}$ NMR $(400 \mathrm{MHz}$, $\left.\mathrm{CDCl}_{3}-d\right) \delta 0.66-0.93(\mathrm{~m}, 12 \mathrm{H}), 0.95-2.32(\mathrm{~m}, 10 \mathrm{H}), 3.18-3.21(\mathrm{t}, 2 \mathrm{H}), 3.96-4.10$ (t, $2 \mathrm{H}), 4.00-4.20(\mathrm{~m}, 1 \mathrm{H}), 4.29-4.51(\mathrm{~m}, 1 \mathrm{H}), 4.84-5.01(\mathrm{~m}, 1 \mathrm{H}), 5.94-6.11(\mathrm{~m}, 1$ H), 6.22 - $6.31(\mathrm{~d}, 1 \mathrm{H}), 6.75$ - $6.92(\mathrm{~d}, 1 \mathrm{H}), 7.12-7.27(\mathrm{~m}, 4 \mathrm{H}), 8.25$ - $8.40(\mathrm{br} \mathrm{s}, 1 \mathrm{H})$, $8.82-8.90(\mathrm{~d}, 1 \mathrm{H})$. HRMS (ESI) calcd for $\mathrm{C}_{27} \mathrm{H}_{41} \mathrm{CIN}_{3} \mathrm{O}_{5}:[\mathrm{M}+\mathrm{H}]^{+}: 522.2735$ Found: 522.2744 .

4.1.10.5. (4S,7S)-18-(3-Chlorophenyl)-7-(hydroxymethyl)-4-isobutyl-1-oxa-3,6,11triazacyclooctadecane-2,5,10-trione 10e

White solid (yield 95\%); m.p $71-72{ }^{\circ} \mathrm{C} .{ }^{1} \mathrm{H}$ NMR $\left(400 \mathrm{MHz}\right.$, DMSO- $\left.d_{6}\right) \delta \mathrm{ppm}$ $0.79-0.94(\mathrm{~d}, 6 \mathrm{H}), 1.15-1.30(\mathrm{~m}, 4 \mathrm{H}), 1.31-1.41(\mathrm{~m}, 4 \mathrm{H}), 1.61-1.81(\mathrm{~m}, 5 \mathrm{H}), 2.00$ - $2.10(\mathrm{~m}, 4 \mathrm{H}), 3.53$ - $3.77(\mathrm{~m}, 5 \mathrm{H}), 4.55$ - $4.74(\mathrm{~m}, 2 \mathrm{H}), 5.75-5.82(\mathrm{~m}, 1 \mathrm{H}), 6.48$ $6.54(\mathrm{t}, 1 \mathrm{H}), 7.21-7.46(\mathrm{~m}, 4 \mathrm{H}), 7.54-7.63(\mathrm{~d}, 1 \mathrm{H}), 7.73$ - $7.83(\mathrm{~d}, 1 \mathrm{H})$. HRMS (ESI) calcd for $\mathrm{C}_{25} \mathrm{H}_{39} \mathrm{ClN}_{3} \mathrm{O}_{5}:[\mathrm{M}+\mathrm{H}]^{+}: 496.2578$ Found: 496.2612 .

4.1.10.6. (4S,7S)-17-(3-Chlorophenyl)-7-(hydroxymethyl)-4-methyl-1-oxa-3,6,11triazacycloheptadecane-2,5,10-trione 10f

White solid (yield 82\%); m.p $154-155^{\circ} \mathrm{C} .{ }^{1} \mathrm{H}$ NMR (400 MHz, DMSO- $\left.d_{6}\right) \delta \mathrm{ppm}$ 0.75 - $0.91(\mathrm{~m}, 2 \mathrm{H}), 1.13-1.25(\mathrm{~m}, 2 \mathrm{H}), 1.39-1.41(\mathrm{~d}, 3 \mathrm{H}), 1.44-1.57(\mathrm{~m}, 2 \mathrm{H}), 1.57$ - $1.71(\mathrm{~m}, 2 \mathrm{H}), 1.79$ - $1.95(\mathrm{~m}, 2 \mathrm{H}), 2.11$ - $2.32(\mathrm{~m}, 2 \mathrm{H}), 3.23$ - $3.38(\mathrm{~m}, 4 \mathrm{H}), 3.72$ - 
$3.90(\mathrm{~m}, 1 \mathrm{H}), 4.64$ - $4.72(\mathrm{~m}, 2 \mathrm{H}), 5.82-5.89(\mathrm{~m}, 1 \mathrm{H}), 6.86$ - 6.97 (br. $\mathrm{s}, 1 \mathrm{H}), 7.22$ $7.45(\mathrm{~m}, 4 \mathrm{H}), 7.57$ - $7.68(\mathrm{~d}, 1 \mathrm{H}), 7.72$ - $7.83(\mathrm{~d}, 1 \mathrm{H})$. HRMS (ESI) calcd for $\mathrm{C}_{21} \mathrm{H}_{31} \mathrm{CIN}_{3} \mathrm{O}_{5}:[\mathrm{M}+\mathrm{H}]^{+}: 440.1952$ Found: 440.1983.

4.1.10.7. (4S,7S)-18-(3-Chlorophenyl)-7-(hydroxymethyl)-4-methyl-1-oxa-3,6,11triazacyclooctadecane-2,5,10-trione $\mathbf{1 0 g}$

White solid (yield 88\%); m.p $192-193^{\circ} \mathrm{C} .{ }^{1} \mathrm{H}$ NMR (400 MHz, DMSO- $\left.d_{6}\right) \delta \mathrm{ppm}$ 0.75 - $0.96(\mathrm{~m}, 4 \mathrm{H}), 1.37$ - $1.58(\mathrm{~d}, \mathrm{~m}, 5 \mathrm{H}), 1.65$ - $1.81(\mathrm{~m}, 2 \mathrm{H}), 1.81$ - $2.10(\mathrm{~m}, 2 \mathrm{H})$, 2.10 - $2.54(\mathrm{~m}, 4 \mathrm{H}), 3.21$ - $3.34(\mathrm{t}, 2 \mathrm{H}), 3.45-3.50(\mathrm{~m}, 3 \mathrm{H}), 4.17-4.28(\mathrm{~m}, 1 \mathrm{H}), 4.56$ - $4.70(\mathrm{~m}, 1 \mathrm{H}), 5.25$ - 5.40 (br s, $1 \mathrm{H}), 5.47$ - $5.82(\mathrm{~m}, 1 \mathrm{H}), 6.14$ - 6.29 (br s, $1 \mathrm{H}), 7.01$ $7.51(\mathrm{~m}, 4 \mathrm{H}) .7 .90-8.00$ (br s, $1 \mathrm{H})$. HRMS (ESI) calcd for $\mathrm{C}_{22} \mathrm{H}_{33} \mathrm{CIN}_{3} \mathrm{O}_{5}:[\mathrm{M}+\mathrm{H}]^{+}$: 454.2109 Found: 454.2477.

4.1.10.8. (20S)-10-(3-Chlorophenyl)-20-(hydroxymethyl)-9-oxa-7, 16,21-triazaspiro [5.16] docosane-8,17,22-trione 10h

White solid (yield 90\%); m.p $107-108^{\circ} \mathrm{C} .{ }^{1} \mathrm{H}$ NMR (400 MHz, $\left.\mathrm{CDCl}_{3}-d\right) \delta \mathrm{ppm}$ 0.82 - $0.92(\mathrm{~m}, 2 \mathrm{H}), 1.12$ - $1.54(\mathrm{~m}, 9 \mathrm{H}), 1.54-1.99(\mathrm{~m}, 10 \mathrm{H}), 2.16-2.43(\mathrm{~m}, 6 \mathrm{H})$, 2.96 - $3.40(\mathrm{~m}, 2 \mathrm{H}), 3.44-3.70(\mathrm{~m}, 2 \mathrm{H}), 5.21-5.24(\mathrm{~s}, 1 \mathrm{H}), 5.54-5.65(\mathrm{~m}, 1 \mathrm{H}), 6.54$ - 6.60 (br. s, $1 \mathrm{H}$ ), 6.71 - 6.84 (d, $1 \mathrm{H}$ ), 7.01 - 7.09 (d, $1 \mathrm{H}), 7.11$ - 7.38 (m, $4 \mathrm{H})$. HRMS (ESI) calcd for $\mathrm{C}_{25} \mathrm{H}_{37} \mathrm{CIN}_{3} \mathrm{O}_{5}:[\mathrm{M}+\mathrm{H}]^{+}: 494.2422$ Found: 494.2440 .

4.1.10.9. (21S)-10-(3-Chlorophenyl)-21-(hydroxymethyl)-9-oxa-7,17,22-triazaspiro [5.17] tricosane-8, 18,23-trione 10i

White solid (yield 94\%); m.p $92-93^{\circ} \mathrm{C} .{ }^{1} \mathrm{H}$ NMR (400 MHz, $\left.\mathrm{CDCl}_{3}-d\right) \delta \mathrm{ppm} 0.84$ $0.92(\mathrm{~m}, 2 \mathrm{H}), 1.14-1.51(\mathrm{~m}, 7 \mathrm{H}), 1.51-1.99(\mathrm{~m}, 10 \mathrm{H}), 2.14-2.47(\mathrm{~m}, 6 \mathrm{H}), 2.94-$ $3.41(\mathrm{~m}, 2 \mathrm{H}), 3.45-3.71(\mathrm{~m}, 2 \mathrm{H}), 5.19-5.21(\mathrm{~s}, 1 \mathrm{H}), 5.53$ - $5.65(\mathrm{~m}, 1 \mathrm{H}), 6.49-6.60$ (br. s, $1 \mathrm{H}), 6.76$ - $6.86(\mathrm{~d}, 1 \mathrm{H}), 6.94-7.04(\mathrm{~d}, 1 \mathrm{H}), 7.11$ - 7.38 (m, $4 \mathrm{H})$. HRMS (ESI) calcd for $\mathrm{C}_{26} \mathrm{H}_{39} \mathrm{ClN}_{3} \mathrm{O}_{5}:[\mathrm{M}+\mathrm{H}]^{+}:$508.2578 Found: 508.2601.

4.1.10.10. (4S,7S)-7-(Hydroxymethyl)-4-isobutyl-17-(3-phenylpropyl)-1-oxa-3,6,11triazacycloheptadecane-2,5,10-trione 10j 
White solid (yield 98\%); m.p $216-217^{\circ} \mathrm{C} .{ }^{1} \mathrm{H}$ NMR (400 MHz, $\left.\mathrm{CDCl}_{3}-d\right) \delta \mathrm{ppm}$ $0.85-1.01(\mathrm{~d}, 6 \mathrm{H}), 1.15-1.81(\mathrm{~m}, 10 \mathrm{H}), 2.09-2.19(\mathrm{~m}, 9 \mathrm{H}), 2.54-2.67(\mathrm{t}, 2 \mathrm{H})$, $3.02-3.14$ (t, 2 H), $3.53-3.74(\mathrm{~m}, 2 \mathrm{H}), 3.90-3.98(\mathrm{~d}, 1 \mathrm{H}), 4.66-4.75(\mathrm{~m}, 1 \mathrm{H}), 4.90$ - $5.00(m, 2 H), 6.07-6.16(d, 1 H), 6.17-6.24(d, 1 H), 7.10$ - $7.20(d, 2 H), 7.24-7.34$ $(\mathrm{m}, 3 \mathrm{H})$. HRMS (ESI) calcd for $\mathrm{C}_{27} \mathrm{H}_{44} \mathrm{~N}_{3} \mathrm{O}_{5}:[\mathrm{M}+\mathrm{H}]^{+}: 490.3281$ Found: 490.3312.

4.1.10.11.

(4S,7S)-7-(Hydroxymethyl)-4-isobutyl-17-pentyl-1-oxa-3,6,11triazacycloheptadecane-2,5,10-trione 10k

White solid (yield 98\%); m.p $230^{\circ} \mathrm{C}$ (d). ${ }^{1} \mathrm{H}$ NMR (400 MHz, $\left.\mathrm{CDCl}_{3}-d\right) \delta \mathrm{ppm} 0.85$ - $0.93(\mathrm{t}, 2 \mathrm{H}), 0.93-1.01(\mathrm{~d}, 6 \mathrm{H}), 1.20-1.34(\mathrm{~m}, 8 \mathrm{H}), 1.38-1.84(\mathrm{~m}, 9 \mathrm{H}), 2.24-$ 2.51 (m, $4 \mathrm{H}$ ), $3.02-3.17$ (br m, $1 \mathrm{H}$ ), $3.44-3.55$ (br. s, $1 \mathrm{H}), 3.54-3.73(\mathrm{~m}, 2 \mathrm{H}), 3.90$ - $4.00(\mathrm{~d}, 1 \mathrm{H}), 4.65$ - $4.75(\mathrm{~m}, 2 \mathrm{H}), 4.86$ - $4.98(\mathrm{~d}, 2 \mathrm{H}), 5.00-5.06(\mathrm{~d}, 1 \mathrm{H}), 6.09$ $6.14(\mathrm{~d}, 1 \mathrm{H}), 6.29-6.39(\mathrm{~d}, 1 \mathrm{H}), 8.03-8.13$ (br. s, $1 \mathrm{H})$. HRMS (ESI) calcd for $\mathrm{C}_{23} \mathrm{H}_{34} \mathrm{~N}_{3} \mathrm{O}_{5}:[\mathrm{M}+\mathrm{H}]^{+}: 442.3281$ Found: 442.3319.

4.1.10.12. (6S,9S)-13-(3-Chlorophenyl)-6-(hydroxymethyl)-9-isobutyl-1,12-dioxa-2,7,10triazacyclooctadecane-3,8,11-trione 35

White solid (yield 97\%); m.p $138-139^{\circ} \mathrm{C} .{ }^{1} \mathrm{H}$ NMR (400 MHz, $\left.\mathrm{CDCl}_{3}-d\right) \delta \mathrm{ppm}$ $0.83-0.97(\mathrm{~d}, 6 \mathrm{H}), 1.21-1.34(\mathrm{~m}, 3 \mathrm{H}), 1.41-1.99(\mathrm{~m}, 9 \mathrm{H}), 2.01-2.10(\mathrm{t}, 2 \mathrm{H}), 2.17$ $-2.30(\mathrm{~m}, 2 \mathrm{H}), 3.54-3.72(\mathrm{t}, 2 \mathrm{H}), 3.80-4.16(\mathrm{~m}, 2 \mathrm{H}), 5.23-5.31(\mathrm{~m}, 1 \mathrm{H}), 5.47-$ $5.57(\mathrm{~m}, 1 \mathrm{H}), 5.69-5.79(\mathrm{~m}, 1 \mathrm{H}), 6.57-6.63(\mathrm{~d}, 1 \mathrm{H}), 6.94-6.99(\mathrm{~d}, 1 \mathrm{H}), 7.15-7.20$ $(\mathrm{s}, 1 \mathrm{H}), 7.23-7.34(\mathrm{~m}, 3 \mathrm{H}), 9.33-9.39(\mathrm{~d}, 1 \mathrm{H})$. HRMS (ESI) calcd for $\mathrm{C}_{24} \mathrm{H}_{37} \mathrm{CIN}_{3} \mathrm{O}_{6}$ : $[\mathrm{M}+\mathrm{H}]^{+}: 498.2371$ Found: 498.2388.

4.1.11. Synthesis of macrocyclic aldehydes 11-21 and 36. General procedure.

An appropriate alcohol $(0.6 \mathrm{mmol})$ was dissolved in anhydrous dichloromethane $(20 \mathrm{~mL})$ under a nitrogen atmosphere and cooled to $0^{\circ} \mathrm{C}$. Dess-Martin periodinane $(1.2$ mmol, 2.0 eq.) was added to the reaction mixture with stirring. The ice bath was removed and the reaction mixture was stirred at room temperature for $3 \mathrm{~h}$ (monitoring by TLC indicated complete disappearance of the starting material). A solution of $40 \mathrm{mM}$ 
sodium thiosulfate in saturated aqueous $\mathrm{NaHCO}_{3}(50 \mathrm{~mL})$ was added and the solution was stirred for another $15 \mathrm{~min}$. The aqueous layer was removed and the organic layer was washed with saturated sodium bicarbonate $(25 \mathrm{~mL})$, water $(2 \times 25 \mathrm{~mL})$ and brine (25 mL). The organic layer was dried over anhydrous sodium sulfate, filtered and concentrated. The yellow residue was purified by flash chromatography (silica gel/methylene chloride/ethyl acetate/methanol) to yield the aldehyde.

4.1.11.1.

(4S, 7S)-4-Isobutyl-2,5,10-trioxo-17-phenyl-1-oxa-3,6,11triazacycloheptadecane-7-carbaldehyde 11

White solid (yield 60\%); m.p $130-131^{\circ} \mathrm{C} .{ }^{1} \mathrm{H}$ NMR (400 MHz, $\left.\mathrm{CDCl}_{3}-d\right) \delta \mathrm{ppm}$ 0.68 - 1.05 (d, $6 \mathrm{H}), 1.40$ - $1.73(\mathrm{~m}, 5 \mathrm{H}), 1.73$ - $1.95(\mathrm{~m}, 4 \mathrm{H}), 1.95$ - $2.21(\mathrm{~m}, 6 \mathrm{H}), 3.20$ - 3.29 (t, $2 \mathrm{H}), 4.45$ - $4.53(\mathrm{~m}, 2 \mathrm{H}), 5.76-5.90(\mathrm{~m}, 1 \mathrm{H}), 7.17$ - $7.35(\mathrm{~m}, 5 \mathrm{H}), 7.40-$ $7.50(\mathrm{~d}, 1 \mathrm{H}), 8.25-8.35(\mathrm{~d}, 1 \mathrm{H}), 8.72-8.80(\mathrm{~d}, 1 \mathrm{H}), 9.55-9.64(\mathrm{~m}, 1 \mathrm{H})$. HRMS (ESI) calcd for $\mathrm{C}_{24} \mathrm{H}_{36} \mathrm{~N}_{3} \mathrm{O}_{5}:[\mathrm{M}+\mathrm{H}]^{+}: 446.2655$ Found: 446.2658 .

4.1.11.2.

(4S,7S)-17-Benzyl-4-isobutyl-2,5, 10-trioxo-1-oxa-3,6,11triazacycloheptadecane-7-carbaldehyde 12

White solid (yield 55\%); m.p $82-83^{\circ} \mathrm{C} .{ }^{1} \mathrm{H}$ NMR (400 MHz, $\left.\mathrm{CDCl}_{3}-d\right) \delta \mathrm{ppm} 0.81$ - 0.97 (d, $6 \mathrm{H}), 1.53$ - $1.69(\mathrm{~m}, 6 \mathrm{H}), 1,91-2.02(\mathrm{~m}, 5 \mathrm{H}), 2.20-2.31(4 \mathrm{H}), 2.70-2.93$ (m, $2 \mathrm{H}), 3.21$ - $3.31(\mathrm{t}, 2 \mathrm{H}), 4.40-4.62(\mathrm{~m}, 2 \mathrm{H}), 4.88-5.04(\mathrm{~m}, 1 \mathrm{H}), 6.20$ - 6.41 (br. d, 1 H), 6.91 - $7.10(d, 1 H), 7.14-7.36(m, 5 H), 7.85$ - $7.92(d, 1 H), 9.53$ - $9.62(s, 1$ H). HRMS (ESI) calcd for $\mathrm{C}_{25} \mathrm{H}_{38} \mathrm{~N}_{3} \mathrm{O}_{5}:[\mathrm{M}+\mathrm{H}]^{+}: 460.2811$ Found: 460.2813.

4.1.11.3. (4S, 7S)-17-(3-Chlorophenyl)-4-isobutyl-2,5,10-trioxo-1-oxa-3,6,11triazacycloheptadecane-7-carbaldehyde 13

White solid (yield 75\%); m.p $90-91^{\circ} \mathrm{C}$. ${ }^{1} \mathrm{H}$ NMR (400 MHz, $\left.\mathrm{CDCl}_{3}-d\right) \delta \mathrm{ppm} 0.74$ - $0.99(\mathrm{~d}, 6 \mathrm{H}), 1.42$ - $1.83(\mathrm{~m}, 5 \mathrm{H}), 2.11$ - $2.43(\mathrm{~m}, 6 \mathrm{H}), 2.47$ - $2.64(\mathrm{~m}, 2 \mathrm{H}), 3.28$ - 3.40 (t, $2 \mathrm{H}), 3.4-3.5(\mathrm{~m}, 2 \mathrm{H}), 4.50-5.60(\mathrm{~m}, 1 \mathrm{H}), 4.62-4.77(\mathrm{~m}, 1 \mathrm{H}), 5.91-6.03(\mathrm{~m}, 1$ H), $6.14-6.24(d, 1 H), 6.96-7.34(m, 4 H), 8.02-8.11(d, 1 H), 8.60-8.65(d, 1 H)$, 
9.54 - $9.61(\mathrm{~s}, 1 \mathrm{H})$. HRMS (ESI) calcd for $\mathrm{C}_{24} \mathrm{H}_{34} \mathrm{CIN}_{3} \mathrm{NaO}_{5}:[\mathrm{M}+\mathrm{Na}]^{+}: 502.2085$ Found: 502.2071 .

4.1.11.4. (4S,7S)-17-(3-Chlorophenyl)-4-(cyclohexylmethyl)-2,5,10-trioxo-1-oxa-3,6,11triazacycloheptadecane-7-carbaldehyde $\mathbf{1 4 A}$

White solid (yield 70\%); m.p $71-72{ }^{\circ} \mathrm{C},{ }^{1} \mathrm{H}$ NMR (400 MHz, $\left.\mathrm{CDCl}_{3}-d\right) \delta 0.66-$ $0.93(\mathrm{~m}, 12 \mathrm{H}), 0.95-2.32(\mathrm{~m}, 10 \mathrm{H}), 3.18-3.21(\mathrm{t}, 2 \mathrm{H}), 3.96-4.10(\mathrm{t}, 2 \mathrm{H}), 4.29-$ $4.51(\mathrm{~m}, 1 \mathrm{H}), 4.84-5.01(\mathrm{~m}, 1 \mathrm{H}), 5.94-6.11(\mathrm{~m}, 1 \mathrm{H}), 6.75-6.92(\mathrm{~d}, 1 \mathrm{H}), 7.12-7.27$ (m, $4 \mathrm{H}), 8.25$ - 8.40 (br s, $1 \mathrm{H}), 8.82$ - $8.90(\mathrm{~d}, 1 \mathrm{H}), 9.48$ - $9.58(\mathrm{~s}, 1 \mathrm{H})$. HRMS (ESI) calcd for $\mathrm{C}_{27} \mathrm{H}_{39} \mathrm{CIN}_{3} \mathrm{O}_{5}:[\mathrm{M}+\mathrm{H}]^{+}: 520.2578$ Found: 520.2771 .

4.1.11.5. (4S,7S)-17-(3-Chlorophenyl)-4-(cyclohexylmethyl)-2,5,10-trioxo-1-oxa-3,6,11triazacycloheptadecane-7-carbaldehyde 14B

White solid (yield 70\%); m.p $75-76^{\circ} \mathrm{C} .{ }^{1} \mathrm{H}$ NMR (400 MHz, $\left.\mathrm{CDCl}_{3}-d\right) \delta 0.66-$ $0.93(\mathrm{~m}, 12 \mathrm{H}), 0.95-2.32(\mathrm{~m}, 10 \mathrm{H}), 3.18-3.21(\mathrm{t}, 2 \mathrm{H}), 3.96-4.10(\mathrm{t}, 2 \mathrm{H}), 4.29$ $4.51(\mathrm{~m}, 1 \mathrm{H}), 4.84-5.01(\mathrm{~m}, 1 \mathrm{H}), 5.94-6.11(\mathrm{~m}, 1 \mathrm{H}), 6.75-6.92(\mathrm{~d}, 1 \mathrm{H}), 7.12-7.27$ (m, $4 \mathrm{H}), 8.25$ - 8.40 (br s, $1 \mathrm{H}), 8.82$ - 8.90 (d, $1 \mathrm{H}), 9.48$ - 9.58 (s, $1 \mathrm{H})$. HRMS (ESI) calcd for $\mathrm{C}_{27} \mathrm{H}_{38} \mathrm{CIN}_{3} \mathrm{NaO}_{5}:[\mathrm{M}+\mathrm{Na}]^{+}: 542.2398$ Found: 542.2506 .

4.1.11.6. (4S,7S)-18-(3-Chlorophenyl)-4-isobutyl-2,5,10-trioxo-1-oxa-3,6,11triazacyclooctadecane-7-carbaldehyde 15

White solid (yield 68\%); m.p $69-70^{\circ} \mathrm{C} .{ }^{1} \mathrm{H}$ NMR $\left(400 \mathrm{MHz}\right.$, DMSO- $\left.d_{6}\right) \delta \mathrm{ppm}$ 0.79 - 0.94 (d, $6 \mathrm{H}), 1.15$ - $1.30(\mathrm{~m}, 4 \mathrm{H}), 1.31$ - $1.41(\mathrm{~m}, 4 \mathrm{H}), 1.61$ - $1.81(\mathrm{~m}, 5 \mathrm{H}), 2.00$ - 2.10 (m, $4 \mathrm{H}), 3.18$ - 3.27 (t, $2 \mathrm{H}), 4.55$ - $4.74(\mathrm{~m}, 2 \mathrm{H}), 5.75$ - $5.82(\mathrm{~m}, 1 \mathrm{H}), 6.48$ - 6.54 (t, $1 \mathrm{H}), 7.21$ - $7.46(\mathrm{~m}, 4 \mathrm{H}), 7.54$ - $7.63(\mathrm{~d}, 1 \mathrm{H}), 8.53$ - $8.59(\mathrm{~d}, 1 \mathrm{H}), 9.57$ - 9.63 (s, 1 $\mathrm{H})$. HRMS (ESI) calcd for $\mathrm{C}_{25} \mathrm{H}_{37} \mathrm{CIN}_{3} \mathrm{O}_{5}:[\mathrm{M}+\mathrm{H}]^{+}: 494.2422$ Found: 494.2446.

4.1.11.7.

(4S,7S)-17-(3-Chlorophenyl)-4-methyl-2,5,10-trioxo-1-oxa-3,6,11triazacycloheptadecane-7-carbaldehyde 16

White solid (yield 70\%); m.p $84-85^{\circ} \mathrm{C} .{ }^{1} \mathrm{H}$ NMR $\left(400 \mathrm{MHz}, \mathrm{CDCl}_{3}-d\right) \delta \mathrm{ppm} 0.79$ - 0.91 (m, $2 \mathrm{H}), 1.13$ - 1.36 (m, $2 \mathrm{H}), 1.44$ - 1.48 (d, $3 \mathrm{H}), 1.76$ - 2.01 (m, 4 H), 2.19 - 
$2.70(\mathrm{~m}, 4 \mathrm{H}), 3.27$ - $3.43(\mathrm{~m}, 2 \mathrm{H}), 4.33$ - $4.40(\mathrm{~m}, 1 \mathrm{H}), 4.63$ - $4.71(\mathrm{~m}, 1 \mathrm{H}), 5.81$ - 5.93 $(\mathrm{m}, 1 \mathrm{H}), 6.06$ - $6.16(\mathrm{~m}, 1 \mathrm{H}), 6.57$ - $6.65(\mathrm{~d}, 1 \mathrm{H}), 6.92$ - $7.01(\mathrm{~d}, 1 \mathrm{H}), 7.10$ - $7.40(\mathrm{~m}, 4$ $\mathrm{H}), 9.56$ - $9.64(\mathrm{~s}, 1 \mathrm{H})$. HRMS (ESI) calcd for $\mathrm{C}_{21} \mathrm{H}_{29} \mathrm{CIN}_{3} \mathrm{O}_{5}:[\mathrm{M}+\mathrm{H}]^{+}: 438.1796$ Found: 438.2153.

4.1.11.8. (4S,7S)-18-(3-Chlorophenyl)-4-methyl-2,5,10-trioxo-1-oxa-3,6,11triazacyclooctadecane-7-carbaldehyde 17

White solid (yield 64\%); m.p $123-124^{\circ} \mathrm{C} .{ }^{1} \mathrm{H}$ NMR (400 MHz, $\mathrm{CDCl}_{3}-d$ ) $\delta \mathrm{ppm}$ 0.83 - 0.91 (m, $2 \mathrm{H}), 1.17$ - $1.38(\mathrm{~m}, 4 \mathrm{H}), 1.42$ - 1.47 (d, $3 \mathrm{H}), 1.80-2.00(\mathrm{~m}, 4 \mathrm{H}), 2.21$ - $2.65(\mathrm{~m}, 4 \mathrm{H}), 3.30$ - $3.41(\mathrm{~m}, 2 \mathrm{H}), 4.35$ - $4.43(\mathrm{~m}, 1 \mathrm{H}), 4.61$ - $4.71(\mathrm{~m}, 1 \mathrm{H}), 5.83$ $5.93(\mathrm{~m}, 1 \mathrm{H}), 6.06-6.14(\mathrm{~m}, 1 \mathrm{H}), 6.67-6.75(\mathrm{~d}, 1 \mathrm{H}), 6.81-6.91(\mathrm{~d}, 1 \mathrm{H}), 7.11-7.35$ $(m, 4 \mathrm{H}), 9.61-9.71(\mathrm{~s}, 1 \mathrm{H})$. HRMS (ESI) calcd for $\mathrm{C}_{22} \mathrm{H}_{31} \mathrm{CIN}_{3} \mathrm{O}_{5}:[\mathrm{M}+\mathrm{H}]^{+}: 452.1952$ Found: 452.2315.

4.1.11.9.

(20S)-10-(3-Chlorophenyl)-8,17,22-trioxo-9-oxa-7,16,21triazaspiro[5.16]docosane-20-carbaldehyde 18

White solid (yield 63\%); m.p $110-111^{\circ} \mathrm{C} .{ }^{1} \mathrm{H}$ NMR (400 MHz, $\left.\mathrm{CDCl}_{3}-d\right) \delta$ ppm $0.91-$ $1.41(\mathrm{~m}, 9 \mathrm{H}), 1.51-1.70(\mathrm{~m}, 5 \mathrm{H}), 2.12$ - $2.16(\mathrm{~m}, 2 \mathrm{H}), 2.20$ - $2.50(\mathrm{~m}, 4 \mathrm{H}), 2.87$ - 3.03 (m, $2 \mathrm{H}), 4.50$ - $4.60(\mathrm{~m}, 1 \mathrm{H}), 5.02$ - $5.10(\mathrm{~m}, 1 \mathrm{H}), 5.68$ - $5.85(\mathrm{~m}, 1 \mathrm{H}), 6.30$ - $6.41(\mathrm{~d}, 1$ H), 7.18 - $7.34(\mathrm{~m}, 4 \mathrm{H}), 7.69$ - $7.74(\mathrm{~d}, 1 \mathrm{H}), 8.23$ - $8.30(\mathrm{~d}, 1 \mathrm{H}), 9.58$ - $9.65(\mathrm{~s}, 1 \mathrm{H})$. HRMS (ESI) calcd for $\mathrm{C}_{25} \mathrm{H}_{35} \mathrm{CIN}_{3} \mathrm{O}_{5}:[\mathrm{M}+\mathrm{H}]^{+}: 492.2265$ Found: 492.2293.

4.1.11.10. (21S)-10-(3-Chlorophenyl)-8,18,23-trioxo-9-oxa-7,17,22-triazaspiro [5.17] tricosane-21-carbaldehyde 19

White solid (yield 65\%); m.p $87-88^{\circ} \mathrm{C} .{ }^{1} \mathrm{H}$ NMR $\left(400 \mathrm{MHz}, \mathrm{CDCl}_{3}-d\right) \delta \mathrm{ppm} 0.90$ - $1.36(\mathrm{~m}, 9 \mathrm{H}), 1.53$ - $1.72(\mathrm{~m}, 7 \mathrm{H}), 2.10$ - $2.14(\mathrm{~m}, 2 \mathrm{H}), 2.14$ - $2.54(\mathrm{~m}, 4 \mathrm{H}), 2.86$ $3.02(\mathrm{~m}, 2 \mathrm{H}), 4.42-4.60(\mathrm{~m}, 1 \mathrm{H}), 5.00-5.11(\mathrm{~m}, 1 \mathrm{H}), 5.66-5.81(\mathrm{~m}, 1 \mathrm{H}), 6.15$ - 6.23 (d, 1 H), 7.19 - $7.36(m, 4$ H), 7.89 - $7.94(d, 1$ H), 8.10 - 8.16 (d, 1 H), 9.55 - 9.62 (s, 1 H). HRMS (ESI) calcd for $\mathrm{C}_{26} \mathrm{H}_{37} \mathrm{CIN}_{3} \mathrm{O}_{5}:[\mathrm{M}+\mathrm{H}]^{+}: 506.2422$ Found: 506.2440.

4.1.11.11. (4S, 7S)-4-Isobutyl-2,5, 10-trioxo-17-(3-phenylpropyl)-1-oxa-3,6,11triazacycloheptadecane-7-carbaldehyde 20 
White solid (yield 60\%); m.p $163-164^{\circ} \mathrm{C} .{ }^{1} \mathrm{H}$ NMR $\left(400 \mathrm{MHz}, \mathrm{CDCl}_{3}-d\right) \delta \mathrm{ppm}$ $0.86-1.03(\mathrm{~d}, 6 \mathrm{H}), 1.15-1.81(\mathrm{~m}, 10 \mathrm{H}), 2.09-2.19(\mathrm{~m}, 9 \mathrm{H}), 2.54-2.67$ (t, $2 \mathrm{H})$, $3.02-3.14$ (t, 2 H), $3.95-4.05(\mathrm{~d}, 1 \mathrm{H}), 4.65-4.73(\mathrm{~m}, 1 \mathrm{H}), 4.90-5.00(\mathrm{~d}, 2 \mathrm{H}), 6.09$ - $6.17(\mathrm{~d}, 1 \mathrm{H}), 6.36-6.44(\mathrm{~d}, 1 \mathrm{H}), 7.12-7.22(\mathrm{~d}, 2 \mathrm{H}), 7.24$ - $7.32(\mathrm{~m}, 3 \mathrm{H}), 9.56$ $9.60(\mathrm{~s}, 1 \mathrm{H})$. HRMS (ESI) calcd for $\mathrm{C}_{27} \mathrm{H}_{41} \mathrm{~N}_{3} \mathrm{O}_{5}:[\mathrm{M}+\mathrm{H}]^{+}: 487.3046$ Found: 487.3051 .

4.1.11.12. (4S, 7S)-4-Isobutyl-2,5,10-trioxo-17-pentyl-1-oxa-3,6,11triazacycloheptadecane-7-carbaldehyde 21

White solid (yield 61\%), m.p $172-173^{\circ} \mathrm{C} .{ }^{1} \mathrm{H}$ NMR $\left(400 \mathrm{MHz}, \mathrm{CDCl}_{3}-d\right) \delta \mathrm{ppm}$ $0.83-0.91$ (t, $2 \mathrm{H}), 0.92-1.01(\mathrm{~d}, 6 \mathrm{H}), 1.20-1.34(\mathrm{~m}, 8 \mathrm{H}), 1.38-1.84(\mathrm{~m}, 9 \mathrm{H}), 2.24$ $-2.51(m, 4 H), 3.15-3.27(m, 1 H), 3.39-3.49(m, 1 H), 3.97-4.07(m, 1 H), 4.63-$ $4.73(\mathrm{~m}, 2 \mathrm{H}), 4.85-4.96(\mathrm{~m}, 2 \mathrm{H}), 4.96-5.03(\mathrm{~d}, 1 \mathrm{H}), 6.14-6.22(\mathrm{~d}, 1 \mathrm{H}), 6.49-6.56$ $(d, 1 \mathrm{H}), 9.56-9.63(\mathrm{~s}, 1 \mathrm{H})$. HRMS (ESI) calcd for $\mathrm{C}_{23} \mathrm{H}_{42} \mathrm{~N}_{3} \mathrm{O}_{5}:[\mathrm{M}+\mathrm{H}]^{+}: 440.3124$ Found: 440.3163.

4.1.11.13. (6S,9S)-13-(3-Chlorophenyl)-9-isobutyl-3,8,11-trioxo-1,12-dioxa-2,7,10triazacyclooctadecane-6-carbaldehyde 36A

White solid (yield (30\%); m.p $62-63^{\circ} \mathrm{C} .{ }^{1} \mathrm{H}$ NMR (400 MHz, $\left.\mathrm{CDCl}_{3}-d\right) \delta \mathrm{ppm}$ $0.83-1.00(\mathrm{~d}, 6 \mathrm{H}), 1.21-1.29(\mathrm{~m}, 4 \mathrm{H}), 1.44-1.96(\mathrm{~m}, 7 \mathrm{H}), 2.36-2.77(\mathrm{~m}, 4 \mathrm{H})$, $4.00-4.22(\mathrm{t}, 2 \mathrm{H}), 5.08-5.11(\mathrm{~m}, 1 \mathrm{H}), 5.45-5.60(\mathrm{~m}, 1 \mathrm{H}), 6.14-6.22(\mathrm{~d}, 1 \mathrm{H}), 6.49$ - $6.56(\mathrm{~d}, 1 \mathrm{H}), 7.12-7.20(\mathrm{~s}, 1 \mathrm{H}), 7.23-7.33(\mathrm{~m}, 3 \mathrm{H}), 7.39-7.44(\mathrm{~d}, 1 \mathrm{H}), 9.59-$ $9.63(\mathrm{~d}, 1 \mathrm{H}), 9.72-9.77(\mathrm{~s}, 1 \mathrm{H})$. HRMS (ESI) calcd for $\mathrm{C}_{24} \mathrm{H}_{34} \mathrm{CIN}_{3} \mathrm{O}_{6}$ : [M] ${ }^{+}: 495.2136$ Found: 495.2279.

4.1.11.14. (6S,9S)-13-(3-Chlorophenyl)-9-isobutyl-3,8,11-trioxo-1,12-dioxa-2,7,10triazacyclooctadecane-6-carbaldehyde 36B

White solid (yield 50\%); m.p $78-79^{\circ} \mathrm{C} .{ }^{1} \mathrm{H}$ NMR (400 MHz, $\left.\mathrm{CDCl}_{3}-d\right) \delta$ ppm 0.81 - $0.99(\mathrm{~d}, 6 \mathrm{H}), 1.23-1.31(\mathrm{~m}, 4 \mathrm{H}), 1.44-1.94(\mathrm{~m}, 7 \mathrm{H}), 2.36-2.70(\mathrm{~m}, 4 \mathrm{H}), 3.58-$ 3.64 (t, $2 \mathrm{H}), 4.00-4.16(\mathrm{~m}, 2 \mathrm{H}), 4.25-4.34(\mathrm{~m}, 1 \mathrm{H}), 5.50-5.63(\mathrm{~m}, 1 \mathrm{H}), 6.60-6.70$ $(\mathrm{d}, 1 \mathrm{H}), 7.12-7.22(\mathrm{~s}, 1 \mathrm{H}), 7.23-7.34(\mathrm{~m}, 3 \mathrm{H}), 7.85-7.91(\mathrm{~d}, 1 \mathrm{H}), 8.22-8.27(\mathrm{~d}, 1$ 
H), $9.72-9.76(\mathrm{~s}, 1 \mathrm{H})$. HRMS (ESI) calcd for $\mathrm{C}_{24} \mathrm{H}_{34} \mathrm{CIN}_{3} \mathrm{O}_{6}:[\mathrm{M}]^{+}: 495.2136$ Found: 495.2283.

4.1.12. Synthesis of alcohols $22 \mathrm{~b}$ and $22 \mathrm{~d}$. General procedure.

To a solution of representative ester $(5 \mathrm{mmol})$ in anhydrous THF $(30 \mathrm{~mL})$ was added lithium borohydride ( $2 \mathrm{M}$ in THF, $7.5 \mathrm{~mL}, 15 \mathrm{mmol}$ ) dropwise, followed by absolute ethyl alcohol $(15 \mathrm{~mL})$, and the reaction mixture was stirred at room temperature overnight. The reaction mixture was then acidified by adding $5 \% \mathrm{HCl}$ and the $\mathrm{pH}$ adjusted to $\sim 2$. Removal of the solvent left a residue which was taken up in ethyl acetate $(100 \mathrm{~mL})$. The organic layer was washed with brine $(25 \mathrm{~mL})$, dried over anhydrous sodium sulfate, filtered, and concentrated to yield compounds $\mathbf{2 2 b}$ and $\mathbf{2 2 d}$ as white solids.

4.1.12.1. (4S, 7S, E)-17-Benzyl-7-(hydroxymethyl)-4-isobutyl-1-oxa-3,6,11triazacycloheptadec-13-ene-2,5,10-trione $\mathbf{2 2 b}$

Sticky solid (yield 83\%); ${ }^{1} \mathrm{H}$ NMR (400 MHz, $\left.\mathrm{CDCl}_{3}-d\right) \delta$ ppm $0.81-0.97$ (d, $\left.6 \mathrm{H}\right), 1.53$ $1.69(\mathrm{~m}, 4 \mathrm{H}), 1,91-2.02(\mathrm{~m}, 5 \mathrm{H}), 2.70-2.93(\mathrm{~m}, 2 \mathrm{H}), 3.53-3.64(\mathrm{~m}, 2 \mathrm{H}), 3.80$ - 3.94 $(\mathrm{m}, 2 \mathrm{H}), 4.40$ - $4.62(\mathrm{~m}, 2 \mathrm{H}), 4.88$ - $5.04(\mathrm{~m}, 1 \mathrm{H}), 5.06$ - $5.26(\mathrm{~m}, 2 \mathrm{H}), 5.68$ - $5.87(\mathrm{~m}$, $2 \mathrm{H}), 6.20$ - 6.41 (br. d, $1 \mathrm{H}$ ), $6.91-7.10$ (d, $1 \mathrm{H}), 7.14$ - $7.36(\mathrm{~m}, 5 \mathrm{H}), 7.85-7.92$ (d, 1 H). HRMS (ESI) calcd for $\mathrm{C}_{25} \mathrm{H}_{38} \mathrm{~N}_{3} \mathrm{O}_{5}:[\mathrm{M}+\mathrm{H}]^{+}: 460.2811$ Found: 460.2831 .

4.1.12.2. (4S, 7S, E)-17-(3-Chlorophenyl)-4-(cyclohexylmethyl)-7-(hydroxymethyl)-1oxa-3,6,11-triazacycloheptadec-13-ene-2,5,10-trione 22d

Sticky solid (yield 80\%); ${ }^{1} \mathrm{H}$ NMR (400 MHz, $\left.\mathrm{CDCl}_{3}-d\right) \delta \mathrm{ppm} 0.66-0.93(\mathrm{~m}, 11 \mathrm{H}), 0.95$ - $2.32(\mathrm{~m}, 10 \mathrm{H}), 3.51$ - $3.61(\mathrm{~m}, 2 \mathrm{H}), 3.74$ - $3.86(\mathrm{~d}, 2 \mathrm{H}), 4.00$ - $4.20(\mathrm{~m}, 1 \mathrm{H}), 4.29$ $4.51(\mathrm{~m}, 1 \mathrm{H}), 4.84$ - $5.01(\mathrm{~m}, 1 \mathrm{H}), 5.42$ - $5.83(\mathrm{~m}, 2 \mathrm{H}), 5.94$ - $6.11(\mathrm{~m}, 1 \mathrm{H}), 6.22$ - 6.31 $(d, 1 \mathrm{H}), 6.75-6.92(\mathrm{~d}, 1 \mathrm{H}), 7.04-7.27(\mathrm{~m}, 4 \mathrm{H})$. HRMS (ESI) calcd for $\mathrm{C}_{27} \mathrm{H}_{38} \mathrm{CIN}_{3} \mathrm{O}_{5}$ : $[\mathrm{M}+\mathrm{H}]^{+}: 519.2500$ Found: 519.2561. 
4.1.13. Synthesis of aldehydes 23 and 24. General procedure.

Representative alcohol $(0.6 \mathrm{mmol})$ was dissolved in anhydrous dichloromethane $(20 \mathrm{~mL})$ under a nitrogen atmosphere and cooled to $0^{\circ} \mathrm{C}$. Dess-Martin periodinane $(0.75$ $\mathrm{g}, 1.78 \mathrm{mmol}, 3.0$ eq.) was added to the reaction mixture with stirring. The ice bath was removed and the reaction mixture was stirred at room temperature for $3 \mathrm{~h}$ (monitoring by TLC indicated complete disappearance of the starting material). A solution of $40 \mathrm{mM}$ sodium thiosulfate in saturated aqueous $\mathrm{NaHCO}_{3}(50 \mathrm{~mL})$ was added and the solution was stirred for another $15 \mathrm{~min}$. The aqueous layer was removed and the organic layer was washed with sodium bicarbonate $(25 \mathrm{~mL})$, water $(2 \times 25 \mathrm{~mL})$ and brine $(25 \mathrm{~mL})$. The organic layer was dried over anhydrous sodium sulfate, filtered and concentrated. The yellow residue was purified by flash chromatography (silica gel/methylene chloride/ethyl acetate/methanol) to yield the desired aldehyde.

4.1.13.1 (4S, 7S, E)-17-Benzyl-4-isobutyl-2,5,10-trioxo-1-oxa-3,6,11triazacycloheptadec-13-ene-7-carbaldehyde 23

White solid (yield 53\%); m.p $88-89^{\circ} \mathrm{C} .{ }^{1} \mathrm{H}$ NMR (400 MHz, $\left.\mathrm{CDCl}_{3}-d\right) \delta \mathrm{ppm} 0.83$ - $0.98(\mathrm{~d}, 6 \mathrm{H}), 1.55$ - $1.70(\mathrm{~m}, 4 \mathrm{H}), 1,93$-2.04 (m, $5 \mathrm{H}), 2.71$ - $2.93(\mathrm{~m}, 2 \mathrm{H}), 3.81$ - 3.95 $(\mathrm{m}, 2 \mathrm{H}), 4.41-4.61(\mathrm{~m}, 2 \mathrm{H}), 4.90-5.05(\mathrm{~m}, 1 \mathrm{H}), 5.08$ - $5.27(\mathrm{~m}, 2 \mathrm{H}), 5.69$ - $5.89(\mathrm{~m}$, $2 \mathrm{H}), 6.20$ - 6.37 (br. d, $1 \mathrm{H}$ ), 6.95 - 7.11 (d, $1 \mathrm{H}), 7.14$ - 7.36 (m, $5 \mathrm{H}), 7.85$ - 7.92 (d, 1 $\mathrm{H}), 9.54-9.67(\mathrm{~s}, 1 \mathrm{H})$. HRMS (ESI) calcd for $\mathrm{C}_{25} \mathrm{H}_{36} \mathrm{~N}_{3} \mathrm{O}_{5}:[\mathrm{M}+\mathrm{H}]^{+}: 458.2655$ Found: 458.2666 .

4.1.13.2. (4S, 7S, E)-17-(3-Chlorophenyl)-4-(cyclohexylmethyl)-2,5,10-trioxo-1-oxa3,6,11-triazacycloheptadec-13-ene-7-carbaldehyde 24

White solid (yield 59\%); m.p $83-84^{\circ} \mathrm{C} .{ }^{1} \mathrm{H}$ NMR (400 MHz, $\left.\mathrm{CDCl}_{3}-d\right) \delta \mathrm{ppm} 0.68$ - $0.95(\mathrm{~m}, 11 \mathrm{H}), 0.99$ - $2.34(\mathrm{~m}, 10 \mathrm{H}), 3.74$ - $3.86(\mathrm{~d}, 2 \mathrm{H}), 4.00$ - $4.20(\mathrm{~m}, 1 \mathrm{H}), 4.29$ $4.51(\mathrm{~m}, 1 \mathrm{H}), 4.84-5.01(\mathrm{~m}, 1 \mathrm{H}), 5.42$ - $5.83(\mathrm{~m}, 2 \mathrm{H}), 5.94-6.11(\mathrm{~m}, 1 \mathrm{H}), 6.22$ - 6.31 
(d, $1 \mathrm{H}), 6.75-6.92(\mathrm{~d}, 1 \mathrm{H}), 7.04-7.27(\mathrm{~m}, 4 \mathrm{H}), 9.56$ - 9.63 (s, $1 \mathrm{H})$. HRMS (ESI) calcd for $\mathrm{C}_{27} \mathrm{H}_{37} \mathrm{ClN}_{3} \mathrm{O}_{5}:[\mathrm{M}+\mathrm{H}]^{+}:$518.2422 Found: 518.2430.

4.1.14. Synthesis of aldehyde bisulfite salts 25-29. General procedure.

To a solution of aldehydes 13, 18, 19, or $21(0.52 \mathrm{mmol})$ in dry ethyl acetate (3.5 $\mathrm{mL}$ ) was added absolute ethanol $(1.8 \mathrm{~mL})$ with stirring, followed by a solution of sodium bisulfite (55 mg; $0.52 \mathrm{mmol})$ in water $(0.5 \mathrm{~mL})$. The reaction mixture was stirred for $3 \mathrm{~h}$ at $50{ }^{\circ} \mathrm{C}$. The reaction mixture was allowed to cool to room temperature and then vacuum filtered. The solid was thoroughly washed with absolute ethanol and the filtrate was dried over anhydrous sodium sulfate, filtered, and concentrated to yield yellowish oil. The oily product was treated with ethyl ether $(2 \times 10 \mathrm{~mL})$ to form white solid. The white solid was stirred with ethyl ether $(5 \mathrm{~mL})$ and ethyl acetate $(2.5 \mathrm{~mL})$ for 5 minutes. Careful removal of the solvent using a pipette left compound as a white solid.

4.1.14.1. Sodium ((4S,7S)-17-(3-chlorophenyl)-4-isobutyl-2,5,10-trioxo-1-oxa-3,6,11triazacycloheptadecan-7-yl) (hydroxy) methanesulfonate 25

White solid (yield 77\%); m.p $145-146^{\circ} \mathrm{C} .{ }^{1} \mathrm{H}$ NMR (400 MHz, DMSO-d 6 ) $\delta \mathrm{ppm}$ 0.81 - $0.97(\mathrm{~d}, 6 \mathrm{H}), 1.42$ - $1.83(\mathrm{~m}, 5 \mathrm{H}), 2.11$ - $2.43(\mathrm{~m}, 6 \mathrm{H}), 2.47$ - $2.64(\mathrm{~m}, 2 \mathrm{H}), 3.28$ 3.40 (t, $2 \mathrm{H}), 3.40-3.50(\mathrm{~m}, 2 \mathrm{H}), 4.50-4.60(\mathrm{~m}, 1 \mathrm{H}), 4.62-4.77(\mathrm{~m}, 1 \mathrm{H}), 5.23-5.31$ (br. s, 1 H), $5.62-5.71(\mathrm{~m}, 1 \mathrm{H}), 5.91-6.03(\mathrm{~m}, 1 \mathrm{H}), 6.14$ - $6.24(\mathrm{~d}, 1 \mathrm{H}), 6.96-7.34$ $(\mathrm{m}, 4 \mathrm{H}), 8.02-8.11(\mathrm{~d}, 1 \mathrm{H}), 8.60-8.65(\mathrm{~d}, 1 \mathrm{H})$. HRMS (ESI) calcd for $\mathrm{C}_{24} \mathrm{H}_{35} \mathrm{CIN}_{3} \mathrm{O}_{8} \mathrm{~S}^{-}:[\mathrm{M}]^{-}: 560.1839$ Found: 560.1925 .

4.1.14.2. Sodium ((20S)-10-(3-chlorophenyl)-8,17,22-trioxo-9-oxa-7,16,21-triazaspiro [5.16] docosan-20-yl) (hydroxy) methanesulfonate 26

White solid (yield $75 \%$ ); m.p $148-149^{\circ} \mathrm{C} .{ }^{1} \mathrm{H}$ NMR (400 MHz, DMSO- $\left.d_{6}\right) \delta \mathrm{ppm}$ 1.07 - $1.23(\mathrm{~m}, 7 \mathrm{H}), 1.23$ - $1.98(\mathrm{~m}, 9 \mathrm{H}), 2.09$ - $2.27(\mathrm{~m}, 6 \mathrm{H}), 3.42-3.56(\mathrm{~m}, 3 \mathrm{H}), 5.12$ - 5.18 (br. s, $1 \mathrm{H}), 5.43$ - $5.66(\mathrm{~m}, 1 \mathrm{H}), 5.78-5.82(\mathrm{~m}, 1 \mathrm{H}), 6.97$ - 7.08 (d, $1 \mathrm{H}), 7.08$ - 
$7.19(\mathrm{~d}, 1 \mathrm{H}), 7.24-7.46(\mathrm{~m}, 4 \mathrm{H}), 8.11-8.17(\mathrm{~d}, 1 \mathrm{H})$. HRMS (ESI) calcd for $\mathrm{C}_{25} \mathrm{H}_{35} \mathrm{CIN}_{3} \mathrm{O}_{8} \mathrm{~S}^{-}:[\mathrm{M}]^{-}: 572.1839$ Found: 572.1849 .

4.1.14.3. Sodium ((21S)-10-(3-chlorophenyl)-8,18,23-trioxo-9-oxa-7,17,22triazaspiro[5.17] tricosan-21-yl) (hydroxy) methanesulfonate 27

White solid (yield 65\%); m.p $145-146^{\circ} \mathrm{C} .{ }^{1} \mathrm{H}$ NMR (400 MHz, DMSO- $\left.d_{6}\right) \delta \mathrm{ppm}$ $0.90-1.36(\mathrm{~m}, 11 \mathrm{H}), 1.53-1.72(\mathrm{~m}, 7 \mathrm{H}), 2.10-2.14(\mathrm{~m}, 2 \mathrm{H}), 2.14-2.54(\mathrm{~m}, 4 \mathrm{H})$, 2.86 - $3.02(\mathrm{~m}, 2 \mathrm{H}), 4.42-4.60(\mathrm{~m}, 1 \mathrm{H}), 5.00-5.11(\mathrm{~m}, 1 \mathrm{H}), 5.13-5.20$ (br. $\mathrm{s}, 1 \mathrm{H})$, 5.66 - $5.81(\mathrm{~m}, 1 \mathrm{H}), 6.15$ - $6.23(\mathrm{~d}, 1 \mathrm{H}), 7.19$ - $7.36(\mathrm{~m}, 4 \mathrm{H}), 7.89$ - $7.94(\mathrm{~d}, 1 \mathrm{H}), 8.10$ $-8.16(d, 1 \mathrm{H})$. HRMS (ESI) calcd for $\mathrm{C}_{26} \mathrm{H}_{37} \mathrm{CIN}_{3} \mathrm{O}_{8} \mathrm{~S}^{-}:[\mathrm{M}]^{-}: 586.1995$ Found: 586.2064.

4.1.14.4. Sodium hydroxyl ((4S,7S)-4-isobutyl-2,5,10-trioxo-17-(3-phenylpropyl)-1-oxa3,6,11-triazacycloheptadecan-7-yl) methanesulfonate 28

White solid (yield 70\%); m.p $173-174^{\circ} \mathrm{C} .{ }^{1} \mathrm{H}$ NMR (400 MHz, DMSO- $\left.d_{6}\right) \delta \mathrm{ppm}$ $0.90-1.03(\mathrm{~d}, 6 \mathrm{H}), 1.15-1.81(\mathrm{~m}, 10 \mathrm{H}), 2.09-2.19(\mathrm{~m}, 9 \mathrm{H}), 2.53-2.64(\mathrm{t}, 2 \mathrm{H})$, $3.08-3.19$ (t, 2 H), $3.50-3.65 \mathrm{~m}, 1 \mathrm{H}), 4.65-4.73(\mathrm{~m}, 1 \mathrm{H}), 4.90-5.00(\mathrm{~d}, 2 \mathrm{H}), 5.21$ $-5.30(\mathrm{~s}, 1 \mathrm{H}), 5.68-5.70(\mathrm{~d}, 1 \mathrm{H}), 6.36-6.44(\mathrm{~d}, 1 \mathrm{H}), 7.12$ - $7.22(\mathrm{~d}, 2 \mathrm{H}), 7.24-7.32$ $(\mathrm{m}, 3 \mathrm{H}), 8.32-8.40(\mathrm{~d}, 1 \mathrm{H})$. HRMS (ESI) calcd for $\mathrm{C}_{26} \mathrm{H}_{37} \mathrm{CIN}_{3} \mathrm{O}_{8} \mathrm{~S}^{-}$: [M] ${ }^{-}: 586.1995$ Found: 586.2064.

4.1.14.5. Sodium hydroxyl ((4S,7S)-4-isobutyl-2,5,10-trioxo-17-pentyl-1-oxa-3,6,11triazacycloheptadecan-7-yl) methanesulfonate 29

White solid (yield $75 \%$ ); m.p $143-144^{\circ} \mathrm{C} .{ }^{1} \mathrm{H}$ NMR (400 MHz, DMSO- $\left.d_{6}\right) \delta \mathrm{ppm}$ $0.85-0.92(\mathrm{t}, 2 \mathrm{H}), 0.93-1.04(\mathrm{~d}, 6 \mathrm{H}), 1.21-1.35(\mathrm{~m}, 8 \mathrm{H}), 1.40-1.85(\mathrm{~m}, 9 \mathrm{H}), 2.22$ $-2.50(\mathrm{~m}, 4 \mathrm{H}), 3.15-3.27(\mathrm{~m}, 1 \mathrm{H}), 3.39-3.49(\mathrm{~m}, 1 \mathrm{H}), 3.97-4.07(\mathrm{~m}, 1 \mathrm{H}), 4.63-$ $4.73(\mathrm{~m}, 2 \mathrm{H}), 4.85$ - $4.96(\mathrm{~m}, 2 \mathrm{H}), 4.96-5.03$ (d, $1 \mathrm{H}), 5.21$ - 5.30 (br. s, $1 \mathrm{H}$ ), 5.67 $5.71(\mathrm{~d}, 1 \mathrm{H}), 6.14-6.22(\mathrm{~d}, 1 \mathrm{H}), 6.49-6.56(\mathrm{~d}, 1 \mathrm{H}), 8.12-8.17(\mathrm{~d}, 1 \mathrm{H})$. HRMS (ESI) calcd for $\mathrm{C}_{23} \mathrm{H}_{42} \mathrm{CIN}_{3} \mathrm{O}_{8} \mathrm{~S}^{-}:[\mathrm{M}]^{-}: 520.2698$ Found: 520.2715 . 


\subsubsection{Synthesis of compound 30.}

A solution of aldehyde $13(1.25 \mathrm{mmol})$ in ethyl acetate $(10 \mathrm{~mL})$ kept at $0^{\circ} \mathrm{C}$ was treated with acetic acid (90 mg; $1.44 \mathrm{mmol}$ ) followed by cyclopropyl isocyanide (92 $\mathrm{mg}$; $1.375 \mathrm{mmol}$ ), and the reaction mixture was stirred at room temperature for $18 \mathrm{~h}$. The solution was concentrated in vacuo and the residue was dissolved in methanol (10 mL) and treated with a solution of $\mathrm{K}_{2} \mathrm{CO}_{3}(0.4 \mathrm{~g} ; 2.95 \mathrm{mmol})$ in water $(7 \mathrm{~mL})$. The reaction mixture was stirred at room temperature for $2 \mathrm{~h}$. Methanol was evaporated off and the aqueous layer was extracted with ethyl acetate $(3 \times 20 \mathrm{~mL})$. The combined organic layers were washed with $5 \% \mathrm{HCl}(2 \times 20 \mathrm{~mL})$ and brine $(25 \mathrm{~mL})$. The organic layer was dried over anhydrous sodium sulfate and the solvent was removed to yield compound 30 as a off-white solid. This was used in the next step without further purification.

4.1.15.1. 2-((4S,7S)-17-(3-Chlorophenyl)-4-isobutyl-2,5,10-trioxo-1-oxa-3,6,11triazacycloheptadecan-7-yl)-N-cyclopropyl-2-hydroxyacetamide 30

Off-white solid (yield (57\%); m.p $189-190^{\circ} \mathrm{C} .{ }^{1} \mathrm{H}$ NMR $\left(400 \mathrm{MHz}\right.$, DMSO- $\left.d_{6}\right) \delta$ ppm $0.37-0.48(\mathrm{~m}, 2 \mathrm{H}), 0.51-0.63(\mathrm{~m}, 2 \mathrm{H}), 0.73-0.96(\mathrm{~d}, 6 \mathrm{H}), 1.06-1.86(\mathrm{~m}, 11$ H), 2.11 - $2.33(\mathrm{~m}, 4 \mathrm{H}), 2.60-2.75(\mathrm{~m}, 1 \mathrm{H}), 3.18-3.23(\mathrm{t}, 2 \mathrm{H}), 3.97$ - $4.16(\mathrm{~m}, 1 \mathrm{H})$, 4.48 - $4.59(\mathrm{~m}, 1 \mathrm{H}), 4.87-4.94(\mathrm{~m}, 1 \mathrm{H}), 5.72-5.87(\mathrm{~m}, 1 \mathrm{H}), 6.26-6.44(\mathrm{~s}, 1 \mathrm{H}), 6.82$ - 6.99 (d, 1 H), 6.99 - 7.08 (d, 1 H), 7.22 - 7.51 (m, 4 H), 7.60 - $7.65(\mathrm{~m}, 1 \mathrm{H}), 7.65$ - 7.80 (d, $1 \mathrm{H})$. HRMS (ESI) calcd for $\mathrm{C}_{28} \mathrm{H}_{42} \mathrm{CIN}_{4} \mathrm{O}_{6}:[\mathrm{M}+\mathrm{H}]^{+}: 565.2793$ Found: 565.2811.

\subsubsection{Synthesis of $\alpha$-ketoamide 31.}

To a solution of compound $30(0.62 \mathrm{mmol})$ in anhydrous dichloromethane (20 $\mathrm{mL}$ ) cooled to $0^{\circ} \mathrm{C}$ and kept under a nitrogen atmosphere was added Dess-Martin periodinane reagent $(0.53 \mathrm{~g}, 1.24 \mathrm{mmol}, 2.0 \mathrm{eq})$ with stirring. The ice bath was removed and the reaction mixture was stirred at room temperature for $3 \mathrm{~h}$. The reaction was 
monitored by TLC until the starting material disappeared. A solution of $10 \%$ aqueous sodium thiosulfate $(20 \mathrm{~mL})$ was added and the solution was stirred for 15 min. The solution was poured into a separatory funnel and the aqueous layer was removed. The organic layer was washed with $10 \%$ aqueous sodium thiosulfate $(20 \mathrm{~mL})$, followed by saturated aqueous sodium bicarbonate $(2 \times 20 \mathrm{~mL})$, water $(2 \times 20 \mathrm{~mL})$ and brine $(20$ $\mathrm{mL}$ ). The organic layer was dried over anhydrous sodium sulfate, filtered and concentrated leaving a yellow solid which was purified by flash chromatography (silica gel/methylene chloride/ethyl acetate/methanol) to yield $\mathbf{3 1}$ as a white solid.

4.1.16.1. 2-((4S,7S)-17-(3-Chlorophenyl)-4-isobutyl-2,5,10-trioxo-1-oxa-3,6,11triazacycloheptadecan-7-yl)-N-cyclopropyl-2-oxoacetamide 31

White solid (yield 50\%); m.p $210^{\circ} \mathrm{C}(\mathrm{d}) .{ }^{1} \mathrm{H}$ NMR (400 MHz, DMSO- $\left.d_{6}\right) \delta \mathrm{ppm}$ 0.34 - $0.44(\mathrm{~m}, 2 \mathrm{H}), 0.49-0.60(\mathrm{~m}, 2 \mathrm{H}), 0.83-0.96(\mathrm{~d}, 6 \mathrm{H}), 1.12-1.84(\mathrm{~m}, 11 \mathrm{H})$, $2.10-2.30(\mathrm{~m}, 4 \mathrm{H}), 2.63-2.75(\mathrm{~m}, 1 \mathrm{H}), 3.18-3.23(\mathrm{t}, 2 \mathrm{H}), 4.00-4.16(\mathrm{~m}, 1 \mathrm{H}), 4.49$ - $4.57(\mathrm{~m}, 1 \mathrm{H}), 4.86$ - $4.92(\mathrm{~m}, 1 \mathrm{H}), 5.75$ - $5.87(\mathrm{~m}, 1 \mathrm{H}), 6.80$ - $6.90(\mathrm{~d}, 1 \mathrm{H}), 6.98$ $7.08(\mathrm{~d}, 1 \mathrm{H}), 7.21-7.50(\mathrm{~m}, 4 \mathrm{H}), 7.62-7.68(\mathrm{~m}, 1 \mathrm{H}), 7.70-7.80(\mathrm{~d}, 1 \mathrm{H})$. HRMS (ESI) calcd for $\mathrm{C}_{28} \mathrm{H}_{40} \mathrm{CIN}_{4} \mathrm{O}_{6}:[\mathrm{M}+\mathrm{H}]^{+}: 563.2636$ Found: 563.2660 .

4.2. Biochemical studies. FRET protease assays.

The FRET protease assay 3CLpro was performed by preparing stock solutions of the substrate (Edans-DFHLQ/GP-Dabcyl) and inhibitor in DMSO and diluting into assay buffer which was comprised of 20mM HEPES buffer, $\mathrm{pH} 8$, containing $\mathrm{NaCl}(200 \mathrm{mM})$, $0.4 \mathrm{mM}$ EDTA, glycerol (60\%), and $6 \mathrm{mM}$ dithiothreitol (DTT). The protease was mixed with serial dilutions of each compound up to $100 \mu \mathrm{M}$ or with DMSO in $25 \mu \mathrm{L}$ of assay buffer and incubated at $37^{\circ} \mathrm{C}$ for $30 \mathrm{~min}$, followed by the addition of $25 \mu \mathrm{L}$ of assay buffer containing substrate. Fluorescence readings were obtained using an excitation 
wavelength of $360 \mathrm{~nm}$ and an emission wavelength of $460 \mathrm{~nm}$ on a fluorescence microplate reader (FLx800; Biotec, Winoosk, VT) $1 \mathrm{~h}$ following the addition of substrate. Relative fluorescence units (RFU) were determined by subtracting background values (substrate-containing well without protease) from the raw fluorescence values, as described previously [33,47-49]. The dose-dependent FRET inhibition curves were fitted with a variable slope by using GraphPad Prism software (GraphPad, La Jolla, CA) in order to determine the $\mathrm{IC}_{50}$ values of the inhibitors.

\subsection{Cell-based inhibition assays.}

The effects of each inhibitor on virus replication were examined against NV or MNV in the NV replicon harboring cells (HG23 cells) or RAW264.7 cells, respectively [33]. Briefly, confluent and semi-confluent HG23 cells were incubated with medium containing DMSO $(<0.1 \%)$ or each compound (up to $20 \mu \mathrm{M})$ for $48 \mathrm{~h}$ for NV. After the incubation, total RNA was extracted and viral genome was quantitated with real-time quantitative RT-PCR (qRT-PCR). For MNV, confluent RAW264.7 cells were inoculated with MNV at a multiplicity of infection (MOI) of 0.1 for $1 \mathrm{~h}$, and the inoculum was replaced with medium containing DMSO $(0.1 \%)$ or each compound (up to $20 \mu \mathrm{M}$ ). The virus-infected cells were further incubated for $24 \mathrm{~h}$, and the replication of virus was measured by the $50 \%$ tissue culture infective dose $\left(\mathrm{TCID}_{50}\right)$ method. The $\mathrm{EC}_{50}$ values were determined by GraphPadPrism software [33].

\subsection{Nonspecific cytotoxic effects.}

The cytotoxic dose for $50 \%$ cell death $\left(\mathrm{CC}_{50}\right)$ for each compound was determined for HG23 cells used in this study. Confluent cells grown in 96-well plates were treated 
with various concentrations ( 1 to $100 \mu \mathrm{M}$ ) of each compound for $48 \mathrm{~h}$. Cell cytotoxicity was measured by a CytoTox 96 nonradioactive cytotoxicity assay kit (Promega, Madison, WI) and crystal violet staining. The in vitro therapeutic index was calculated by dividing the $\mathrm{CC}_{50}$ by the $\mathrm{EC}_{50}$.

\subsection{X-ray crystallographic studies. Crystallization and Data Collection.}

Purified NV 3CL pro in $100 \mathrm{mM} \mathrm{NaCl}, 50 \mathrm{mM}$ PBS pH 7.2, $1 \mathrm{mM}$ DTT at a concentration of $10 \mathrm{mg} / \mathrm{mL}$ was used for preparation of the NV 3CLpro:inhibitor complexes. A $100 \mathrm{mM}$ stock solution of the inhibitors was prepared in DMSO and the NV 3CLpro:inhibitor complex was prepared by mixing $9 \mu \mathrm{L}$ of inhibitor $(3 \mathrm{mM})$ with 291 $\mu \mathrm{L}(0.49 \mathrm{mM})$ of NV 3CLpro and incubating on ice for $1 \mathrm{~h}$. The buffer was exchanged to $100 \mathrm{mM} \mathrm{NaCl}, 20 \mathrm{mM}$ Tris pH 8.0 in a Vivaspin-20 (MWCO=5kDa, Vivaproducts, Inc.) concentrator and the sample was concentrated to $10.0 \mathrm{mg} / \mathrm{mL}$ for crystallization screening. All crystallization experiments were conducted Compact Jr. (Rigaku Reagents) sitting drop vapor diffusion plates at $20{ }^{\circ} \mathrm{C}$ using equal volumes of protein and crystallization solution equilibrated against $75 \mu \mathrm{L}$ of the latter. Crystals of the inhibitor 13 complex (NV 3CLpro:13), that displayed a prismatic morphology, were obtained from the Index HT screen (Hampton Research) condition H12 (30\% (w/v) PEG $2000 \mathrm{MME}, 150$ potassium bromide) in 1-2 days. Crystals of the complex with inhibitor 21 (NV 3CLpro:21) were also obtained from the Index HT G5 condition. Samples were transferred to a fresh drop composed of $80 \%$ crystallization solution and $20 \%$ PEG 400 and stored in liquid nitrogen. X-ray diffraction data were collected at the Advanced Photon Source IMCA-CAT beamline 17-ID using a Dectris Pilatus 6M pixel array detector. 


\subsection{Structure Solution and Refinement.}

Intensities were integrated using XDS [50-51] via Autoproc [52] and the Laue class analysis and data scaling were performed with Aimless [53] which suggested that the highest probability Laue class was $2 / m$ and space group C2. The Matthew's coefficient [54] suggested that there was a single molecule in the asymmetric unit $\left(\mathrm{Vm}=1.8 \AA^{3} / \mathrm{Da}\right.$, \% solvent=32\%). Structure solution was conducted by molecular replacement with Phaser [55] using a previously determined structure of inhibitor bound NV 3CLpro (PDB: 3UR9) [33] as the search model. Structure refinement using and manual model building were conducted with Phenix [56] and Coot [57] respectively. Anisotropic atomic displacement parameters were refined for all atoms except solvent molecules for the NV 3CLpro:13 structure. Disordered side chains were truncated to the point for which electron density could be observed. Structure validation was conducted with Molprobity [58] and figures were prepared using the CCP4MG package [59].

\subsection{Accession Codes}

Coordinates and structure factors were deposited to the Worldwide Protein Databank (wwPDB) with the accession codes 5TG1 (NV 3CLpro:13) and 5TG2 (NV 3CLpro:21).

\section{ACNOWLEDGMENTS}

The generous financial support of this work by the National Institutes of Health (Al109039) is gratefully acknowledged. Use of the University of Kansas Protein Structure Laboratory was supported by a grant from the National Institute of General 
Medical Sciences (P30GM110761) from the National Institutes of Health. Use of the IMCA-CAT beamline 17-ID at the Advanced Photon Source was supported by the companies of the Industrial Macromolecular Crystallography Association through a contract with Hauptman-Woodward Medical Research Institute. Use of the Advanced Photon Source was supported by the U.S. Department of Energy, Office of Science, Office of Basic Energy Sciences under contract no. DE-AC02-06CH11357. 


\section{REFERENCES}

[1] K.Y. Green, Caliciviridae: The Noroviruses. In Fields Virology; D.M. Knipe, P.M. Howley, Eds.; Lippincott Williams \& Wilkins; Philadelphia, 1 (2007) 949-979.

[2] B.E. Lee, X.L. Pang, New strains of norovirus and the mystery of viral gastroenteritis epidemics. Can. Med. Assoc. 185 (2013) 1381-1382.

[3] G.L. Parra, K.Y. Green, Genome of emerging norovirus Gll.17, United States, 2014. Emerg. Infect. Dis. 21(2015) 1477-1479.

[4] H.L. Koo, N. Ajami, R.L. Atmar, H.L. DuPont, Noroviruses: the leading cause of gastroenteritis worldwide. Discov. Med. 10(2010) 61-70.

[5] A.J. Hall, B.A. Lopman, D.C. Payne, M.M. Patel, P.A. Gastanaduy, J. Vinje, U.D. Parashar, Norovirus disease in the United States. Emerg. Infect. Dis. 19(2013) 1198-1205.

[6] S.M. Bartsch, B.A. Lopman, S. Ozawa, A.J. Hall, B.Y. Lee, Global economic burden of norovirus gastroenteritis. PLoS One 11(4) (2016): e0151219.

[7] G. Belliott, B.A. Lopman, K. Ambert-Balay, P. Pothier, The burden of norovirus gastroenteritis: an important foodborne and healthcare-related infection. Clin. Microbiol. Infect. 20 (2014) 724-730.

[8] National Institutes of Health/U.S. National Library of Medicine/Medline Plus. Norovirus, a Costly Bug. https://www.nih.gov/medlineplus/news/fullstory_158512.html. 
[9] K. Pringle, B. Lopman, E. Vega, J. Vinje, U.D. Parashar, A.J. Hall, Noroviruses: epidemiology, immunity and prospects for prevention. Future Microbiol. 10 (2015) 53-67.

[10] K. Bok, K.Y.Green, Norovirus gastroenteritis in immunocompromised patients. N. Engl. J. Med. 367 (2012) 2126-2132.

[11] E. Robilotti, S. Deresinski, Pinsky, B. A. Noroviruses. Clin. Microbiol. Rev. 28(2015) 134-164.

[12] C.F. Lanata, C. L. Fischer-Walker, A.C. Olascoaga, C.X. Torres, M. KJ. Aryee, R.E. Black, Global causes of diarrheal disease mortality in children $<5$ years of age: a systematic review. PLoS One 8(2013) e72788.

[13] A.J. Hall, Noroviruses: the perfect human pathogen. J. Infect. Dis. 205 (2012) 16221624.

[14] M.D. Moore, R.M. Goulter, L.A. Jaykus, Human norovirus as a foodborne pathogen: challenges and developments. Ann. Rev. Food Sci. Technol. 6(2015) 411-433.

[15] Y. Kim, A.C. Galasiti Kankanamalage, K-O. Chang, W.C. Groutas, Recent advances in the discovery of norovirus therapeutics. J. Med. Chem. 58(2015) 94389450.

[16] A.C. Galasiti Kankanamalage, P.M. Weerawarna, Y. Kim, K.O. Chang, W.C. Groutas, Anti-norovirus therapeutics: a patent review (2010-2015). Expert Opin. Ther. Pat. 26(2016) 297-308.

[17] B.V. Venkataraman Prasad, S. Shanker, Z. Muhaxhiri , L. Deng, J-M. Choi, M.K. Estes, Y. Song, T. Palzkill, R.L. Atmar, Antiviral targets of human noroviruses. Curr. Opin. Virol 18(2016) 117-125. 
[18] S. Weerasekara, A.M. Prior, D.H. Hua, Current tools for norovirus drug discovery. Expert Opin. Drug Discov. 11(2016) 529-541.

[19] J. Kocher, L. Yuan, Norovirus vaccines and potential anti-norovirus drugs: recent advances and future perspectives. Future Virol. 10(2015) 899-913.

[20] J. Rocha-Pereira, J. Neyts, D. Jochmans, Norovirus: targets and tools in antiviral drug discovery. Biochem. Pharmacol. 91(2014) 1-11.

[21] R.L. Atmar, F. Baehner, J.P. Cramer, E. Song, A. Borkowski, P.M. Mendelman, Rapid responses to 2 virus-like particle norovirus vaccine candidate formulations in healthy adults: a randomized controlled trial. J. Infect. Dis. 214(2016) 845-853.

[22] S.M. Karst, S.A. Tibbets, Recent advances in understanding norovirus pathogenesis. J. Med. Virol. 88(2016) 1837-1843.

[23] S.M. Karst, C.E. Wobus, A working model of how noroviruses infect the intestine. PLoS Pathog. Feb 27; 11(2) (2015) e1004626.

[24] L.G. Thorne, I.G. Goodfellow, Norovirus gene expression and replication. J. Gen. Virol. 95(2014) 278-291.

[25] S.M. Karst, The influence of commensal bacteria on infection with enteric viruses. Nat. Rev. Microbiol. 14(2016) 197-204.

[26] R.C. Orchard, C.B. Wilen, J.G. Doench, M.T. Baldridge, B.T. McCune, Y-C.J. Lee, S. Lee, S.M. Pruett-Miller, C.A. Nelson, C.A. Fremont, H.W. Virgin, Discovery of a proteinaceous cellular receptor for a norovirus. Science 10(2016) 1126 science.aaf1220

[27] R.J. Hussey, L. Coates, R.S. Gill, P.T. Erskine, S.-F. Coker, E. Mitchell, J.B. Cooper, R. Broadbridge, I.N. Clarke, P.R. Lambden, P.M. Shoolingin-Jordan, Structural study 
of norovirus $3 \mathrm{C}$ specificity: binding of a designed active site-directed peptide inhibitor. Biochemistry 50(2011) 240-249.

[28] M.E. Hardy, T.J. Crone, J.E. Brower, K. Ettayebi, Substrate specificity of the Norwalk virus 3C-like proteinase. Virus Res. 89(2002) 29-39.

[29] Z. Muhaxhiri, L. Deng, S. Shanker, B. Sankaran, M.K. Estes, T. Palzkill, Y. Song, B.V. Venkataram Prasad, Structural basis of substrate specificity and protease inhibition in Norwalk virus. J. Virol. 87(2013) 4281-4292.

[30] D. Takahashi, Y. Hiromasa, Y. Kim, A. Anbanandam, X. Yao, K.O. Chang O. Prakash, Structural and dynamics characterization of norovirus protease. Protein Sci. 22(2013) 347-357.

[31] M. Allaire, M.M. Chernaia, B.A. Malcolm, M.N. James, Picornaviral 3C cysteine proteinases have a fold similar to chymotrypsin-like serine proteinases. Nature 369(1994) 72-76.

[32] Nomenclature used is that of Schechter, L. and Berger, A. Biochem. Biophys. Res. Comm. 27(1967) 157-162, where $S_{1}, S_{2}, S_{3}, \ldots S_{n}$ and $S_{1}{ }^{\prime}, S_{2}{ }^{\prime}, S_{3}{ }^{\prime}, \ldots S_{n}^{\prime}$ correspond to the enzyme subsites on the $\mathrm{N}$-terminus and $\mathrm{C}$-terminus side, respectively, of the scissile bond. Each subsite accommodates a corresponding amino acid residue side chain designated $P_{1}, P_{2}, P_{3}, \ldots P_{n}$ and $P_{1}{ }^{\prime}, P_{2}{ }^{\prime}, P_{3}{ }^{\prime}, \ldots . . P_{n}{ }^{\prime}$ of a substrate or inhibitor. $P_{1}$ is the primary substrate specificity residue and $P_{1}-P_{1}{ }^{\prime}$ is the scissile bond.

[33] A.C. Galasiti Kankanamalage, Y. Kim, P.M. Weerawarna, R.A.Z. Uy, V.C. Damalanka, S.R. Mandadapu, K.R. Alliston, N. Mehzabeen, K.P. Battaille, S. Lovell, K-O. Chang, W.C. Groutas, Structure-guided design and optimization of dipeptidyl 
inhibitors of norovirus $3 \mathrm{CL}$ protease. Structure-activity relationships and biochemical, x-ray crystallographic, cell-based and in vivo studies. J. Med. Chem. 58(2015) 31443155 .

[34] J.D. Tyndall, D.P. Fairlie, Proteases universally recognize beta strands in their active sites. Chem. Rev. 105 (2005) 973-999.

[35] J.D. Tyndall, D.P. Fairlie, Macrocycles mimic the extended peptide conformation recognized by aspartic, serine, cysteine, and metallo proteases. Current Med. Chem. 8(2001) 893-907.

[36] P. Leeson, R.J. Young, Molecular property design: does everyone get it? MedChemLett 6(2015) 722-725.

[37] N. Meanwell, Improving drug candidates by design: a focus on physicochemical properties as a means of improving compound disposition and safety. Chem. Res. Toxicol. 24(2011) 1420-1456.

[38] A. Bhat, L.R. Roberts, J.J. Dwyer, Lead discovery and optimization strategies for peptide macrocycles. Eur. J. Med. Chem. 94(2015) 471-479.

[39] E. Marsault, M.L. Peterson, Macrocycles are great cycles: applications, opportunities, and challenges of synthetic macrocycles. J. Med. Chem. 54(2011) 1961-2004.

[40] F. Giordanetto, J. Kihlberg, Macrocyclic drugs and clinical candidates: what can medicinal chemists learn from their properties? J. Med. Chem. 57(2014) 278-295.

[41] B.C. Doak, J. Zheng, D. Dobritzsch, J. Kihlberg, How beyond the rule of 5 drugs and clinical candidates bind to their targets. J. Med. Chem. 59(2016) 2312-2327. 
[42] P. Matsson, B.C. Doak, B. Over, J. Kihlberg, Cell permeability beyond the rule of 5. Adv. Drug Deliv. Rev. 101(2016) 42-61.

[43] B.C. Doak, J. Zheng, D. Dobritzsch, J. Kihlberg, How beyond the rule of 5 drugs and clinical candidates bind to their targets. J. Med. Chem. 59(2016) 2312-2327.

[44] A. Alex, D.S. Millan, M. Perez, F. Wakenhut, G.A. Whitlock, Intramolecular hydrogen bonding to improve membrane permeability and absorption in beyond the rule of five chemical space. Med. Chem. Commun. 2(2011) 669-674.

[45] A.T. Bockus, K.W. Lexa, C.R. Pye, A.S. Kalgutkar, J.W. Gardner, K.C.R. Hund, W.M. Hewitt, J.A. Schwochert, E. Glassey, D.A. Price, A.M. Mathiowetz, S. Liras, M.P. Jacobson, R.S. Lokey, Probing the physicochemical boundaries of cell permeability and oral bioavailability in lipophilic macrocycles inspired by natural products. J. Med. Chem. 58(2015) 4581-4589.

[46] P. Thansandote, R.M. Harris, H.L. Dexter, G.L. Simpson, S. Pal, R.J. Upton, K. Valko, Improving the passive permeability of macrocyclic peptides: balancing permeability with other physicochemical properties. Bioorg. Med. Chem. 23(2015) 322-327.

[47] Y. Kim, S. Lovell, K-C. Tiew, S. R. Mandadapu, K.R. Alliston, , K.P. Battaille, W.C. Groutas, K-O. Chang, Broad spectrum antivirals against $3 \mathrm{Cl}$ or $3 \mathrm{C}$-like proteases of picornaviruses, noroviruses and coronaviruses. J. Virol. 6(2012) 11754-11762.

[48] V.C. Damalanka, Y. Kim, K.R. Alliston, P.M. Weerawarna, A.C. Galasiti Kankanamalage, G.H. Lushington, N. Mehzabeen, K.P. Battaille, S. Lovell, K-O. Chang, W.C. Groutas, Oxadiaxole-based vell-permeable macrocyclic transition state inhibitors of norovirus 3CL protease. J. Med. Chem. 59(2016) 1899-1913. 
[49] P.M. Weerawarna, Y. Kim, A.C. Galasiti Kankanamalage, V.C. Damalanka, G.H. Lushington, K.R. Alliston, N. Mehzabeen, K.P. Battaille, S. Lovell, K-O. Chang, W.C. Groutas,Structure-based design and synthesis of triazole-based macrocyclic inhibitors of norovirus protease: structural, biochemical, spectroscopic and antiviral studies. Eur. J. Med. Chem. 25(2016) 300-318.

[50] W. Kabsch, Automatic Indexing of Rotation Diffraction Patterns. J. Appl. Crystallogr. 21(1988) 67-72.

[51] W. Kabsch, Xds. Acta Crystallogr D Biol Crystallogr. 66(2010) 125-132.

[52] C. Vonrhein, C. Flensburg, P. Keller, A. Sharff, O. Smart, W. Paciorek, T. Womack, G. Bricogne, Data processing and analysis with the autoPROC toolbox. Acta Crystallogr. D. Biol. Crystallogr. 67(2011) 293-302.

[53] P.R. Evans, An Introduction to Data Reduction: Space-group Determination, Scaling and Intensity Statistics. Acta Crystallogr. D. Biol. Crystallogr. 67(2011) 282-292.

[54] B. W. Matthews, Solvent content of protein crystals. J. Mol. Biol. 33(1968) 491-497.

[55] A.J McCoy, R.W. Grosse-Kunstleve, P.D. Adams, M. Winn, L.C. Storoni, R.J. Read, Phaser Crystallographic Software. J. Appl. Cryst. 40(2007) 658-674.

[56] P.D. Adams, P.V. Afonine, G. Bunkoczi, V.B. Chen, I.W. David, , N. Echols J.J. Headd, L-W. Hung, G.J. Kapral, R.W. Grosse-Kunstleve, A.J. McCoy, N.W. Moriarty, R. Oeffner, R.J. Read, D.C. Richardson, J.S. Richardson, T.C. Terwilliger, P.H. Zwart, PHENIX: a Comprehensive Python-based System for Macromolecular Structure Solution. Acta Crystallogr. Sect D: Biol. Crystallogr. 66(2010) 213-221.

[57] P. Emsley, B. Lohkamp, W.G. Scott, K. Cowtan, Features and Development of Coot. Acta Crystallogr. Sect D: Biol.Crystallogr. 66(2010) 486-501. 
[58] V.B. Chen, W.B. Arendall, J.J. Headd, D.A. Keedy, R.M. Immormino, G.J. Kapral, L.W. Murray, J.S. Richardson, D.C. Richardson, MolProbity: All-atom Structure Validation for Macromolecular Crystallography. Acta Crystallogr. Sect D: Biol. Crystallogr. 66(2010) 12-21.

[59] L. Potterton, S. McNicholas, E. Krissinel, J. Gruber, K. Cowlan, P. Emlsey, G.N. Murshudov, S. Cohen, A. Perrakis, M. Noble, Developments in the CCP4 Molecular Graphics Project. Acta Crystallogr. Sect D: Biol. Crystallogr. 60(2004) 2288-2294.

[60] P. Evans, Scaling and Assessment of Data Quality. Acta Crystallogr. Sect D: Biol. Crystallogr. 62(2006) 72-82.

[61] K. Diederichs, and P.A. Karplus, Improved R-factors for Diffraction Data Analysis in Macromolecular Crystallography. Nat Struct Biol, 4(1997) 269-275.

[62] M.S. Weiss, Global Indicators of X-ray Data Quality. J. Appl. Crystallogr. 34(2001) 130-135.

[63] P.A. Karplus, and K. Diederichs, K. Linking Crystallographic Model and Data Quality. Science 336(2012) 1030-1033.

[64] P. Evans, Biochemistry. Resolving Some Old Problems in Protein Crystallography. Science 336(2012) 986-987. 
Table 1. Activity and cell toxicity of compounds 11-12, 20, 28, 13, 25, 31, 14a-b, 15-18, 26, 19, $27,21,29$, and $36 A-B$ (all values are $\mu \mathrm{M}$ ).

\begin{tabular}{|c|c|c|c|c|c|c|c|c|}
\hline Compound & $\mathbf{R}_{1}$ & $\mathbf{R}_{\mathbf{2}}$ & $\mathbf{x}$ & Ring Size & $\begin{array}{c}\mathrm{IC}_{50}(\mu \mathrm{M}) \\
(\mathrm{NV}) \\
\end{array}$ & $\begin{array}{c}\mathrm{EC}_{50}(\mu \mathrm{M}) \\
(\mathrm{NV})\end{array}$ & $\begin{array}{c}\text { EC50 } \\
(\mu \mathrm{M}) \\
(\mathrm{MNV}) \\
\end{array}$ & $\begin{array}{r}\text { TC50 } \\
\text { (EC50) }\end{array}$ \\
\hline 11 & Phenyl & Leu & $\mathrm{CHO}$ & 17 & 1.3 & 7.7 & $>20$ & $>100$ \\
\hline 12 & Benzyl & Leu & $\mathrm{CHO}$ & 17 & 4.6 & 8.8 & $>20$ & $>100$ \\
\hline 20 & $\begin{array}{l}\text { Propyl } \\
\text { benzene }\end{array}$ & Leu & $\mathrm{CHO}$ & 17 & 4.2 & 7.5 & $>20$ & 71.5 \\
\hline 28 & & & $\mathrm{CH}(\mathrm{OH}) \mathrm{SO}_{3} \mathrm{Na}$ & & 6.8 & 4.6 & $>20$ & 69.2 \\
\hline 13 & & & $\mathrm{CHO}$ & & 1.5 & 1.8 & 13.2 & $>100$ \\
\hline 25 & $\begin{array}{l}m \text {-Cl- } \\
\text { phenyl }\end{array}$ & Leu & $\begin{array}{c}\mathrm{CH}(\mathrm{OH}) \mathrm{SO}_{3} \mathrm{Na} \\
(\mathrm{C}=\mathrm{O})(\mathrm{C}=\mathrm{O}) \\
\text { Cyclopropyl }\end{array}$ & 17 & 1.1 & 1.6 & 15.1 & $>100$ \\
\hline $\begin{array}{l}14 \text { (major) } \\
14 \text { (minor) }\end{array}$ & $\begin{array}{l}m \text {-Cl- } \\
\text { phenyl }\end{array}$ & Cha & $\mathrm{CHO}$ & 17 & $\begin{array}{l}4.1 \\
6.5\end{array}$ & $\begin{array}{l}2.1 \\
2.5\end{array}$ & $\begin{array}{l}4.3 \\
6.5\end{array}$ & $\begin{array}{l}62.4 \\
45.3\end{array}$ \\
\hline 15 & $\begin{array}{l}m \text {-Cl- } \\
\text { phenyl }\end{array}$ & Leu & $\mathrm{CHO}$ & 18 & 6.3 & 5.4 & $>20$ & 67.4 \\
\hline $\begin{array}{l}16 \\
17\end{array}$ & $\begin{array}{c}m \text {-Cl- } \\
\text { phenyl }\end{array}$ & Ala & $\mathrm{CHO}$ & $\begin{array}{l}17 \\
18\end{array}$ & $\begin{array}{l}>100 \\
62.3\end{array}$ & $\begin{array}{l}>20 \\
9.5\end{array}$ & $\begin{array}{l}>20 \\
>20\end{array}$ & $\begin{array}{l}>100 \\
>100\end{array}$ \\
\hline 18 & & spirocyclo & $\mathrm{CHO}$ & & $>100$ & $>20$ & $>20$ & 62.4 \\
\hline 26 & $m-\mathrm{Cl}-$ & hexyl & $\mathrm{CH}(\mathrm{OH}) \mathrm{SO}_{3} \mathrm{Na}$ & 17 & $>100$ & $>20$ & $>20$ & 48.5 \\
\hline 19 & phenyl & & $\mathrm{CHO}$ & & $>100$ & $>20$ & $>20$ & 53.3 \\
\hline 27 & & & $\mathrm{CH}(\mathrm{OH}) \mathrm{SO}_{3} \mathrm{Na}$ & 18 & $>100$ & $>20$ & $>20$ & 46.6 \\
\hline 21 & & & $\mathrm{CHO}$ & & 3.2 & 3.1 & 12.1 & 72.7 \\
\hline 29 & $n$-pentyl & Leu & $\mathrm{CH}(\mathrm{OH}) \mathrm{SO}_{3} \mathrm{Na}$ & 17 & 5.1 & 3.5 & 14.6 & 78.5 \\
\hline $\begin{array}{l}36 \mathrm{~A} \\
36 \mathrm{~B}\end{array}$ & $\begin{array}{c}m-\mathrm{Cl}- \\
\text { phenyl }\end{array}$ & Leu & $\mathrm{CHO}$ & 18 & $\begin{array}{l}30.5 \\
46.7 \\
\end{array}$ & $\begin{array}{l}3.6 \\
5.1 \\
\end{array}$ & $\begin{array}{l}15.5 \\
13.4 \\
\end{array}$ & $\begin{array}{l}68.3 \\
73.8 \\
\end{array}$ \\
\hline 23 & Benzyl & Leu & $\mathrm{CHO}$ & 17 & 2.5 & 3.1 & $>20$ & $>100$ \\
\hline 24 & $\begin{array}{c}m \text {-Cl- } \\
\text { phenyl }\end{array}$ & Cha & $\mathrm{CHO}$ & 17 & 1.3 & 1.5 & 3.1 & 42.3 \\
\hline
\end{tabular}


Table 2. Crystallographic data for NV 3CLpro:inhibitor 13 and 21 structures

NV 3CLpro:13

NV 3CLpro:21

\section{Data Collection}

Unit-cell parameters $\left(\AA{ }^{\circ}{ }^{\circ}\right)$

Space group

Resolution $(\AA)^{1}$

Wavelength $(\AA)$

Temperature $(\mathrm{K})$

Observed reflections

Unique reflections

$$
<1 / \sigma(I)>1
$$

Completeness $(\%)^{1}$

Multiplicity ${ }^{1}$

$R_{\text {merge }}(\%)^{1,2}$

$R_{\text {meas }}(\%)^{1,4}$

$R_{\text {pim }}(\%)^{1,4}$

$\mathrm{CC}_{1 / 2}{ }^{1,5}$

\section{Refinement}

Resolution $(\AA)^{1}$

Reflections (working/test) ${ }^{1}$

$R_{\text {factor }} / R_{\text {free }}(\%)^{1,3}$

No. of atoms

(Protein/Ligand/Water)

Model Quality

R.m.s deviations

Bond lengths $(\AA)$

Bond angles $\left({ }^{\circ}\right)$

Average $B$-factor $\left(\AA^{2}\right)$

All Atoms

Protein

Ligand

Water

Coordinate error(maximum likelihood) $(\AA)$

$$
\begin{gathered}
a=64.40, b=36.49, c=61.47, \\
\beta=112.5
\end{gathered}
$$

C2

$31.83-1.40(1.42-1.40)$

1.0000

100

83,610

25,218

$13.4(1.9)$

96.8 (95.3)

$3.3(3.2)$

$4.8(69.1)$

$5.8(82.9)$

$3.1(45.4)$

$0.998(0.704)$

31.83-1.40

$24,030 / 1,183$

$14.3 / 19.2$

$1,253 / 33 / 128$ $a=67.02, \quad b=36.70, c=61.72$,
$\beta=110.2$

C2

32.79-1.75 (1.78-1.75)

1.0000

100

46,353

14,350

$9.5(1.9)$

$99.6(94.6)$

$3.2(2.4)$

$8.2(46.4)$

$9.8(58.9)$

$5.4(35.6)$

$0.996(0.780)$

32.79-1.75

$13,624 / 710$

$17.6 / 22.7$

$1,196 / 31 / 83$

0.009

0.01

1.035

0.998

19.2

20.4

17.9

19.7

20.9

22

31.4

29.9

0.15

0.19 


\section{Ramachandran Plot}

Most favored (\%)

1) Values in parenthesis are for the highest resolution shell.

2) $\quad R_{\text {merge }}=\sum_{h k l} \Sigma_{i}\left|l_{i}(h k l)-<l(h k l)>\right| / \sum_{h k l} \Sigma_{i} l_{i}(h k l)$, where $l_{i}(h k l)$ is the intensity measured for the ith reflection and $\langle/(h k l)>$ is the average intensity of all reflections with indices $h k l$.

3) $\quad R_{\text {factor }}=\Sigma_{h k l}|| F_{\text {obs }}(h k l)|-| F_{\text {calc }}(h k l)|| / \Sigma_{h k l}\left|F_{\text {obs }}(h k l)\right|$; Rfree is calculated in an

identical manner using $5 \%$ of randomly selected reflections that were not included in the refinement.

4) $\quad R_{\text {meas }}=$ redundancy-independent (multiplicity-weighted) $R_{\text {merge }}[53,60] . R_{\text {pim }}=$ precision-indicating (multiplicity-weighted) $R_{\text {merge }}[61-62]$.

5) $\mathrm{CC}_{1 / 2}$ is the correlation coefficient of the mean intensities between two random half-sets of data [63-64]. 


\section{Scheme 1}

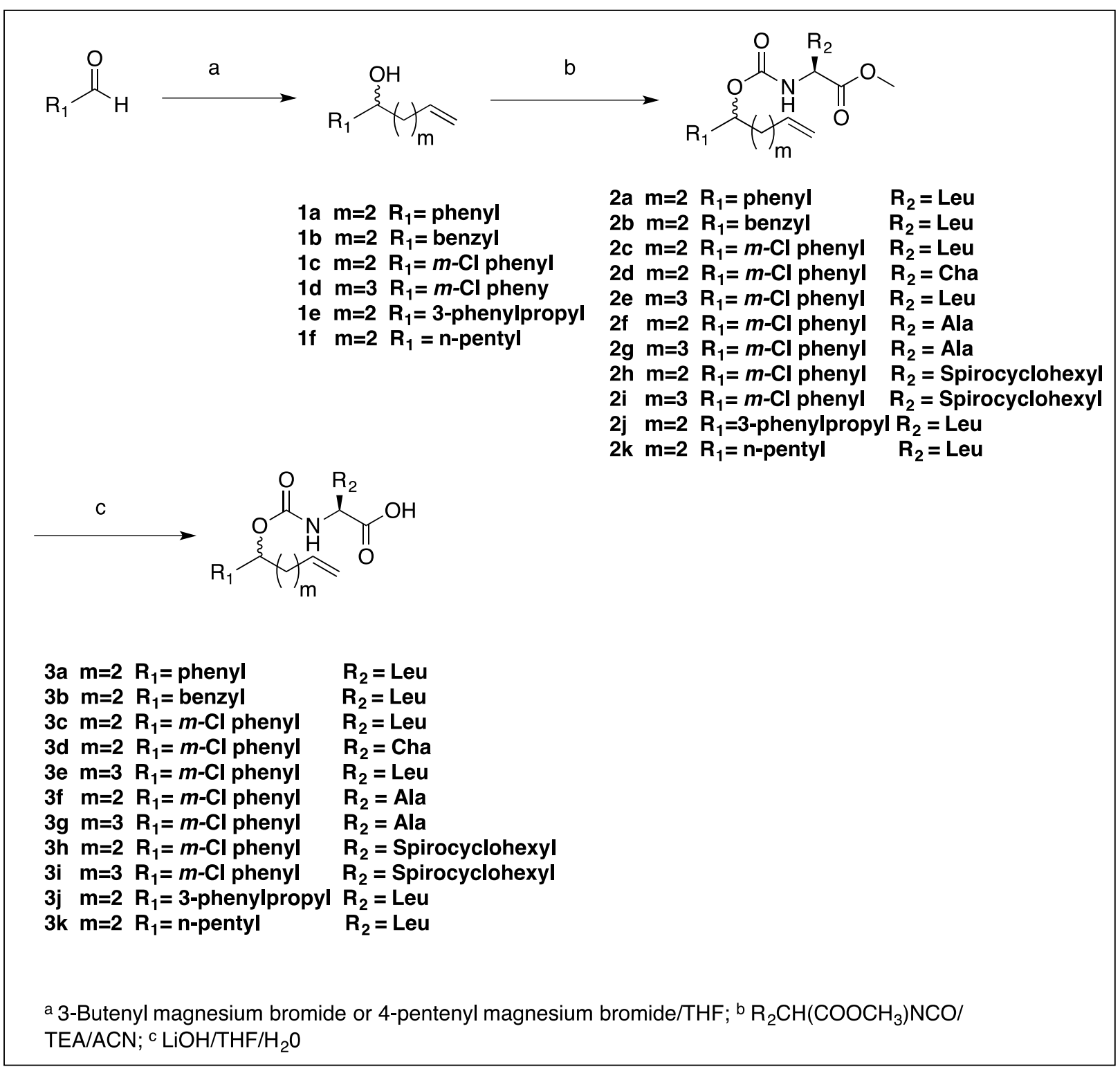




\section{Scheme 2}

A)<smiles>[R2]C(N)C(=O)OC</smiles>

4

$$
\begin{array}{ll}
4 a & R_{2}=\text { Alanine } \\
4 b & =\text { Leucine } \\
4 c & =\text { Cyclohexyl alanine } \\
4 d & =\text { Spirocyclohexyl glycine }
\end{array}
$$

B)

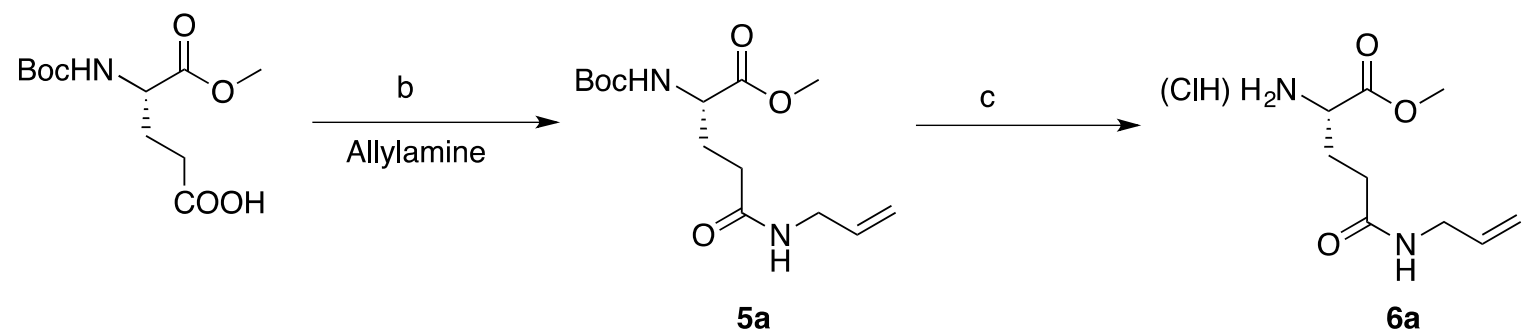

C)<smiles>COC(=O)[C@H](CCC(=O)O)NC(=O)OCCO</smiles><smiles>C=CCONC(=O)CC[C@H](NC(=O)OCc1ccccc1)C(=O)OC</smiles>

$5 b$<smiles>C=CCONC(=O)CC[C@H](N)C(=O)OC</smiles>

6b

a Tricholoromethyl chloroformate/1,4-dioxane; b EDCI/HOBt/DIEA/DMF; ${ }^{c} 4 \mathrm{M} \mathrm{HCl}$ in 1,4 -dioxane 


\section{Scheme 3}

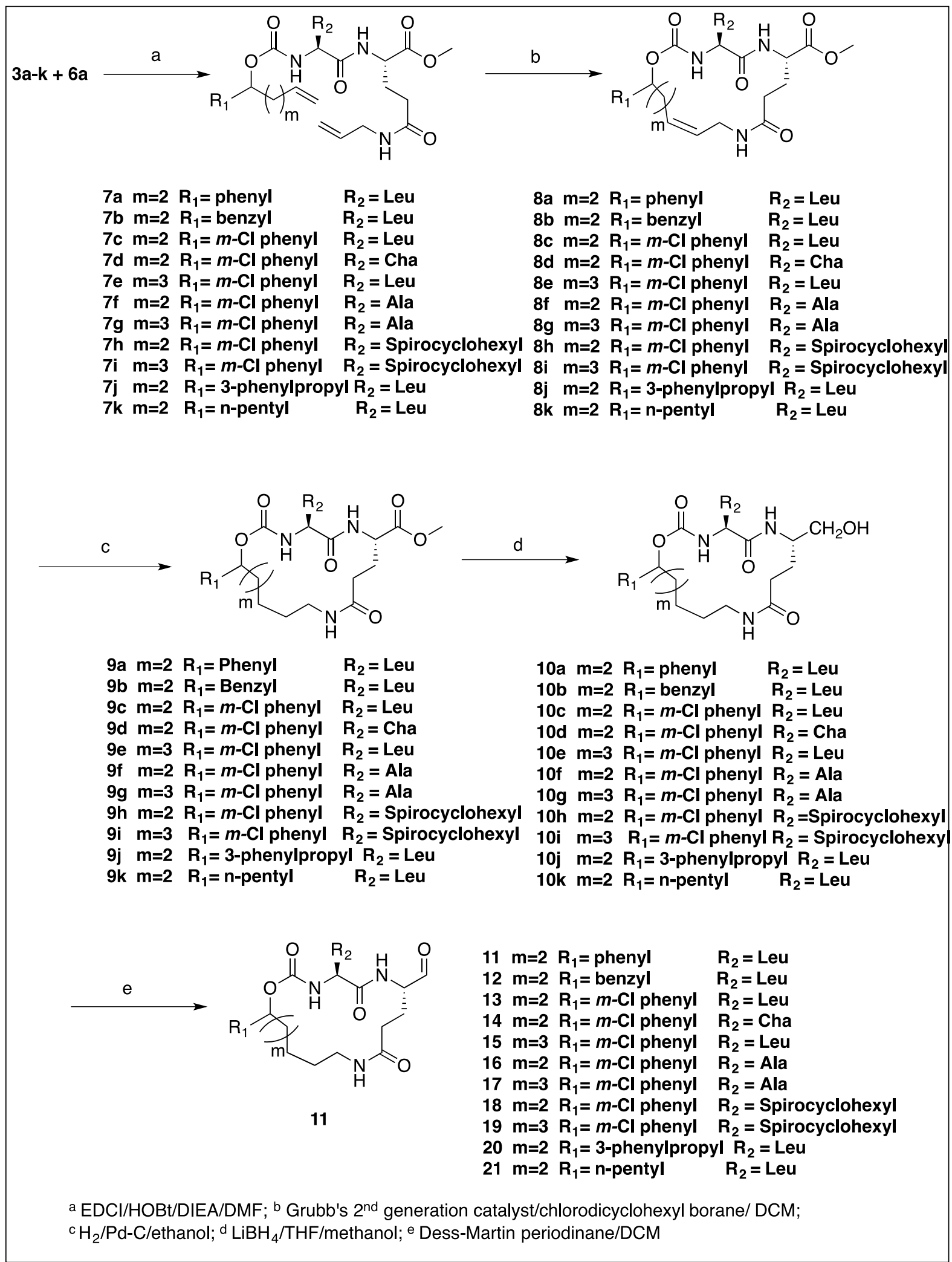




\section{Scheme 4}

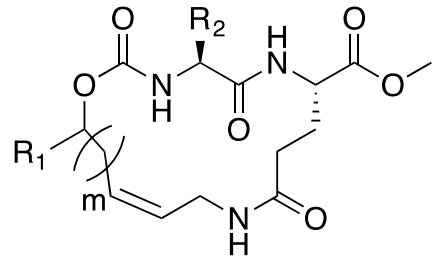

$\longrightarrow$

$8 \mathrm{~b} \mathbf{m}=2 \mathbf{R}_{1}=$ benzyl $8 \mathrm{~d} m=2 R_{1}=m-\mathrm{Cl}$ phenyl $R_{2}=$ Cha

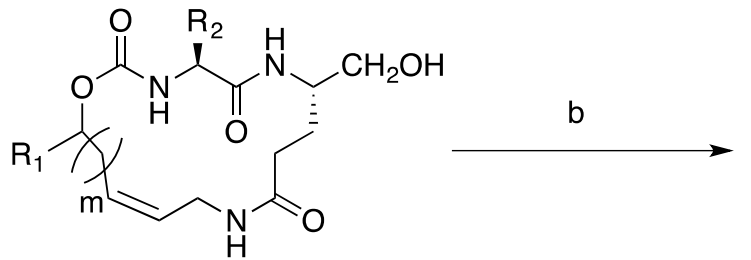

22b $m=2 \quad R_{1}=$ benzyl $\quad R_{2}=$ Leu

$22 \mathrm{~d} m=2 \quad R_{1}=m-\mathrm{Cl}$ phenyl $R_{2}=$ Cha

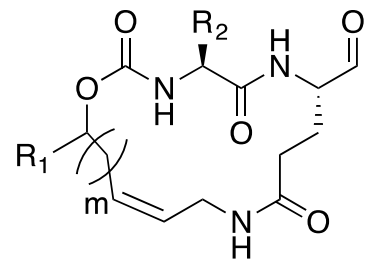

$23 \mathrm{~m}=2 \mathbf{R}_{1}=$ benzyl $\quad \mathbf{R}_{2}=$ Leu

$24 m=2 R_{1}=m-C l$ phenyl $R_{2}=$ Cha

a $\mathrm{LiBH}_{4} / \mathrm{THF} /$ methanol; b Dess-Martin periodinane/DCM 


\section{Scheme 5}<smiles>[R2][C@H](NC(=O)OC([R7])(C)C)C(=O)N[C@H](C=O)CCC(=O)NCCCC</smiles>

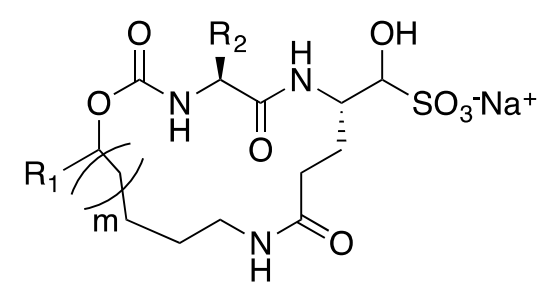

$13 \mathrm{~m}=2 \quad \mathrm{R}_{1}=\mathrm{m}-\mathrm{Cl}$ phenyl $\mathrm{R}_{2}=$ Leu

$18 \mathrm{~m}=2 \quad R_{1}=m-C l$ phenyl $\quad R_{2}=$ Spirocyclohexyl

$19 \mathrm{~m}=3 \quad R_{1}=\mathrm{m}-\mathrm{Cl}$ phenyl $R_{2}=$ Spirocyclohexyl

$20 \mathrm{~m}=2 R_{1}=3$-phenylpropyl $R_{2}=$ Leu

$21 \mathrm{~m}=2 \quad R_{1}=n-p e n t y l$

$\mathbf{R}_{2}=\mathrm{Leu}$
$25 \mathrm{~m}=2 \quad R_{1}=\mathrm{m}-\mathrm{Cl}$ phenyl $\quad R_{2}=$ Leu

$26 \mathrm{~m}=2 \quad R_{1}=\mathrm{m}-\mathrm{Cl}$ phenyl $R_{2}=$ Spirocyclohexyl

$27 \mathrm{~m}=3 \quad R_{1}=\mathrm{m}-\mathrm{Cl}$ phenyl $R_{2}=$ Spirocyclohexyl

$28 \mathrm{~m}=2 \quad R_{1}=3$-phenylpropyl $R_{2}=$ Leu

$29 \mathrm{~m}=2 \quad R_{1}=n$-pentyl $\quad R_{2}=$ Leu

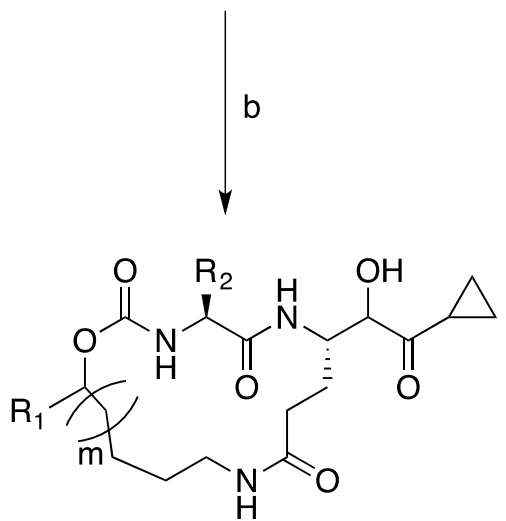

$30 \mathrm{~m}=2 \quad R_{1}=\mathrm{m}-\mathrm{Cl}$ phenyl $\mathbf{R}_{2}=$ Leu

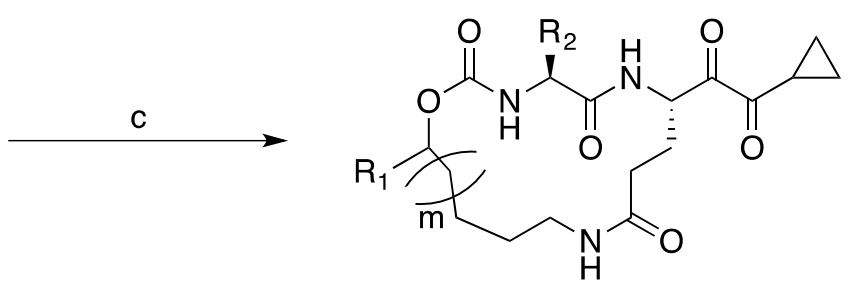

$31 \mathrm{~m}=2 \quad R_{1}=\mathrm{m}-\mathrm{Cl}$ phenyl $R_{2}=$ Leu

a $\mathrm{NaHSO}_{3} / \mathrm{H}_{2} \mathrm{O}$ /ethyl acetate/ethanol/diethyl ether; b Cyclopropyl isocyanide; c Dess-Martin periodinane/DCM 
Scheme 6

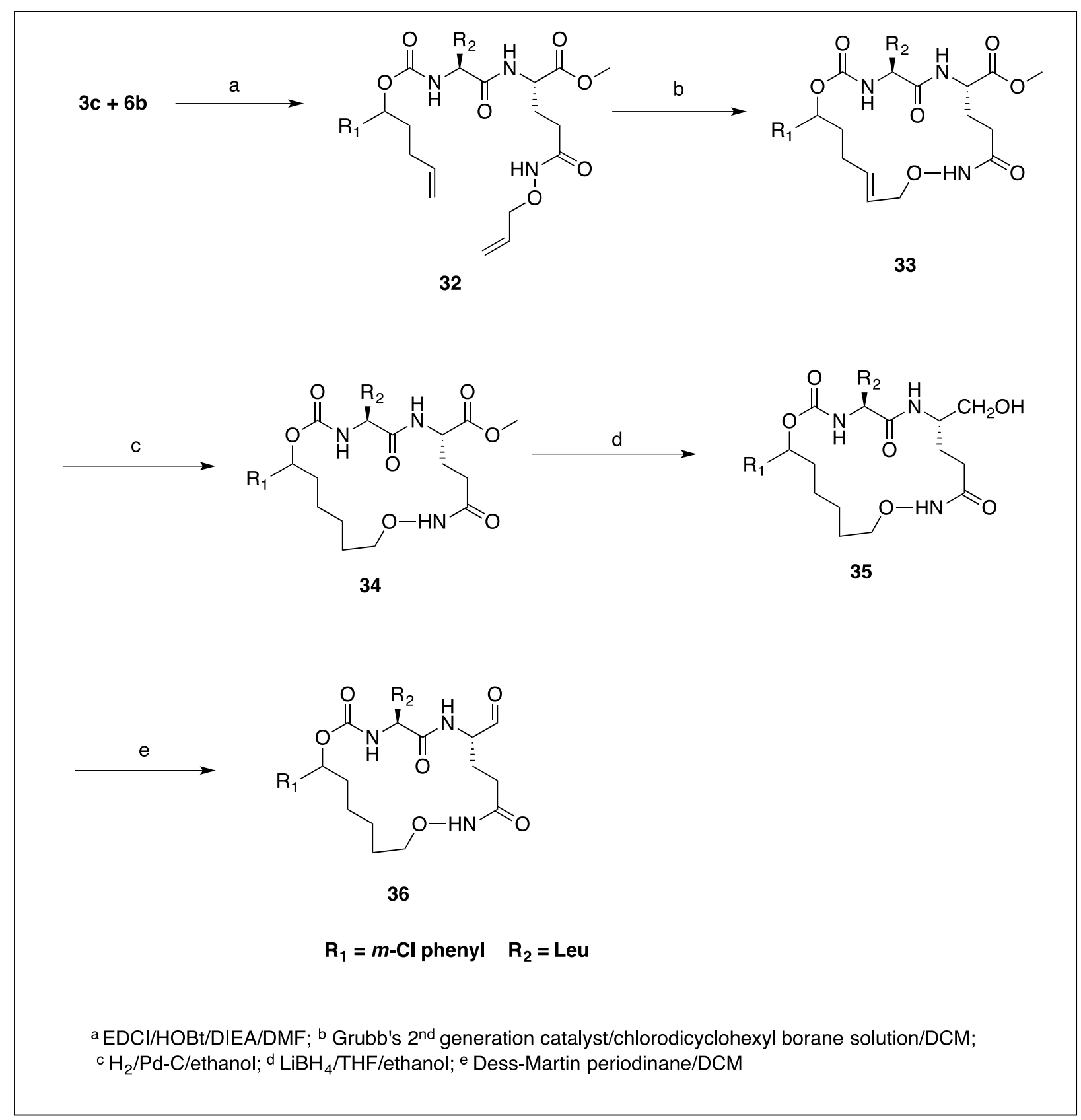


Fig. 1. General structure of macrocyclic inhibitor (I)

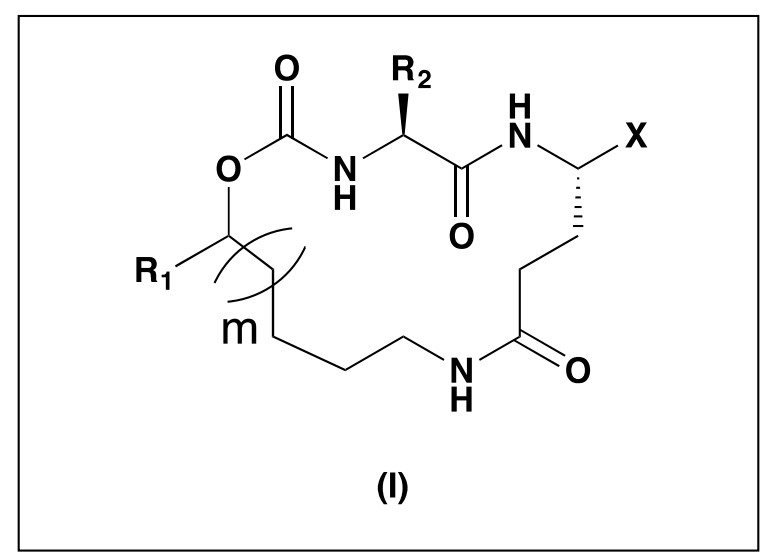


Fig. 2. View of the $F_{0}-F_{c}$ omit map for inhibitor 13 (green mesh) contoured at $3 \sigma$

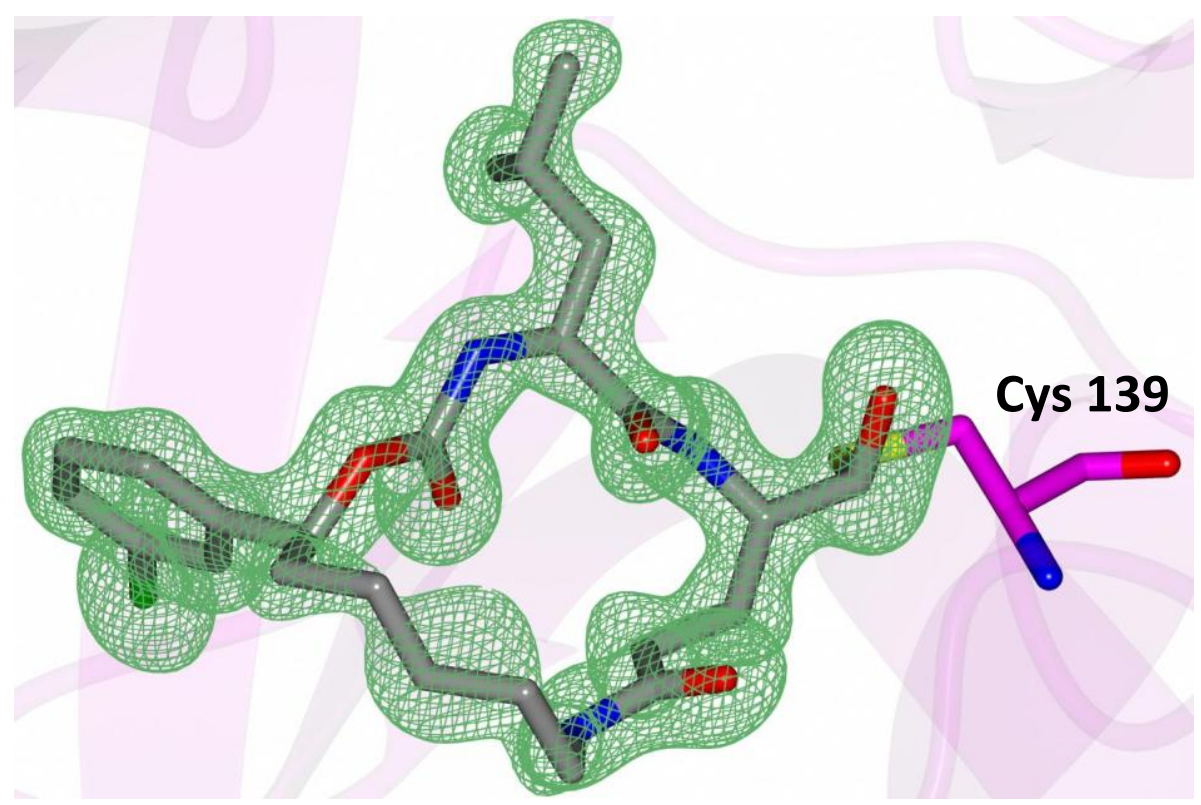


Fig. 3. Hydrogen bond interactions (dashed lines) between NV 3CLpro and inhibitor 13. Contacts to water molecules are indicated by the solid lines

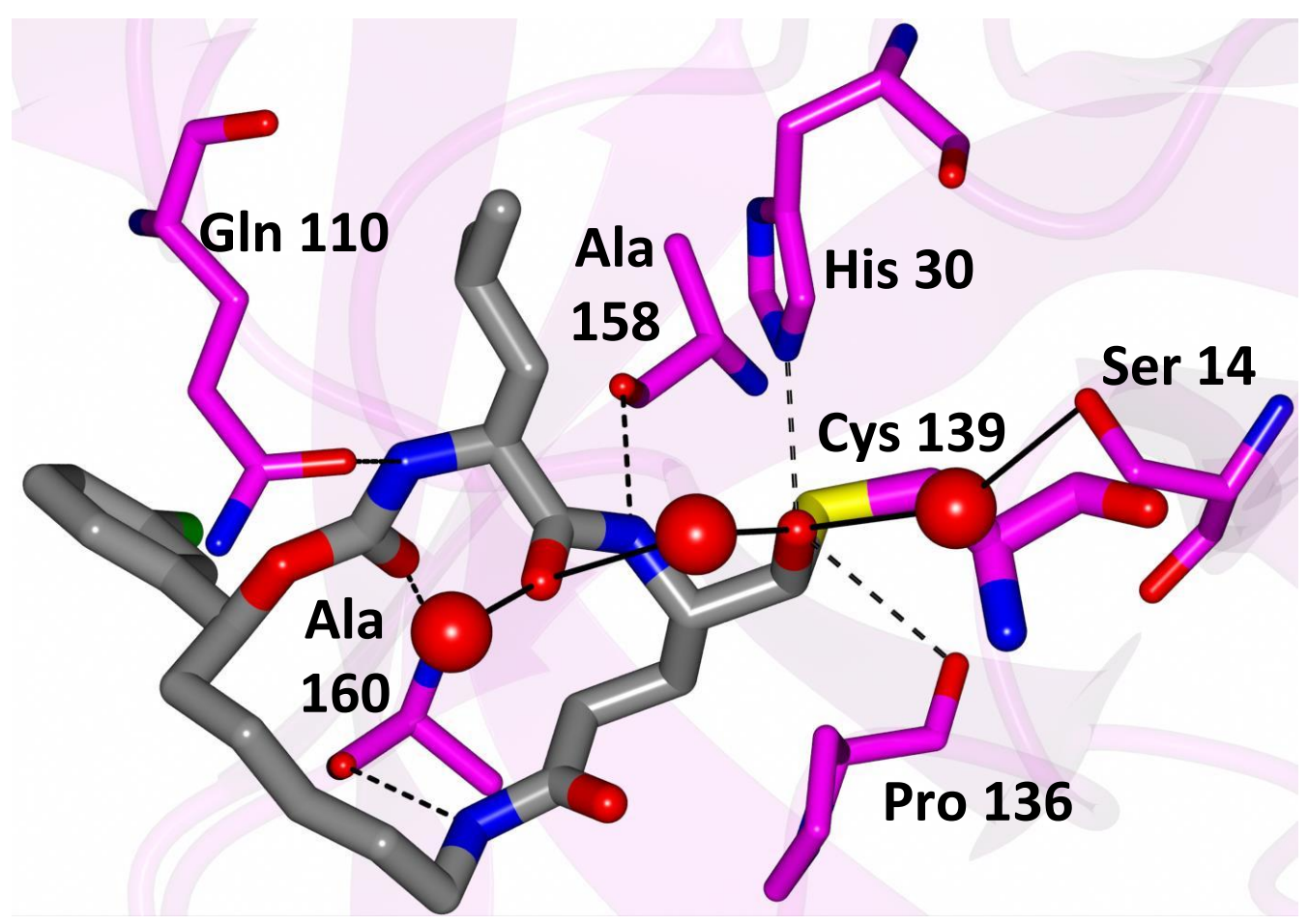


Fig. 4. Two views showing the electrostatic surface representation NV 3CLpro binding site of inhibitor 13. A) View of the active site and B) the $m$-chlorophenyl group in the hydrophobic $S_{4}$ pocket. View is rotated counterclockwise approximately $90^{\circ}$ about the vertical axis relative to panel $A$.

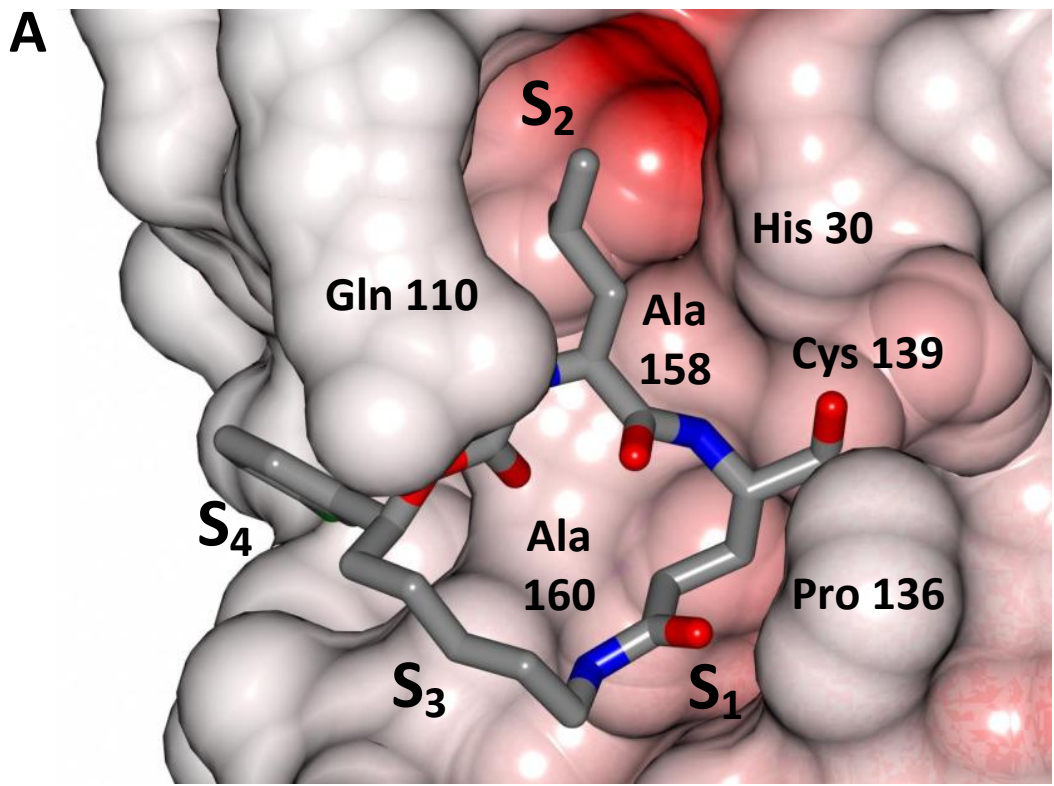

B

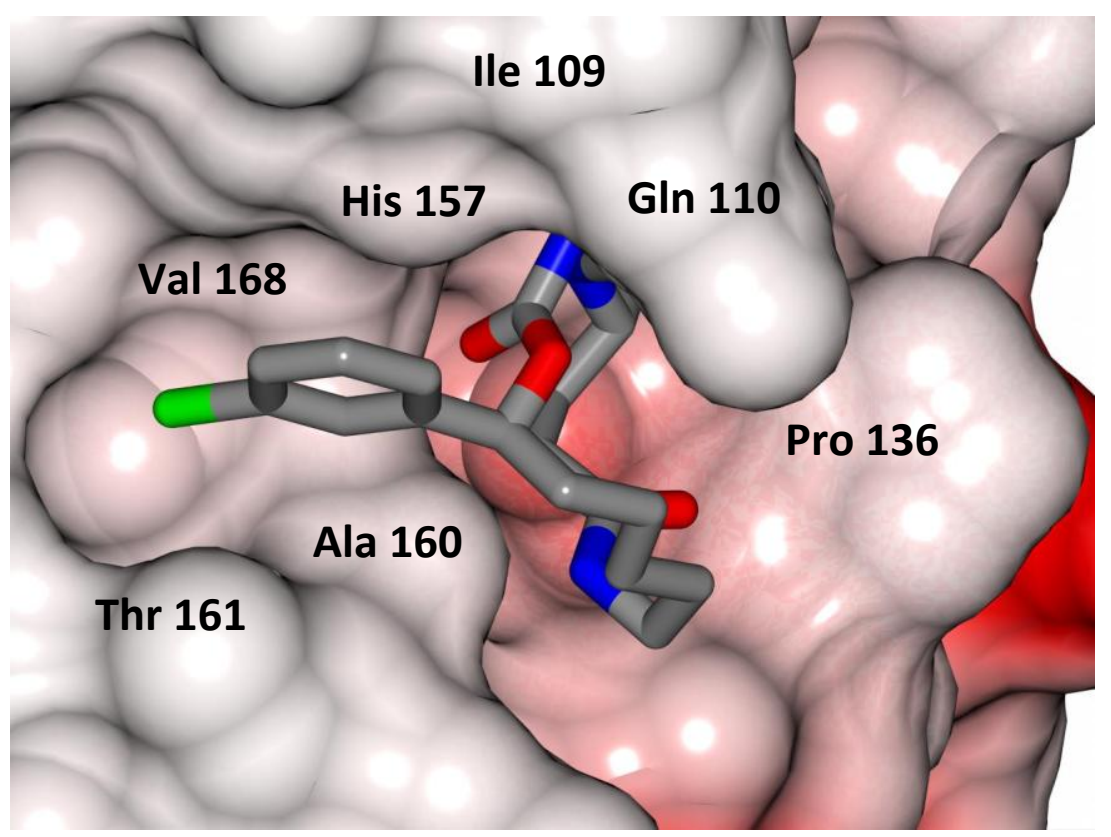


Fig. 5. View of the m-chlorophenyl of inhibitor $\mathbf{1 3}$ which is positioned in a hydrophobic pocket of NV 3CLpro.

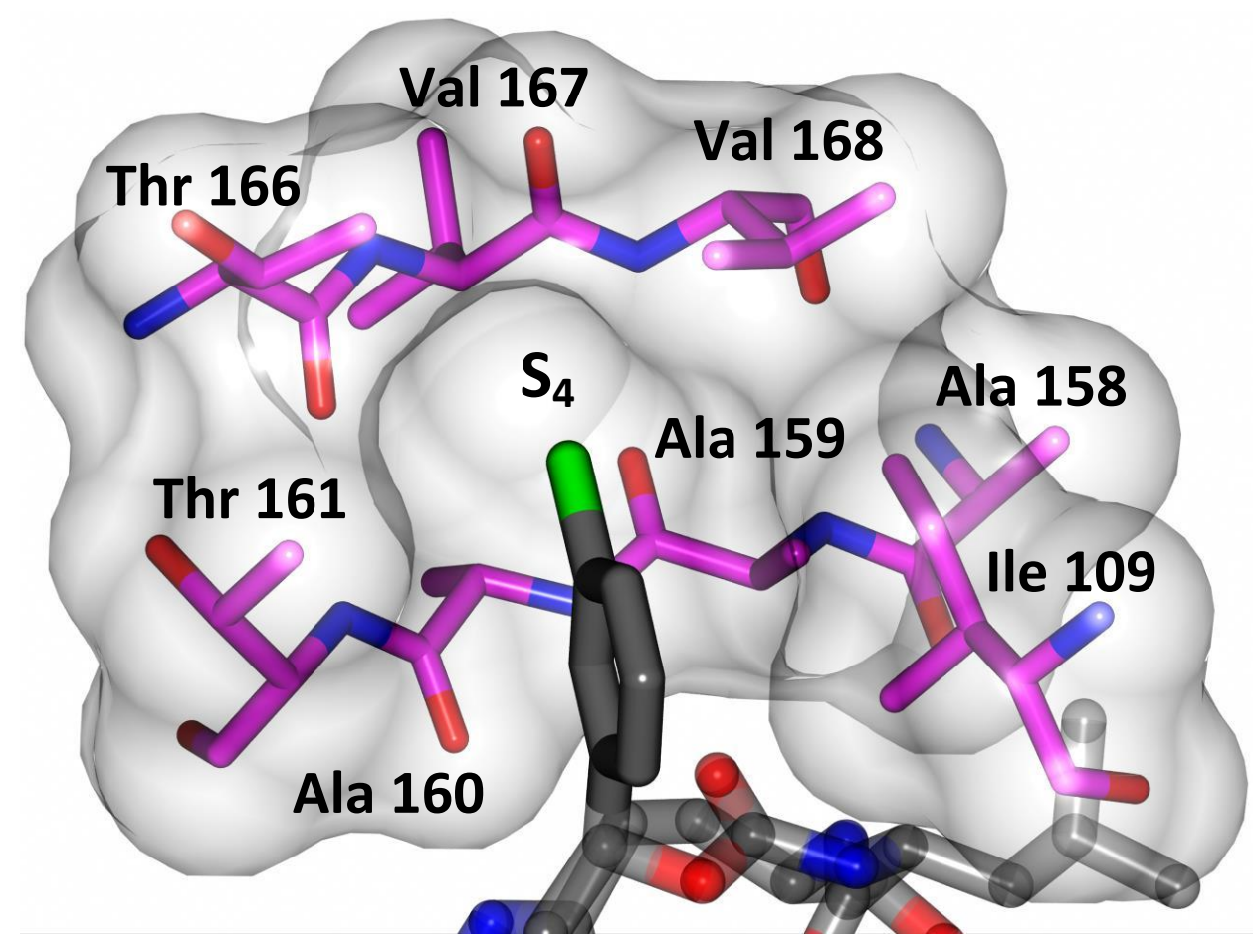


Fig. 6. $F_{o}-F_{c}$ omit map of inhibitor 21 (green mesh) contoured at $3 \sigma$.

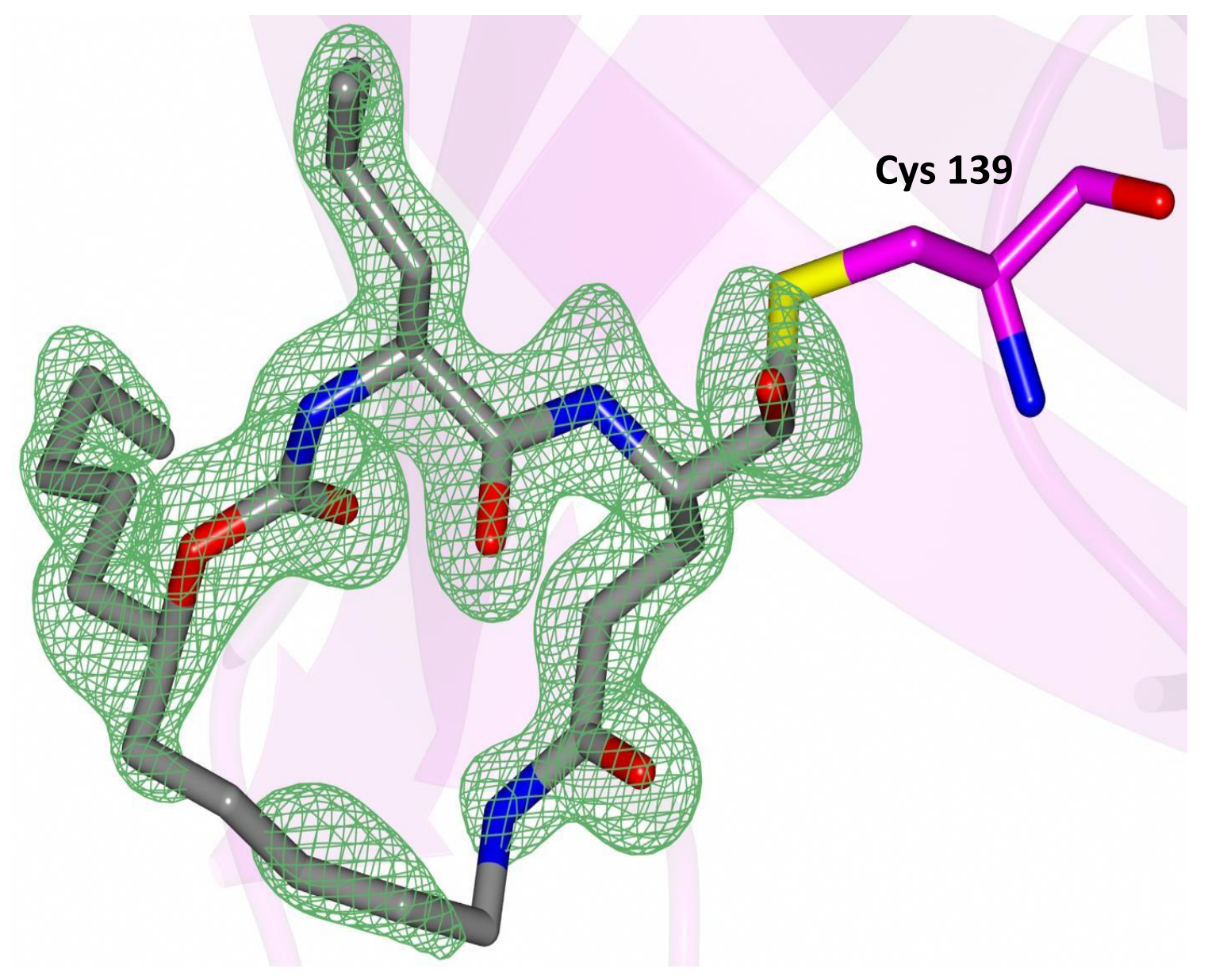


Fig. 7. Surface representation of NV $3 C L$ protease with bound inhibitor 21 to the active site and with neighboring residues colored yellow (nonpolar), cyan (polar), and white (weakly polar). A) View of the inhibitor in the $S_{1} / S_{2}$ pocket and $B$ ) the $S_{4}$ pocket. View is rotated counterclockwise approximately $90^{\circ}$ about the vertical axis relative to panel $A$.
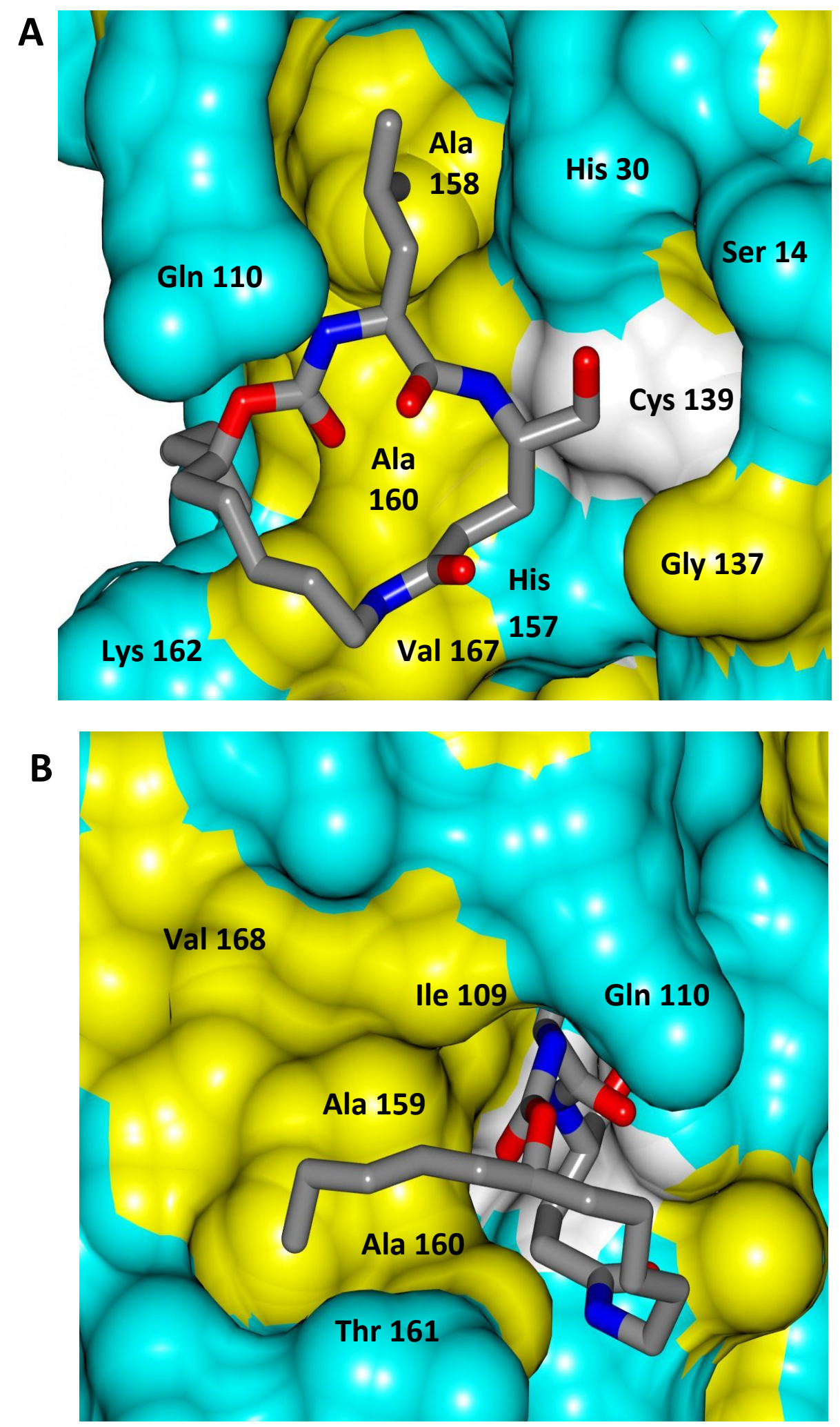
Fig. 8. Hydrogen bond interactions (dashed lines) between inhibitor 21 and NV $3 \mathrm{CL}$ protease.

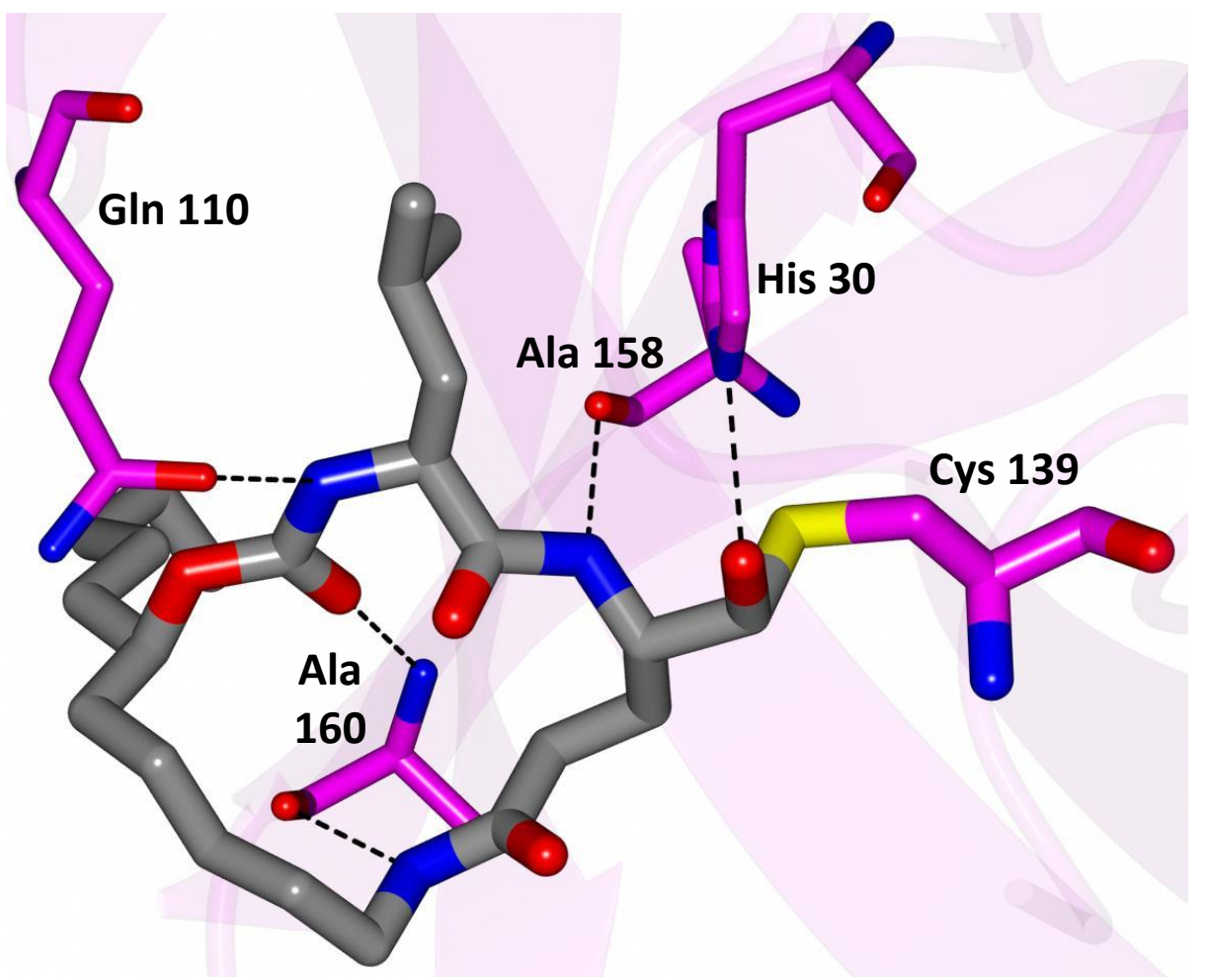


Fig. 9. Electrostatic surface representation of NVPro showing the aliphatic chain of inhibitor 21 positioned in a hydrophobic $S_{4}$ pocket.

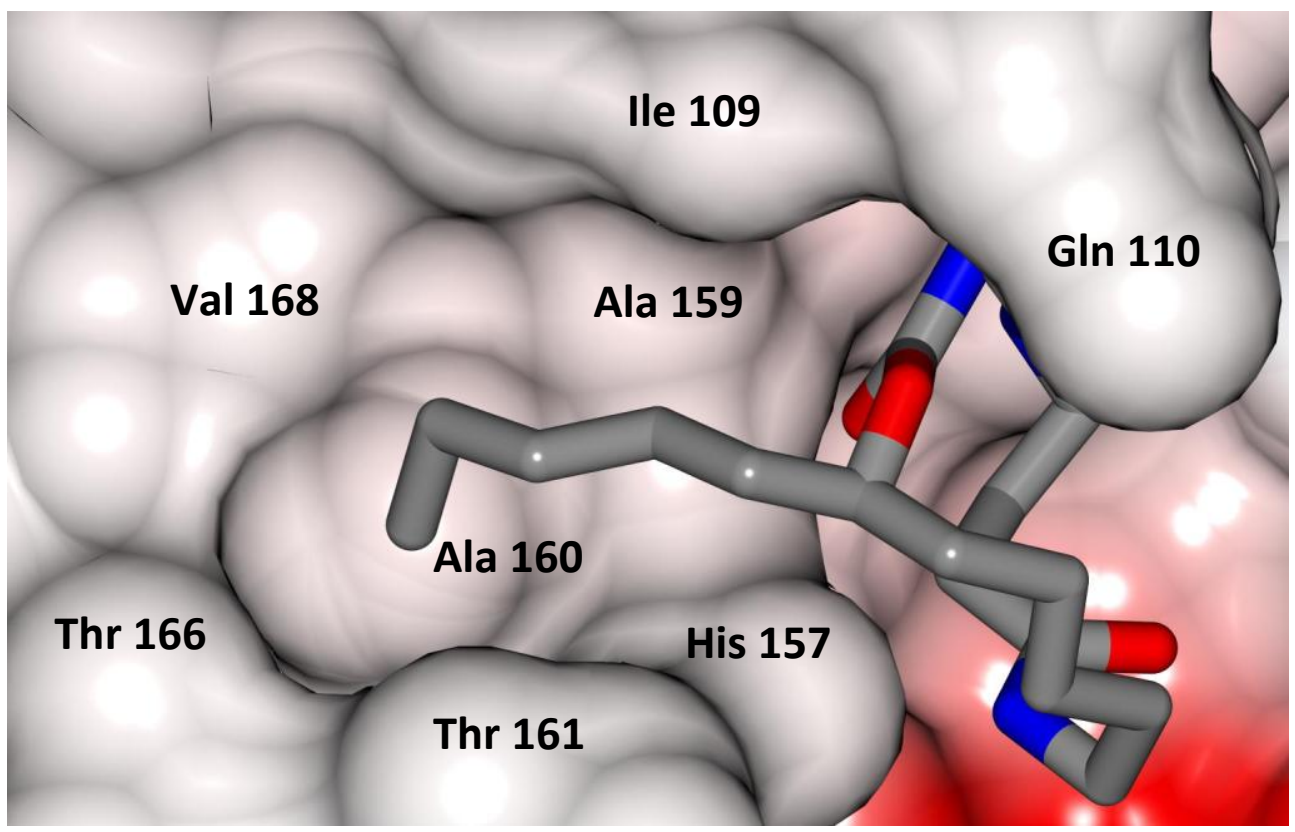




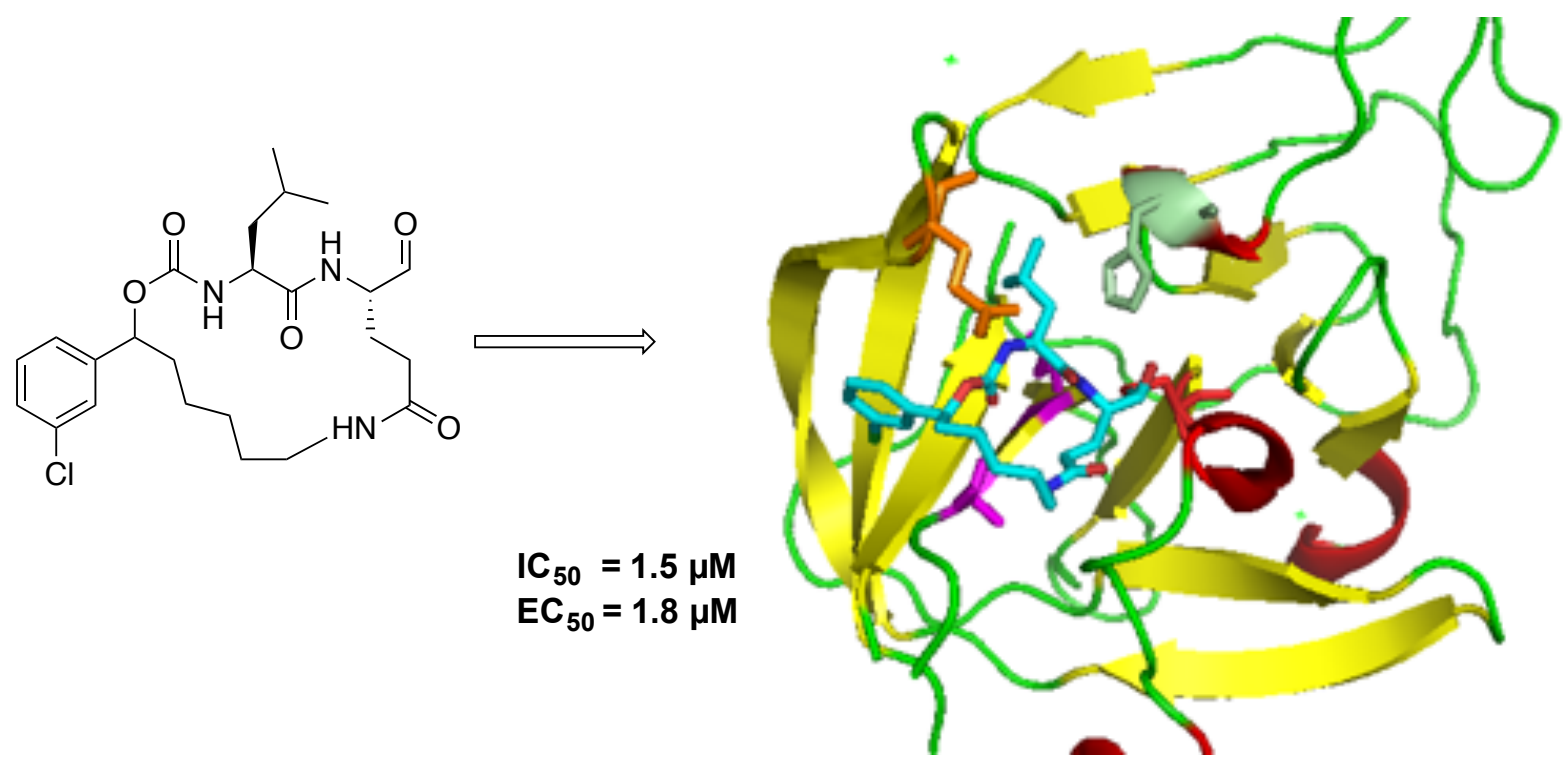

